Digital Comprehensive Summaries of Uppsala Dissertations from the Faculty of Science and Technology 438

\title{
On the Attachment of Lightning Flashes to Grounded Structures
}

\author{
MARLEY BECERRA
}

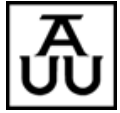

ACTA UNIVERSITATIS UPSALIENSIS UPPSALA 2008
ISSN 1651-6214

ISBN 978-91-554-7216-0

urn:nbn:se:uu:diva-8871 
Dissertation presented at Uppsala University to be publicly examined in Häggsalen, Ångströmlaboratoriet, Lägerhyddsvägen 1, Uppsala, Thursday, June 5, 2008 at 13:15 for the degree of Doctor of Philosophy. The examination will be conducted in English.

\begin{abstract}
Becerra, M. 2008. On the Attachment of Lightning Flashes to Grounded Structures. Acta Universitatis Upsaliensis. Digital Comprehensive Summaries of Uppsala Dissertations from the Faculty of Science and Technology 438. 85 pp. Uppsala. ISBN 978-91-554-7216-0.
\end{abstract}

This thesis deals with the physical modeling of the initiation and propagation of upward positive leader discharges from grounded structures during lightning strikes. It includes the analysis of upward leaders initiated under the influence of the electric field produced by a dominant negative cloud charge and due to the combined action of a negative thundercloud and a descending downward stepped negative leader. Thus, a self-consistent model based on the physics of leader discharges is developed for the evaluation of the attachment of lightning flashes to any kind of grounded structure. The predictions of the model have been found to be in good agreement with the results of laboratory long air gap experiments and with classical and altitude rocket triggered lightning experiments.

Due to the high application level and predictive power of the developed model, several contributions to the physical understanding of factors influencing the initiation and propagation of upward positive leaders during thunderstorms have been made. For instance, it has been found that the initiation of upward connecting leaders is strongly affected by the average velocity of the downward stepped leader. Similarly, it is shown that the switching voltage impulses used in the laboratory do not "fairly approximate" the electric fields produced by a descending downward leader, as claimed by supporters of Early Streamer Emission (ESE) devices. Furthermore, it is found that the space charge layer created by corona at ground level significantly increases the thundercloud electric fields required to initiate upward lightning leaders from tall objects. On the other hand, it is also shown that the upward leader velocity depends on the downward leader average velocity, the prospective return stroke current, the lateral distance of the downward leader channel and the ambient electric field.

By implementing the model to the analysis of complex structures, it has been observed that the corners of actual buildings struck by lightning coincide rather well with the places characterized by low leader inception electric fields. Besides, it has been found that the leader inception zones of the corners of complex structures do not define symmetrical and circular regions as it is generally assumed.

Keywords: Lightning, Lightning attachment, Positive leader discharges, Lightning protection, Thunderstorms, Numerical modeling

Marley Becerra, Department of Engineering Sciences, Box 534, Uppsala University, SE-75121 Uppsala, Sweden

(C) Marley Becerra 2008

ISSN 1651-6214

ISBN 978-91-554-7216-0

urn:nbn:se:uu:diva-8871 (http://urn.kb.se/resolve?urn=urn:nbn:se:uu:diva-8871) 
"All religions, arts and sciences are branches of the same tree. All these aspirations are directed toward ennobling man's life, lifting it from the sphere of mere physical existence and leading the individual towards freedom 》

Albert Einstein

"Todas las religiones, artes y ciencias son ramas del mismo árbol. Todas esas aspiraciones están encaminadas a ennoblecer la vida del hombre, elevándolo de la esfera de la mera existencia física y llevándolo hacia la libertad»"

Albert Einstein

To

My princess and our dreams

My beloved mother

My other praying mother

A

Mi princesa y nuestros sueños

Mi madre

Mi madre intercesora 



\section{List of Papers}

The present thesis summarizes the following published papers, which will be referred to in the text by their roman numerals.

I Becerra, M., Cooray, V.; A simplified physical model to determine the lightning upward connecting leader inception, IEEE Transactions on Power Delivery, Vol. 21, No. 2, 2006, pp. 897-908, ISSN: 0885-8977.

Paper presented at the CIGRE W.G C4.4.01 meeting in Avignon, France 2004. Conference paper version presented at the International Conference on Lightning and Static Electricity ICOLSE 2005 in Seattle, US and at the VIII International Symposium on Lightning Protection SIPDA 2005 in Sao Paulo, Brazil.

II Becerra, M., Cooray, V.; Time dependent evaluation of the lightning upward connecting leader inception, Journal of Physics D: Applied Physics, Vol. 39, No. 21, 2006, pp. 46954702.

Conference paper version presented at the $28^{\text {th }}$ International Conference on Lightning Protection ICLP 2006 in Kanazawa, Japan.

III Becerra, M., Cooray, V.; Laboratory experiments cannot be utilized to justify the action of Early Streamer Emission terminals, Journal of Physics D: Applied Physics, Vol. 41, No. 8, 2008, 085204 (8pp). doi:10.1088/022-3727/41/8/08/085204.

Conference paper version presented at the IX International Symposium on Lightning Protection SIPDA 2007 in Iguazu, Brazil.

IV Becerra, M., Cooray, V., Soula, S., Chauzy, S.; Effect of the space charge layer created by corona at ground level on the inception of upward lightning leaders from tall towers, Journal of Geophysical Research, Vol. 112, 2007, D12205. doi:10.1029/2006JD008308.

Conference paper version presented at the $13^{\text {th }}$ International Conference on Atmospheric Electricity ICAE 2007 in Beijing, China. 
V Becerra, M., Cooray, V.; A self-consistent upward leader propagation model, Journal of Physics D: Applied Physics, Vol. 39, No. 16, 2006, pp. 3708-3715.

Conference paper version presented at the $28^{\text {th }}$ International Conference on Lightning Protection ICLP 2006 in Kanazawa, Japan.

VI Becerra, M., Cooray, V.; On the velocity of positive connecting leaders associated with negative downward lightning leaders, Geophysical Research Letters, Vol. 35, L02801, 2008, doi:10.1029/2007GL032506.

Conference paper version presented at the IX International Symposium on Lightning Protection SIPDA 2007 in Iguazu, Brazil.

VII Becerra, M., Cooray, V., Hartono, Z.; Identification of lightning vulnerability points on complex grounded structures, Journal of Electrostatics, Vol. 65, 2007, pp. 562-570.

Paper presented at the CIGRE W.G C4.4.01 meeting in Sao Paulo, Brazil, 2005. Conference paper version presented at the International Conference on Lightning and Static Electricity ICOLSE 2005 in Seattle, US.

VIII Becerra, M., Cooray, V., Roman, F., Lightning striking distance of complex structures, IET Generation, Transmission and Distribution, Vol. 2, No. 1, 2008, pp. 131-138.

Conference paper version presented at the $28^{\text {th }}$ International Conference on Lightning Protection ICLP 2006 in Kanazawa, Japan.

Reprint of these papers in the appendix of this thesis were made with kind permission from the publishers: (C) 2006 IEEE, (C) 2006, 2008 Institute of Physics IOP, (C) 2007, 2008 American Geophysical Union AGU, (C) 2007 Elsevier B.V and (C) 2008 IET.

Other contributions of the author, not included in this thesis

IX Montano, R., Becerra, M., Cooray, V.; Resistance of spark channels, IEEE Transactions on Plasma Physics, Vol. 34, No. 5, 2006, pp. 1610-1619.

X Becerra, M., Cooray, V; Velocity of laboratory electrical discharges at low pressure, Eos Trans. AGU, 87(52), Fall Meet. Suppl., 2006, Abstract AE42A-05. 
XI Becerra, M., Valente, M., Cooray, V., Williams, E., Golka, R.; Laboratory experiments of streamers at air pressures ranging from 10 to $60 \mathrm{mBar}$, $2^{\text {nd }}$ International workshop on streamers, sprites, leaders, lightning: from micro-to macroscales, Leiden, The Netherlands, 2007.

XII Theethayi, N., Becerra, M., Thoottappillil, R., Diendorfer, G., Cooray, V., Heidler, F., Rakov, V.; On the effective height of towers on mountaintops from the perspective of lightning attachment, Second International Symposium on Lightning Physics and Effects, COST Action P18 Lightning, Vienna, Austria, 2007.

XIII Cooray, V., Becerra., M., Rahman, M.; On the NOx generation in 'cold' electrical discharges, Proceedings of the $13^{\text {th }}$ International Conference on Atmospheric Electricity, Beijing, China, 2007, pp. 257-261.

XIV Becerra, M., Cooray, V, Silva, A., Piantini, A.; Lightning attachment to power transmission lines - on the validity of the electrogeometric model - , Submitted to the $29^{\text {th }}$ International Conference on Lightning Protection ICLP, Uppsala, Sweden, 2008.

XV Becerra, M., Roman, F., Cooray, V.; Lightning attachment to common structures: Is the rolling sphere method really adequate?, Submitted to the $29^{\text {th }}$ International Conference on Lightning Protection ICLP, Uppsala, Sweden, 2008.

XVI Cooray, V., Becerra, M., Rakov, V.; On the electric field at the tip of dart leaders in lightning flashes, Proceedings of the $28^{\text {th }}$ International Conference on Lightning Protection ICLP, Kanazawa, Japan, 2006, pp. 339-344, ISBN 4-9902110-2-2.

XVII Arevalo, L., Becerra, M., Roman, F.; Understanding the point discharge DC current produced by corona needles, Proceedings of the $28^{\text {th }}$ International Conference on Lightning Protection ICLP, Kanazawa, Japan, 2006, pp. 1328-1333, ISBN 49902110-2-2.

XVIII Arevalo, L., Becerra, M., Roman, F.; Numerical simulations of the corona current development, Proceedings of the VIII International Symposium on Lightning Protection SIPDA, Sao Paolo, Brazil, 2005, pp. 218-223, ISSN 1676-9899. 
XIX Cooray, V., Diendorfer, G., Nucci, C.A., Pavanello, D., Rachidi, F., Becerra, M., Rubinstein, M., Schulz, W.; On the effect of the finite ground conductivity on electromagnetic field radiated by lightning to tall towers, Proceedings of the 28th International Conference on Lightning Protection ICLP, Kanazawa, Japan, 2006, pp. 267-272, ISBN 4-9902110-2-2.

XX Becerra, M., Cooray, V.; Effect of the initial electron density and the secondary Townsend coefficient on the simulated prebreakdown current under quasi-uniform electric fields, JENSEN DEVICES AB, Internal Research Report, 2006.

XXI Becerra, M., Cooray, V.; Study of the effect of wall floating semiconducting stripes on the initiation of breakdown in gas discharge tubes, JENSEN DEVICES AB, Internal Research Report, 2005. 


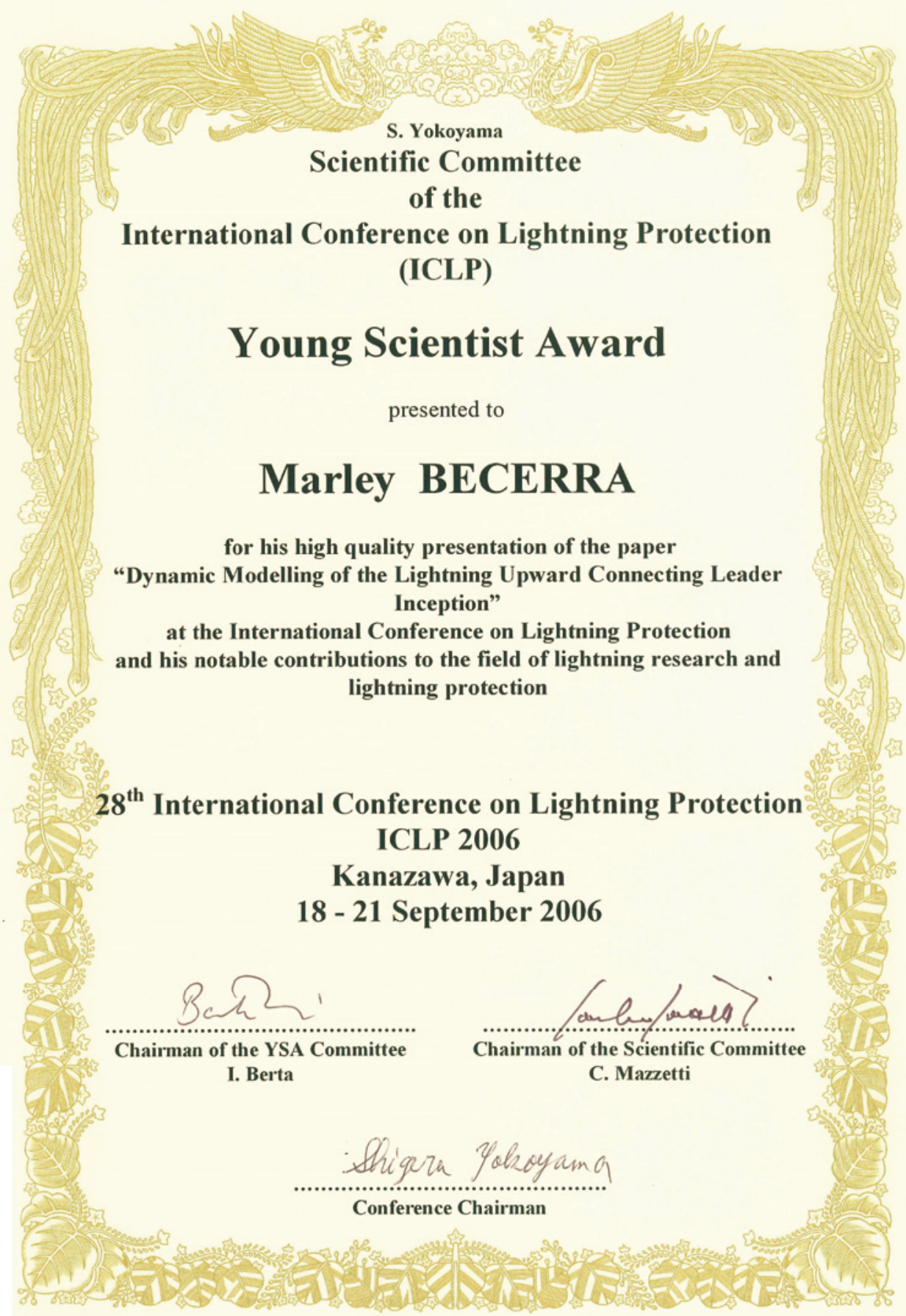





\section{Contents}

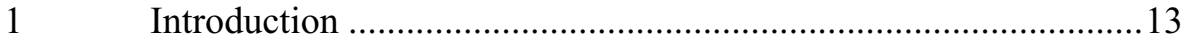

1.1 The lightning protection problem …………................................. 13

1.2 Towards a better physical understanding of the attachment of lightning flashes to grounded structures .......................................... 18

1.3 The context of this thesis .............................................................21

2 Initiation of lightning upward positive leaders ..............................26

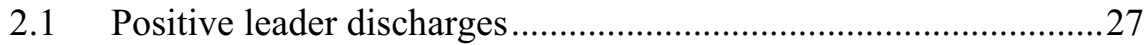

2.2 Existing leader inception models .....................................................31

2.3 The proposed leader inception model .............................................. 32

2.3.1 Evaluation of the static upward leader inception.........33

2.3.2 Evaluation of the dynamic upward leader inception ..33

2.4 On the validity of the existing leader inception models for lightning

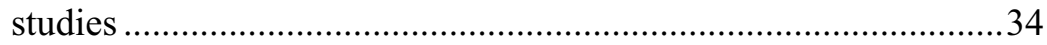

2.5 On the validity of the Early Streamer Emission claim ...................40

2.6 The space charge layer and the initiation of upward lightning .......42

3 Interception of downward lightning stepped leaders by upward

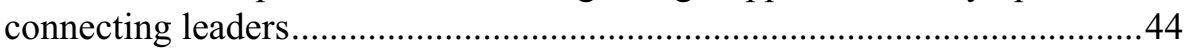

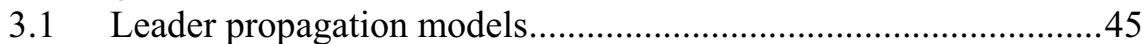

3.2 Self-consistent modelling of the upward leader propagation ........49

3.3 A Self-consistent Lightning Interception Model -SLIM - ............53

$4 \quad$ Lightning attachment to complex grounded structures..................56

4.1 The International Standard on protection of structures against

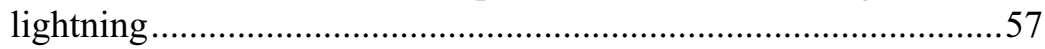

4.2 Physics-based analyses of lightning attachment to grounded

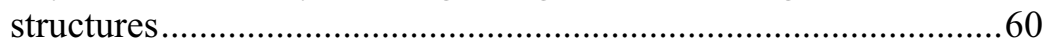

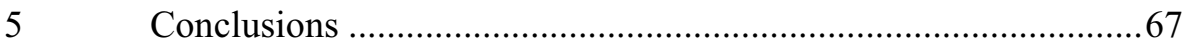

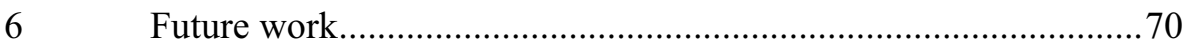

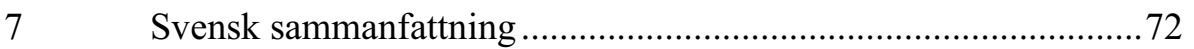

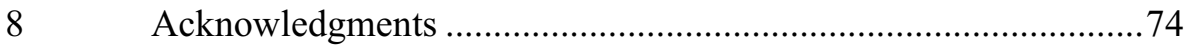

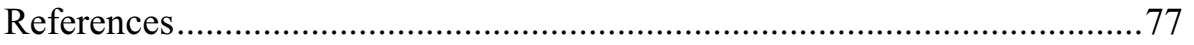





\section{Introduction}

"Most people can only judge of things by the experiences of ordinary life, but phenomena outside the scope of this are really quite numerous. How insecure it is to investigate natural principles using only the light of common knowledge and subjective ideas"

Joseph Needham, Science and Civilization in China, 1986.

\subsection{The lightning protection problem}

A lightning flash can be considered as a transient high-current electrical discharge that lowers the charge of the thundercloud to ground. Rough estimates show that worldwide a total of 100 lightning flashes strike the surface of the earth each second [1]. Some of these flashes may strike people or other different objects on the ground surface such as buildings, transmission lines, telecommunication towers, oil storage tanks, etc., causing loss of life and damage or destruction to property.

During the middle ages, lightning had been regarded as a divine expression, a fearful force against which there was not possible protection other than prayers and the ringing of church bells [2]. Ironically, churches were often struck by lightning because of the high elevation of the church spires and towers, setting them on fire or killing bell ringers [3]. However, it was until 1753 that Benjamin Franklin suggested the use of grounded pointed conductor rods above houses, churches, ships, etc., to protect them against the destructive consequences of a lightning strike [4]. Thus, Franklin published the first instructions of a lightning protection system for small dwellings, churches and agricultural buildings made of wood [5], which were frequently destroyed by fires started by lightning:

"It has pleased God in his Goodness to Mankind, at length to discover to them the means of securing their habitations and other buildings from mischief by thunder and lightning. The method is this: provide a small iron rod... but of such a length that one end being three or four feet in the moist ground, the other may be six or eight feet above the highest part of the building... A house thus furnished will not be damaged by lightning" [6] 
After this, the use of lightning rods rapidly spread in the United States and Europe, after the successful action of lightning rods was observed during storms in Philadelphia. The purpose of this lightning protection system was to safeguard structures against fire and structural damage. Nevertheless, the dispute on the range of protection offered by lightning rods started soon after a lightning flash missed a lightning rod installed as suggested by Franklin on a powder mill at Purfleet in 1777 [7]. Even though the powder did not ignite, the incident sparked the controversy about the effectiveness of the instructions to install lightning rods. Only 45 years after the incident, Gay-Lussac suggested that a lightning rod protects effectively against lightning strikes in a circular space around it, whose radius is twice the height of the rod [5]. However, several different values of the ratio between the radius of the protection zone and the height of the rod were suggested by different scientists. Literature surveys in the history of the lightning rod during the nineteenth century show that the protection ratio varied between 0.125 and 9 [8].

In $1876 \mathrm{~J}$. C. Maxwell speculated that even though a lightning rod on a building protected its surroundings, it attracted more lightning flashes towards the building than if the rod had not been installed. Maxwell suggested the use of an enclosed metal shell around a house instead of the use of a lightning rod, following the principle of the Faraday cage [5]. In this way, a lightning flash would strike the top of the metal shell and it would proceed safely to earth, while the interior of the metal shell is protected. An example of the Faraday cage effect is found in all-metal vehicles such as cars and airplanes. However, it is impractical to install a full metallic shell around normal structures such as buildings, substations, etc. Instead, a mesh of wire conductors is recommended to be installed on the whole exposed surface of the structure to be protected. This alternative protection scheme is nowadays called the Faraday cage type [5] or the protective mesh method. In this case, the spacing between conductors is the key factor that defines the efficiency of such lightning protection system.

In the early decades of the $20^{\text {th }}$ century, the quick expansion of the transmission system networks considerably increased the exposure of the power grid to lightning. Due to the importance of maintaining a reliable and continuous service under all practical conditions, the lightning problem was then closely related to the economic development of the transmission and utilization of electric energy [9]. Thus, the use of shielding ground conductors overhead the phase conductors was introduced as a measure to mitigate the problems caused by direct lightning strikes to the power transmission lines. At the same time, the protective angle method was suggested as the basis for the installation of shielding wires in transmission lines and lightning rods in electrical substations. This method considers that any object located inside a zone limited by the envelope surface generated from a lightning rod or a shielding wire to the ground, at a fixed angle to the vertical, is protected against a direct lightning strike. 
Given the similarities between the lightning flash and the electric sparks shown by Franklin himself [3], several attempts were made to estimate the protective area of lightning rods and conductors based in scale models in the laboratory. AC (alternating current) and DC (direct current) voltages were initially used for such studies until the impulse voltage generator became available as standard equipment in high voltage laboratories [8]. Nevertheless, the question of the validity of the extrapolation of results obtained in laboratory to be applied to the lightning discharge remains controversial since then. Despite of this, values of the protective angle varying between 20 and 75 degrees were suggested from empirical criteria or scale laboratory models [10]. The values of the protective angle were formalized by Wagner and coworkers $[10,11]$ and since then, fixed angles are still in use today as a design tool [12].

In the early sixties, Horvath [13] proposed the use of a fictitious sphere for the location of lightning rods, based on the concept of protected spaces bordered by circular arcs. This method considers that a lightning flash strikes a structure at the places that touch the surface of a fictitious sphere that is rolled over it. Even though no knowledge about the proper radius of the sphere was available at that time, values equal to 15 and $50 \mathrm{~m}$ were suggested depending upon the desired level of lightning protection. This approach is the essence of the well-known rolling sphere method.

Few years later, new studies of the attachment of lightning flashes to transmission lines were boosted when the failures of the shielding ground conductors (Figure 1.1) were recognized as a substantial mode of outages in power transmission lines [14]. The poor lightning performance of Extra High Voltage $(\mathrm{EHV})$ power lines $(345 \mathrm{kV})$ in the United States, redirected the attention of scientists and engineers towards the problem related to the location of shielding ground conductors to effectively protect the phase conductors against direct strikes [15]. Thus, the main interest was the definition of the steps required to locate the shield wires to intercept all the lightning flashes striking the power transmission lines with prospective peak currents above a minimum amplitude.

Consequently, a better alternative to the protective angle method used for the design of lightning protection systems was developed [5, 16]. This alternative, called the electrogeometric method (EGM), considers that the protection zone of any lightning rod or shielding conductor is not purely geometrical but that it also depends upon the amplitude of the lightning return stroke current. In an attempt to further develop the existing transmission line shielding theory, Armstrong and Whitehead [17] proposed a modified version of the EGM. Essentially, it considers that the exposure of a conductor to lightning flashes is given by the surface of an imaginary arc with radius $r_{s s}$ (Figure 1.1). The exposure of the earth is represented by a line located at a distance $r_{s g}$ above ground level, which was assumed to be equal to the product of the radius $r_{s s}$ and a proportionality constant $K_{s g}$. 


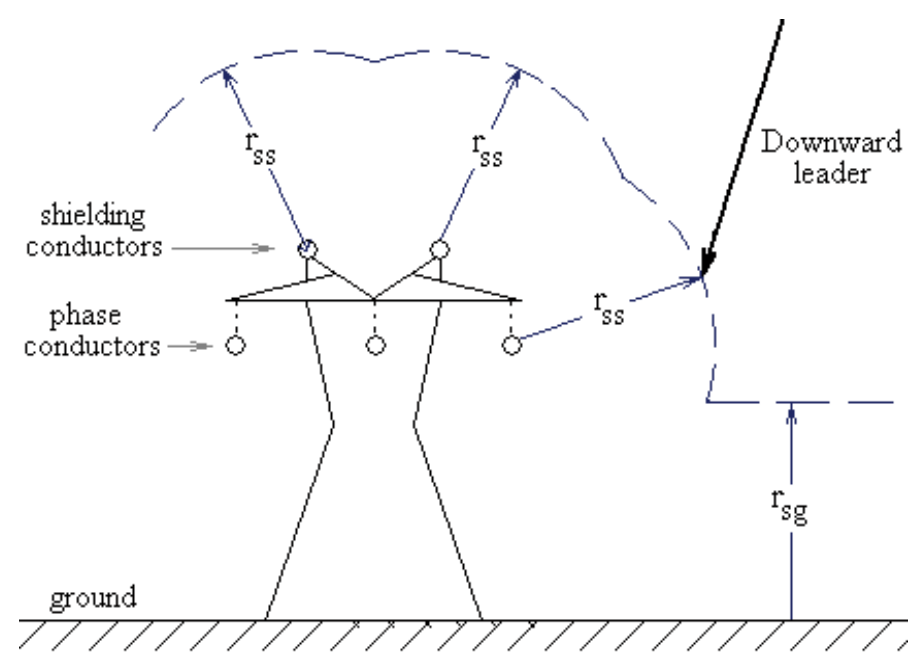

Figure 1.1. Sketch of a power transmission line and the lightning exposure arcs of the conductors according to the electrogeometric theory. This example shows a transmission line with expected shielding failures.

According to Armstrong and Whitehead's electrogeometric theory, the geometry of an effectively protected transmission line is such that the exposure arcs of the shielding ground wires and the exposure line of the earth entirely covers the phase conductors and their exposure surfaces [17]. The radius $r_{s s}$ is the distance from the conductor where the downward leader, if personality is ascribed to it, would decide the object it will strike. Thus, $r_{s s}$ was estimated by extrapolating the switching breakdown voltages measured in a rod to rod air gap - up to $5 \mathrm{~m}$ long - and representing the downward leader by a rod electrode with a potential given by the Wagner lightning stroke model [19]. From this analysis, the widely-know analytical relation between the radius $r_{s s}$ and the return stroke peak current $I_{p}$ in the form $r_{s s}=a \cdot I_{p}^{b}$ was proposed [17]. In order to reach a satisfactory agreement between their shielding theory and the field observations, Armstrong and Whitehead [17] calibrated the constant $K_{s g}$ with data of effectively shielded transmission lines in the United States. Hence, $K_{s g}$ was adjusted such that the effective shielding angle predicted by the electrogeometric theory agreed with the shielding angles of existing high performance transmission lines. Later, small changes to the constant parameters $a$ and $b$ were performed by Brown and Whitehead [18], Gilman and Whitehead [20] and Love [14] among others. In addition, further calibration of the EGM was performed with data of shielding failures from an intensive field campaign supported by the Edison Electrical Institute $[15,21]$.

In spite of the uncertainties of the EGM, the usefulness of this method has been demonstrated for the lightning design of power transmission lines [14]. Nonetheless, the accuracy of the electrogeometric theory may well be the 
result of self-cancelling errors introduced by the assumptions considered by Whitehead and coworkers [15]. Because of the apparent agreement of the electrogeometric theory with field observations, it has been used also today for calculations of lightning attachment to a large diversity of other structures such as buildings [22], power substations [23], airplanes [24], etc. The main justification for this extension of the EGM theory is that there is not any other reliable set of statistics concerned to lightning strikes to structures, except the one used to calibrate the EGM. Thus, the electrogeometric theory has been used also to define the rolling sphere radius and to evaluate the value of the protective angle in the lightning protection standards [25-27].

However, the EGM is far from perfect since it is based on a gross oversimplification of the physical nature of the lightning discharge [8, 28]. Furthermore, the calibration of the Whitehead electrogeometric theory only involved shielding failures in transmission lines produced by lightning currents in the lower region of the current amplitude frequency distribution, ranging between about $3 \mathrm{kA}$ and $9 \mathrm{kA}[17,18]$. For this reason, it is expected that the electrogeometric theory correctly predicts the performance of transmission lines similar to the ones used in the calibration. But there are still open questions regarding the extrapolation of the EGM predictions to other kind of structures. Whitehead himself questioned the validity of extrapolating the results of his theory to $500 \mathrm{kV}$ EHV lines or ultimately to UHV (Ultra High Voltage) lines [15]. Interestingly, field observations of lightning strikes to phase conductors of UHV transmission lines [29] have recently shown disagreement with the predictions of the Whitehead's EGM.

Thus, there is a considerable world-wide interest on the improvement of the IEC International Standard on Lightning Protection of Structures [2527]. It includes the development of improved methods for location of lightning rods on complex and vulnerable structures. This is motivated by the increasing need for the effective lightning protection of vulnerable grounded structures such as buildings with fire hazards, oil storage tanks, structures for storage of explosives and inflammable materials, etc. However, the design of the lightning protection systems for such structures still relies on the empirical protective angle method, the mesh method and the rolling sphere method.

Furthermore, new lightning protection devices have been introduced in the market during the last years. The promoters of such devices claim that they have a larger lightning protection range than a conventional Franklin lightning rod or that they can completely avoid lightning strikes. The former devices are usually called Early Streamer Emission devices (ESE) [30] and the later are known as Dissipation Array Systems (DAS) [31]. Due to the theoretical and practical difficulties to either approve or reject these new devices [30], there is an ongoing controversy between scientists and manufacturers about the validity of these claims and the efficiency of these devices. In addition, new methods have been proposed by ESE manufacturers for positioning of lightning rods given the limitations of the current lightning 
protection practice [32-34]. These methods have also been subject of discussion and controversy $[35,36]$.

\subsection{Towards a better physical understanding of the attachment of lightning flashes to grounded structures}

During almost 150 years after Franklin introduced the lightning rod, no relevant scientific progress related to the nature of the lightning discharge was made. The ideas prevailing during that time were more or less philosophical speculations and ideas motivated by different workers [37]. It was only at the beginning of the twentieth century when the lightning photography and spectroscopy initiated a real progress in the scientific research of the lightning flash [38].

Particularly, a new method of obtaining direct information regarding the mode of development of the lightning discharge was development with the invention of the Boys camera in 1926 [39]. Thus, the high-speed photographic measurements of Schonland and coauthors [39-41] showed that the downward lightning flash from a negative cloud develops in the form of a leader discharge that propagates in a stepped manner from the cloud towards the ground. This discharge is hereinafter called the downward stepped leader. As the downward leader approaches to ground, self-propagating electrical discharges are initiated from sharp objects on the ground, beginning the attachment process. Thus, one or more of these discharges, called upward connecting leaders, travel upwards trying to meet the downward coming leader. When an upward connecting leader succeeds to attach the downward stepped leader, a highly conductive path is created through which the high lightning current, called the first return stroke current, is drained to the ground. After this current has ceased to flow, it is possible that a flash may end or that it may keep on with more several strokes if additional charges in the thundercloud are available to the top of the already existing lightning channel [1].

One of the first attempts to study the physical conditions for the attachment of downward leaders to grounded structures was made by Golde [5]. He suggested that the downward stepped leader approaches to ground until the potential gradient at the surface of a grounded object has increased sufficiently as to initiate an upward connecting leader. As a first approximation of the critical gradient required for the leader inception, Golde extrapolated the critical breakdown electric fields obtained in long air gaps under longfronted impulse voltages [5]. Furthermore, Golde used the term striking distance to define the distance between the downward stepped leader and the grounded object tip when the upward leader discharge is initiated [8]. This 
definition follows the same descriptive terminology already used by Franklin to refer to the distance where the point to be struck is determined [3]. In order to avoid confusion with other definitions of the striking distance [17], it is hereafter called the striking - inception - distance.

Based on the observation of lightning flashes to the Empire State Building in New York, McEachron [42] reported in 1939 that upward leader discharges could also be triggered by the electric field produced by thunderclouds. He observed that upward leaders are initiated if the thundercloud ambient electric field is high enough so that the leaders propagate upward until they connect with the charge pockets in the electrified cloud before any downward leader occurs. This kind of discharge is usually known as upward initiated lightning. However, the polarity of the charge lowered to ground was not reported by McEachron [43]. It was not until 1967 when Berger [44] clearly identified the polarity and type of cloud to ground lightning discharges. Based on photographic records and current oscillograms of several lightning strikes to two $70 \mathrm{~m}$ tall TV masts in the San Salvatore Mountain, Switzerland, Berger found four different types of lightning flashes:

- Downward moving stepped negatively charged leaders lowering negative cloud charge to ground or downward negative lightning.

- Upward moving positively charged leaders lowering negative cloud charge to ground, or upward initiated negative lightning.

- Downward moving positively charged leaders lowering positive cloud charge to ground, or downward positive lightning.

- Upward moving stepped negatively charged leaders lowering positive cloud charge to ground, or upward initiated positive lightning.

Interestingly, Berger found that upward initiated lightning flashes occurred much more frequent to his masts than downward lightning flashes [44]. Even though upward initiated lightning is mostly triggered by very tall structures [45], Berger also observed that upward lightning could often be initiated from other objects of moderate height on the top of the San Salvatore Mountain. As to downward lightning, Berger confirmed that upward connecting leaders are initiated under the influence of downward moving leaders and that the junction point where both leaders meet is shorter than about half the striking - inception - distance. Also, Berger pointed out that the striking distances observed for the lightning strikes to his towers were notably longer than the gap distances used in laboratory studies, which were not longer than $5 \mathrm{~m}$ long at that time [37]. Consequently, he mentioned based on his observations that it is not possible to justify the theories that connect laboratory breakdown voltages and the lightning striking distance [44]. Nonetheless, Berger also recognized that the physical knowledge gathered from experiments with long sparks in the laboratory could be used to understand the complicated nature of the lightning discharge [37]. 
Later in 1971, Les Renardieres group started a pioneering research project on laboratory long air gap discharges [46]. This project provided not only extensive empirical data but also theoretical analysis of the statistical behaviour and physical characteristics of the initiation and propagation of positive and negative leaders [46-49]. Thus, it constitutes the milestone of the physical modelling of leader discharges in the laboratory [50-53], and it opened the doors to the theoretical study of lightning leaders [54-59]. Since it is generally believed that downward negative lightning flashes probably account for about $90 \%$ or more of all global cloud-to-ground discharges [38], the study of upward positive leaders has been mainly addressed in the literature. Studies of negative upward leaders are less common given the fact that the physics of these discharges is still not well understood [60].

Based on the analysis of several photographs of lightning strikes to a $70 \mathrm{~m}$ tall mast in South Africa, Eriksson suggested in 1979 that the successful connection of the downward leader by a newly initiated upward leader depends on the relative velocities of both leaders [61]. In this way, Eriksson suggested that both upward and downward leaders intercept at a given distance from the struck point, called the interception distance. Also, he suggested that the attachment of the downward leader can only take place within a defined geometric zone called the collection volume. The lateral extension of this volume was defined by the downward and upward leader velocity ratio (taken as unity by Eriksson) and by the striking - inception - distance. This distance was estimated by using the critical radius concept [64] used to evaluate the condition for initiation of leaders in long sparks.

In 1999, Dellera and Garbagnati [65, 66] proposed a more sophisticated method of analysis compared with Eriksson's, which is usually known as the leader progression model. It involves the iterative simulation of the propagation of both leaders based on electrostatic calculations. In this case, the leader initiation condition is also evaluated with the critical radius concept [64]. Both leaders are modeled by line charges and are assumed to approach with a relative velocity ratio equal to four immediately after the upward leader initiation and equal to one close to interception. Later, Rizk [67, 69] presented a similar leader propagation model than Dellera and Garbagnati, but based on his own leader inception model [70]. The propagation of the upward leader is simulated by considering a unitary velocity ratio and the vector velocity directed towards the tip of the unperturbed downward leader. The upward leader is modeled as a channel with a constant average potential gradient obtained from a semi-empirical expression from laboratory experiments [68]. 


\subsection{The context of this thesis}

There is today an important need for improving the IEC Standard on Protection of Structures against Lightning [25-27]. This is motivated by the fact that the new results of research conducted in the twentieth century have had very little effect on the standardization of lightning protection systems [71]. Thus, a request has been made to the scientific lightning community through the CIGRE Working Group WG 33.01.03 on Lightning to develop better procedures to evaluate in detail the lightning exposure of structures. For this reason, a thorough study of the state of the art of lightning attachment was conducted in 1997 by the Task Force on lightning attachment [72]. This study showed that the leader propagation models used for the simulation of the lightning attachment to structures represent important improvements to appropriately model the lightning attachment to grounded structures. Moreover, it showed that some predictions of these models agree with several phenomena experienced in the field. Despite of this fact, it was also concluded that further developments are still required to improve these models, particularly related to their basic assumptions. Hence, the major improvements suggested by the CIGRE WG 33.01.03 for the further development of the leader propagation models are related to [72]:

a. The physical evaluation of the inception of upward leaders: the calculation of the conditions required to initiate upward connecting leaders from grounded structures have been done based on leader inception methods derived for long air sparks $[64,70]$. However, there are doubts about the validity of these criteria when applied to evaluate the conditions of upward leader inception under natural lightning [73]. Moreover, these criteria cannot take into account the effect of asymmetries, complex geometries or surrounding objects since they have been derived for simple rods or conductors only. In addition, the existing leader inception criteria do not consider the difference between unstable leaders (precursors) and self-propagating leaders, which have been identified in rocket triggered experiments [74-76]. On top of this, the existing leader initiation criteria have not been able to bring light to a conclusive discussion on the efficiency of the new technologies on lightning protection such as the Early Streamer Emission devices (ESE) [30] and the Dissipation Array Systems (DAS) [31].

b. The ambient electric field under a thundercloud: the effect of the thundercloud ambient electric field has not been properly addressed by the leader propagation models. They disregard the effect of any space charge produced between the cloud and the ground on the thundercloud electric field. Particularly, the ambient electric field is strongly shielded by the space charge layer created by corona at irregularities on the ground surface. During the development of a thunderstorm, the space 
charge layer can drift upwards up to some hundreds of meters [77, 78], distorting the electric field even at those altitudes. This can be highly important for the appropriate evaluation of the risk of lightning strikes to tall structures caused by upward initiated lightning.

c. Parameters directly taken from laboratory experiments: the main physical properties of the upward leaders, namely the charge per unit length or the leader channel potential gradient, are taken from leaders obtained in laboratory long air gaps [46-49]. Nevertheless, the leader formation conditions under natural lightning are believed to be considerably different compared with those in the laboratory under switching voltages [76]. For this reason it is not proper to use values taken from laboratory experiments and directly extrapolate them to describe physical properties of upward connecting leaders. Therefore, an improved leader propagation model should be capable of self-consistently estimate the physical properties of upward leaders under the influence of the downward moving leader [59].

d. The leader velocities: the evaluation of the attachment point between the downward and the upward leaders strongly depends on their velocity. The existing leader propagation models assume a before-hand chosen velocity ratio to describe the relative propagation of the upward leader compared with the movement of the downward stepped leader. Because of the lack of data, Eriksson [62,63] and Rizk [67, 69] assumed that the downward and the upward leaders propagate with the same velocity (ratio equal to one). In the case of the leader model of Dellera and Garbagnati $[65,66]$, this ratio was assumed to be four immediately after the upward leader initiation and then gradually decreases to one as the two leaders get closer to the attachment point. Since the chosen velocity ratio can significantly affect the junction trajectories and the estimation of the interception distances, more realistic values according to the latest available data are required.

e. The representation of the downward leader: the physical processes related to the attachment of lightning flashes to grounded structures are all driven by the electric field produced by the descent of the downward leader [79]. Thus, the choice of the charge per unit length distributed along the downward leader is one of the most influencing factors on the lightning attachment evaluation. Since it is necessary for practical reasons to relate the downward leader charge to the prospective return stroke peak current, appropriate relationships are required. This also includes the careful evaluation of the charge distribution along the leader channel, such that the calculated electric fields reproduce values measured by different authors. However, the values currently used of the downward charge density are derived by semi-empirical considerations that neglect the effect of branches. Regarding the propagation of the downward leader, it is still a controversial issue whether a downward 
lightning stepped leader propagates unaffected by any structure on ground or not. Moreover, if a change of direction during the downward leader propagation is considered, it is required to evaluate the effect of the chosen simulation step lengths on the predictions of the models.

f. Flash polarity: The lightning propagation models only consider downward negative flashes. Even though downward positive flashes are less frequent, they have a higher destructive power due to their higher peak current, duration and energy levels compared with negative lightning. In addition, positive lightning can be the dominant type of cloud to ground lightning during cold seasons, during dissipation stages of thunderstorms, etc [38].

Based on the previous points, the CIGRE WG 33.01.03 report [72] concluded that further research was required in the following major areas:

- Lightning physics regarding the initiation and propagation of upward leaders under the influence of down-coming stepped leaders. This includes theoretical and experimental studies related to parameters such as charge distribution in thunderstorms, ambient electric field profiles and the physical parameters of upward connecting leaders.

- Update and improvement of the leader propagation models. In order to reduce the dependence of the predictions of the models on the considered assumptions, the current knowledge on leader discharges and lightning physics has to be incorporated.

- Further development of self-consistent models for the simulation of leaders under triggered and natural lightning. If possible, these models should have a high application level.

Fortunately, there is nowadays a better knowledge of the physical parameters involved on the initiation and propagation of upward leaders. This is partly due to the several experiments conducted at instrumented tall towers [44, $61,80-86]$ and to the use of rocket triggered lightning techniques [74-76], and partly due to the improvement in theoretical leader inception and propagation models [54-59]. From the experimental perspective, different experiments with natural and triggering lightning have provided valuable information about the physical properties of upward and downward leaders under natural conditions. On the other side, the theoretical models have clarified the basic physical mechanisms of leader discharges and have settled the basis for the simulation of upward lightning leaders.

Therefore, a research project was started in 2003 at the Division for Electricity, Uppsala University, within the framework of the CIGRE Working Group WG 4.4.01 Task Force on lightning attachment. This project was intended to contribute, with a more physical approach, to the proper evalua- 
tion of the attachment of lightning flashes to grounded structures. Particularly, it represents further work on the research area related to the development of a self-consistent model for the simulation of upward leaders during lightning strikes. Due to the high application level and the predictive power of the developed model, some contributions to the physical understanding of the parameters that influence the initiation and propagation of upward positive lightning leaders during thunderstorms have also been made. In this way, the work presented in this doctoral thesis presents contributions related to the improvements (a) to (d) suggested by the CIGRE WG 33.01.03 report [72] for further development of the lightning leader propagation models.

Thus, Paper I introduces the first version of a physical model developed to evaluate the initiation of upward positive leaders during lightning strikes. As a first approximation, a static condition is considered. It assumes that the electric field that drives the initiation of the upward leader (produced by either the thundercloud charge or a descending stepped leader) does not vary during the inception process. The proposed model is applied to predict the background electric field required to initiate an upward leader from a lightning rod and from one corner of a rectangular building. The estimations of the leader model are compared with other existing leader inception criteria and with the results of a triggered lightning experiment [76]. Furthermore, a simplified algorithm is introduced to facilitate the use of the model by any engineer or designer to evaluate the initiation of upward lightning leaders from any grounded structure.

The extension and improvement of the model presented in Paper I into a time-dependant leader inception model is presented in Paper II. In this case, the dynamic condition for initiation of upward connecting leaders under the influence of downward moving leaders is introduced. It takes into account the time variation of the electric field produced by the approach of the downward stepped leader. Furthermore, it considers the shielding effect produced by the space charge created by streamers and aborted leaders generated before the initiation of the self-propagating leader. The model is validated by comparing its predictions with the initiation time of leaders in the laboratory under switching voltage waveforms and with an altitude rocket triggered lightning experiment [74]. Based on the predictions of the model, the effect of the tip radius on the efficiency of lightning rods as well as the field observations of competing lightning rods $[85,86]$ are analyzed and discussed.

The analysis of the efficiency of Early Streamer Emission (ESE) devices [30] to launch upward connecting leaders before a conventional Franklin rod is presented in Paper III. The dynamic leader inception model presented in Paper II is used to simulate the laboratory experiment under which the early streamer emission concept was found [87, 88]. The model is also applied to evaluate the early streamer emission concept on the inception of upward connecting leaders under natural lightning. The differences between leaders 
in laboratory under switching waveforms and under natural lightning are described. The validity of the ESE claims is discussed based on the obtained results.

Paper IV presents an application of the static leader inception model of Paper I to evaluate the conditions required to initiate upward lightning from tall slender structures in presence of the corona space charge layer. The temporal evolution of the space charge layer created during a typical thunderstorm is simulated and its effect on the initiation of upward lightning from tall towers is evaluated. The effect of the neutral aerosol concentration of the site on the ambient electric field profile and the minimum thundercloud electric field required to initiate upward positive leaders is also presented.

A self-consistent model for the evaluation of the upward connecting leader propagation is introduced in Paper $\mathbf{V}$. This paper complements the analysis presented in Paper II. In this way, both the initiation and the propagation of upward connecting leaders are simulated under the dynamic conditions imposed by the descent of the downward stepped leader. The main physical properties of the upward connecting leader are self-consistently calculated from its inception until the attachment with the downward stepped leader. In addition, the predictions of the model are compared with the results of an altitude rocket triggered lightning experiment [74]. The validity of using a constant charge per unit length taken from laboratory experiments to describe the upward leader channel is discussed.

Paper VI presents the analysis of the factors that influence the propagation velocity of upward connecting positive leaders. The development of upward connecting leaders initiated from a tall tower is self-consistently simulated with the model presented in Papers II and $\mathbf{V}$ under different conditions. Hence, the effect of the prospective return stroke peak current, the downward stepped leader average velocity and location as well as the ambient electric field on the time variation of the upward leader velocity is studied.

Papers VII and VIII introduce the practical implementation of the model proposed in Paper I for the analysis of lightning attachment to grounded complex structures. In the first paper, the background electric field required to initiate upward leaders from the corners of complex actual buildings struck by lightning in Kuala Lumpur is computed and compared with the observed lightning strike points. The main aim of this paper is to describe a physics-based method to assess the location of vulnerable places to be struck by lightning on complex grounded structures. In the latter, the striking - inception - distances of the same buildings studied in Paper VII were computed in the presence of the downward leader. The leader inception zones were computed taking into account the horizontal position of the downward leader channel respective to the analyzed corners. A qualitative comparison of the obtained results with the predictions of the existing methods is presented. 


\section{Initiation of lightning upward positive leaders}

"As soon as any of the thunder-clouds come over the kite, the pointed wire will draw the electric fire from them; and the kite, with all the twine, will be electrified"

From a Letter of Benjamin Franklin to Mr. Peter Collinfon concerning an electrical kite, 1752.

During a thunderstorm, positive upward leader discharges can be initiated from grounded structures under the influence of the electric fields produced by either an active thundercloud with dominant negative charge (upward initiated negative lightning) or by the descent of a downward negative stepped leader (downward negative lightning). In the former case, upward positive leaders are triggered by the presence of tall structures or from objects with moderate height (lower than $100 \mathrm{~m}$ ) located on mountain tops under charged thunderclouds [89]. They appear to coincide in time with long horizontal strokes between clouds [37], which provide the high electric field required to initiate upward leaders in the absence of a downward leader. In the latter case, one or several upward connecting leaders are initiated at sharp grounded objects by the rapidly increasing electric field produced as the downward stepped leader approaches to ground. Then, the incepted upward leaders start to propagate towards the downward moving leader trying to make connection with it [38].

The initiation of upward leaders is the first condition necessary to get a lightning strike to a protruding grounded object. Thus, it is generally believed that a lightning flash strikes a structure at the point where a selfpropagating upward positive leader is first incepted [8]. Consequently, the upward leader inception is a key step on the evaluation of lightning attachment to grounded objects. This is because the prediction of the upward leader initiation is the starting point for any leader propagation model [72]. On the other hand, the knowledge on the conditions required to initiate upward leaders under thunderclouds is important to evaluate the risk of upward lightning initiated from tall towers.

The present chapter is devoted to the physics and modelling of upward leaders initiated from grounded objects. Only upward positive leader dis- 
charges associated to negative lightning flashes are studied in this document. Hence, the leader inception models proposed to evaluate the initiation of upward lightning positive leaders are briefly described and discussed. A physics-based model to estimate the upward leader inception conditions in both upward initiated and downward lightning is also introduced. In addition, the proposed model is used to evaluate the differences between leader discharges in the laboratory and under natural conditions. Besides, the effect of the space charge layer on the initiation of upward lightning is analysed in the last section of this chapter.

\subsection{Positive leader discharges}

The leader discharge is the main physical mechanism of breakdown in long air gaps [46]. The time-evolved stages of the leader positive discharges have been identified from streak photographs taken in laboratory experiments when switching impulse voltages are applied to long air gaps [46-48]. As it is schematically shown in Figure 2.1, a first streamer corona burst is created (time $t_{l}$ ) when the electric field on the surface of the positive electrode is high enough to initiate streamers. This condition is known as the streamer inception. Once initiated, a streamer starts propagating from the electrode and then splits into many branches forming a conical volume [47]. These branched streamers develop from a common stem. The space charge injected in the gap by the first corona distorts the electric field in the configuration and produces a dark period where no streamers are created. The duration of the dark period $\left(t_{2}-t_{1}\right)$ depends upon the injected charge and the rate of increase of the applied voltage [47].
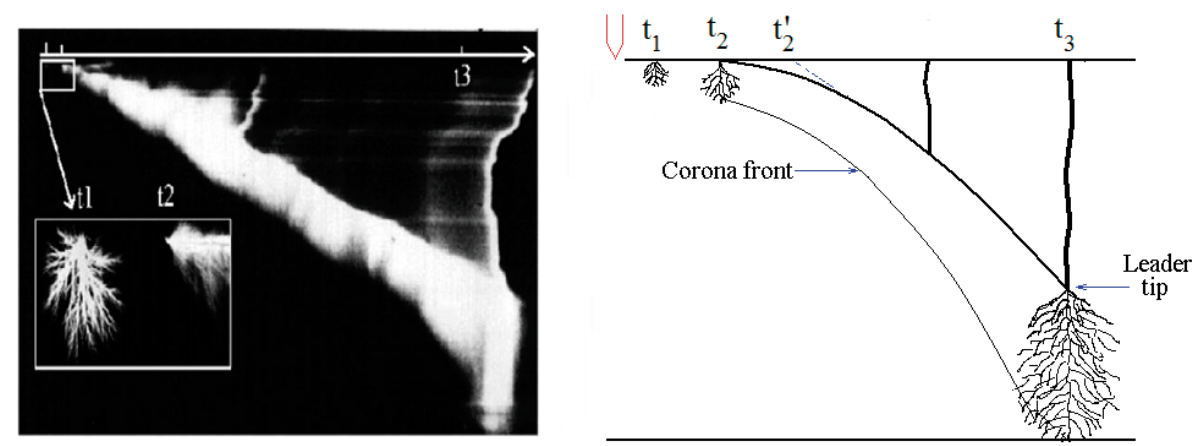

Figure 2.1. Streak image and sketch of the development of positive leaders in laboratory long air gaps (adapted from [56]).

After the dark period, a second corona burst is incepted (time $t_{2}$ ) as the total electric field on the surface of the electrode increases due to the increase in 
the applied voltage. Depending upon the energy input supplied by the streamers, the temperature of the stem of the second corona burst can reach a critical value around $1500 \mathrm{~K}$ [50], leading to the creation of the first leader segment. This transition from streamer to leader is usually called the unstable leader inception. It takes place if the total charge $\Delta Q$ in the second or subsequent corona bursts is equal to or larger than about $1 \mu \mathrm{C}$ [50]. This value corresponds to the critical charge required to thermalize the stem of the streamer, after at least one corona burst (first corona) has occurred.

However, the transition from streamer to leader is not sufficient to guarantee the stable propagation of the newly created leader. Only when the energy available in front of the leader tip is high enough to sustain the thermalization of its channel and the creation of new leader segments, the leader starts continuously propagating (time $t^{\prime}{ }_{2}$ ) with streamers developing at its tip (Figure 2.2). This condition is defined as the stable leader inception.

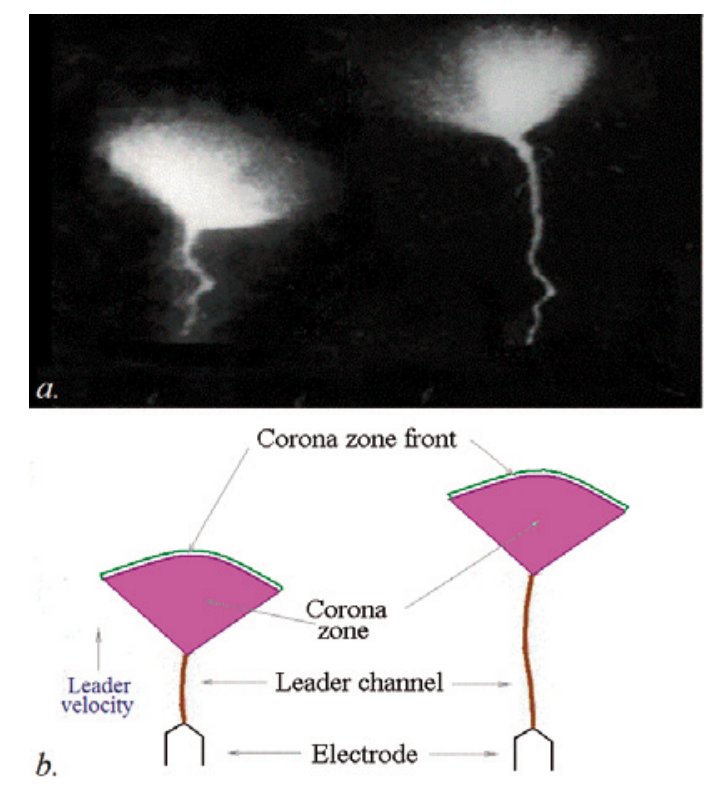

Figure 2.2. Detail of the structure of positive leader discharges. $a$ ) Frame image (adapted from [56]), $b$ ) sketch of the leader channel and the corona zone at its tip.

In the laboratory, it has been observed that positive leaders propagate continuously with an approximately constant velocity [47]. The estimated velocity of positive leaders in the laboratory ranges between $10^{4}$ and $3 \times 10^{4} \mathrm{~m} \mathrm{~s}^{-1}$. The leader velocity has been correlated to the leader current through a proportionality term, which represents the charge per unit length required to thermalize a leader segment [46-48]. This parameter, which depends mainly on the rise time of the applied electric field and the absolute humidity, has been estimated between 20 and $50 \mu \mathrm{C} \mathrm{m}^{-1}$ [50]. 
The last stage of the leader propagation is the final jump (time $t_{3}$ in Figure 2.1). It takes place when the streamers of the leader corona reach the opposite electrode. This stage is characterized by the creation of a high conductivity path that short circuits the gap and leads to the voltage collapse and the rapid increase of the current [46].

Even though positive leaders are not easily detectable with streak photographs under natural conditions [37], optical measurements of upward leaders triggered by tall towers (upward initiated lightning) have fortunately been recorded. Interestingly, the first optical measurements of upward lightning from tall towers suggested that upward positive leaders sometimes exhibit a kind of stepping $[42,44]$. The estimated velocity of the observed upward lightning leaders ranged between $4 \times 10^{4}$ and $10^{6} \mathrm{~m} \mathrm{~s}^{-1}[42,44]$. Later measurements [81-83] report estimates of the velocity of upward leaders ranging between $6 \times 10^{4}$ and $1.4 \times 10^{6} \mathrm{~m} \mathrm{~s}^{-1}$. In that case, however, all the upward leaders that were observed propagated continuously without any stepped motion [83].

The first measurements of upward connecting leaders (under the influence of downward stepped leaders) reported in the literature appeared in 1990 [80]. The average propagation velocity of the observed upward connecting leaders initiated from a tall tower ranged from $8 \times 10^{4}$ to $2.7 \times 10^{5} \mathrm{~m} \mathrm{~s}^{-1}$. Unfortunately, it is not possible to distinguish between positive or negative upward connecting leaders in the dataset reported in [80] since neither the polarity nor the return stroke peak current were reported. Recently, the propagation of an upward connecting leader initiated from a tower under the influence of a branched descending stepped leader has been detected with an intensified, high-speed camera in the USA [84]. The minimum detected velocity of the upward connecting leader was $2.7 \times 10^{4} \mathrm{~m} \mathrm{~s}^{-1}$ after inception and then the velocity gradually increased to a value close than $2.5 \times 10^{5} \mathrm{~m} \mathrm{~s}^{-}$ 1 just before the connection with the downward leader. The descending stepped leader propagated with an average velocity of $2.5 \times 10^{5} \mathrm{~m} \mathrm{~s}^{-1}$. No record of the upward leader current has been made in any of these experiments with tall instrumented towers.

On the other hand, rocket triggered lightning experiments have been an intensive source of information about upward positive leaders under natural conditions $[1,38]$. Experiments with triggered lightning can provide information about upward leaders either triggered by the thundercloud electric field or initiated by the descent of a triggered downward stepped leader.

In the case of classical triggering, an upward positive leader is launched from the tip of a rocket trailing a thin grounded wire under an active thundercloud [38]. The inception of the upward leader usually takes place when the rocket is at an altitude of 200 to $300 \mathrm{~m}$ [1]. As the rocket ascends, several current pulses are usually measured before the inception of the selfpropagating upward leader [74-76]. This current pulses are attributed to unstable aborted leaders (precursors) launched from the tip of the triggering 
rocket, which stop propagating after some few meters. The charge of individual pulses has been estimated in the order of several tens of microcoulombs [74]. After these pulses, the current gradually damp out and merge into a slowly varying current of few amperes [76]. As the upward leader keeps moving towards the thundercloud, the measured current can reach few hundred of amperes [74, 90]. Streak images in classical rocket triggered lightning show upward leader velocities ranging between $2 \times 10^{4}$ and $10^{5} \mathrm{~m}$ $\mathrm{s}^{-1}$ [75]. In some experiments [75, 91], the triggered upward leader appears to propagate with discontinuous luminosity of its tip (Figure 2.3.a), which has been interpreted as stepping [38]. In some other experiments [90], the upward positive leaders appear to propagate continuously (Figure 2.3.b).
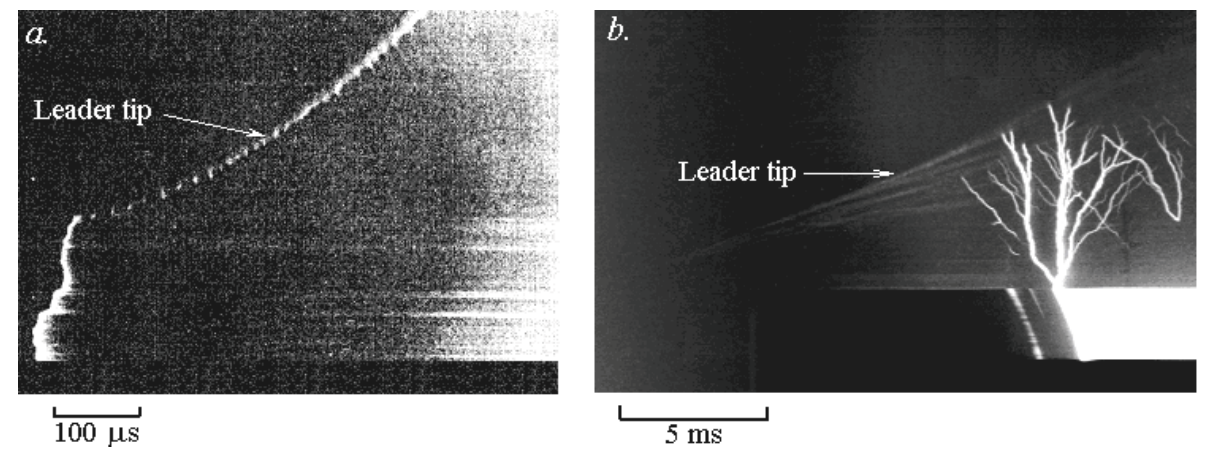

Figure 2.3. Streak image of upward positive leaders initiated with the classical rocket triggered lightning technique. $a$ ) upward leader propagating with discontinuous luminosity at its tip (adapted from [91]). b) upward leader continuously propagating (adapted from [90]).

In the triggering technique called altitude triggering [38], the ascending rocket is trailing a thin wire that is not grounded. Usually, this floating wire is connected to an insulating wire followed by a grounded wire. Similar to classical triggering, an upward positive leader is launched from the rocket tip by the ambient thundercloud electric field. Some microseconds later, an upward connecting positive leader is also initiated from the grounded wire under the influence of a downward negative leader triggered from the bottom end of the floating wire. Up to date, few experiments with altitude rocket triggered lightning have been reported in the literature [74, 75]. It has been reported that a small current of few amperes with superimposed pulses starts to flow in the ground wire when the upward connecting leader is incepted [74]. In response to the descent of the triggered downward stepped leader, the upward leader current continuously increases with superimposed pulses, which suggests stepping [74]. Since upward connecting leaders created in altitude rocket triggered lightning are very faint, no streak image or velocity estimation is available. 


\subsection{Existing leader inception models}

Due to the importance of the leader initiation condition on the evaluation of breakdown in long sparks, leader inception models were first proposed in the literature to estimate the breakdown voltage in the laboratory. The critical radius concept introduced by Carrara and Thione [64] and the generalized leader inception model of Rizk [70] are the main leader inception models proposed for laboratory long sparks.

The critical radius concept considers that a positive leader is initiated at the corona inception voltage obtained if the electrode's curvature was defined by a critical radius, for any configuration with electrode radius equal to or smaller than the critical radius [64]. It is based on the fact that the breakdown voltage in sphere-plane and conductor-plane configurations remains almost constant for electrodes with radius lower than the critical value and increases accordingly with the corona inception voltage for larger radii. Under switching impulse voltages $230 / 3000 \mu$ s, the critical radius was observed to increase with gap length, reaching an asymptotic value of about 0.1 and $0.36 \mathrm{~m}$ for conductor-plane and sphere-plane configurations [64].

The Rizk model is based on the observed correspondence that exists between the conditions prevailing at the moment of the final jump and the initial stage of the leader development. This condition takes place when impulse voltages with critical rise time of about $500 \mu$ s are applied. As a result, a generalized equation to compute the voltage required to incept a continuous propagating leader from any configuration was proposed in [70]. An attempt to extend the generalized leader inception model of Rizk to other geometries is reported in [92].

These models were soon extrapolated to evaluate the initiation of upward lightning leaders under natural conditions from rods, masts, power lines [61, 62, 65, 66, 68, 69] and from buildings [93]. Moreover, further experiments in the laboratory were performed under configurations that resemble in a better way the conditions of a lightning rod under a thundercloud $[94,95]$. In the case of the critical radius concept, it was found that the asymptotic value of the critical radius for earthed electrodes placed between ground and a metallic net energized with a negative switching voltage impulses $500 / 6000 \mu$ s was about $0.28 \mathrm{~m}$ [94]. For the same configuration, the generalized leader inception model of Rizk was in good agreement with the experimental results [95].

Based on experimental results obtained in long gaps, other models have been developed for the initiation of upward leaders from grounded structures. Petrov and Waters [96] proposed a leader inception criterion based on the length of the streamer zone and the range of electric field intensification produced by the presence of a grounded object. For this reason, it is usually called the field intensification model [32]. It assumes that a positive upward leader can successfully develop when the streamers from the structure ex- 
tend beyond a critical length equal to $0.7 \mathrm{~m}$. The electric field over the streamer zone must exceed a value equal to $500 \mathrm{kV} \mathrm{m}^{-1}$. A similar approach was followed by Akyuz and Cooray [97] but considering a critical streamer length of $2 \mathrm{~m}$. The field intensification model was extended in [98] by assuming that the stable propagation of the incepted leader is reached if the rate of change of the potential induced by the downward leader at the tip of

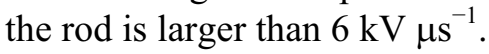

Later, Bazelyan and Raizer [99] also proposed a model to determine the conditions required to initiate upward leaders. It is based on a set of semiempirical expressions derived from experiments in laboratory long gaps, which describe the velocity, electric field and current of the upward leader.

With the development of theoretical leader inception and propagation models [54-59], a most appropriate way to evaluate the initiation of upward leaders under natural conditions was available. Thus, Lalande [57] applied the physical model for the leader propagation in long gaps proposed in [52] to derive an equation for the critical background electric field necessary to initiate stable upward leaders. This critical field, called the stabilization electric field, was calculated for rods and conductors. He assumed that the background electric field does not vary during the inception process, which corresponds to the case of upward lightning from tall towers or triggering rockets. Few years later, Lalande [56] introduced a second equation for the stabilization electric field from rods, conductors and triggered rockets. No further information of the changes introduced to the model was given.

\subsection{The proposed leader inception model}

Due to the evident differences in the time variation of the electric fields produced by thunderclouds and those produced by the descent of a downward moving leader, the concept of static and dynamic upward leader inception is introduced in Papers I and II. The static case corresponds to the initiation of upward leaders from tall grounded structures under the influence of the electric field produced by a thundercloud with dominant negative charge (upward initiated negative lightning). The dynamic case corresponds to the initiation of upward connecting leaders from grounded objects under the influence of the changing electric field produced by the descent of a downward negative stepped leader (downward negative lightning). The differences in the leader inception conditions for both cases are similar to the equivalent case of leaders initiated in the laboratory under DC voltages and under impulse voltages. 


\subsubsection{Evaluation of the static upward leader inception}

For the static case, the leader inception model presented in Paper I assumes that a stable upward positive leader is initiated when the background electric field is high enough for the stable propagation of the leader at least along the first few meters. The charge injected in the corona zone in front of the leader channel is computed and used to determine the leader advancement step. The relation between the leader velocity and the current proposed by Gallimberti [50] is used for the calculations.

During each simulation step, the corona charge is evaluated by assuming that the electric field in the corona zone is constant [52]. The leader potential gradient is assumed to vary as a function of the leader length according to a semi-empirical equation derived by Rizk [70]. The corona charge calculation is performed in 3 dimensions in order to consider the analysis of leaders initiated from structures with and without axial symmetry such as buildings, complex structures, etc. The analysis of the leader propagation is iteratively performed until the leader stops moving or until the leader advancement steps continuously expand. This last condition defines the stable leader inception condition. Similar to the analysis of Lalande [57], this model also assumes that the background electric field does not vary during the inception process.

Furthermore, in order to facilitate its implementation for practical cases, a simplified algorithm of the leader inception model is also introduced in Paper I. It is based on an iterative geometrical analysis of the potential distribution in front of the analyzed structure, such that a set of equations are iteratively solved to evaluate whether an upward leader is able to propagate or not. This model has been used to evaluate the effect of the space charge layer on the thundercloud electric fields required to initiate upward lightning leaders from tall towers in Paper IV. In addition, the model is used to compute the leader inception conditions from grounded complex structures in Papers VII and VIII. An independent analysis of the likely lightning striking points in wind mill farms, performed with the leader inception model presented in Paper I, has been reported in a doctoral thesis at the Technical University of Denmark [100].

\subsubsection{Evaluation of the dynamic upward leader inception}

For the case of upward connecting positive leaders initiated under the influence of the electric field produced by the descent of a downward stepped leader, a time dependent leader inception model is introduced in Paper II. It corresponds to an improved and extended version of the model presented in Paper I, which account for the time variation of the electric field as well as for the space charge left by streamers and aborted leaders produced before the stable leader inception takes place. In this case, the simulation is initiated 
by computing the height of the downward leader tip where the streamer inception takes place. Once the first streamer is initiated, its charge is computed by using the same representation of the corona zone as in the static case [52]. This charge is then used to calculate the duration of the dark period where no streamers are produced. A new streamer burst is generated until the streamer inception condition is satisfied again due to the increase of the electric field caused by the descent of the downward leader. This analysis is repeated until the total charge of any subsequent corona burst is equal to or larger than $1 \mu \mathrm{C}$ [50]. This condition defines the streamer to leader transition (unstable leader inception) in which the first leader segment is created.

The simulation of the leader propagation is started by evaluating the potential at the tip of the first leader segment. In order to improve the calculation of the leader tip potential used in the static case, the thermohydrodynamical model of the leader channel proposed by Gallimberti [50] is used instead. The total corona charge in front of the leader segment is computed with the charge simulation method or with the geometrical analysis of the potential distribution before and after the corona formation. Then, the electric field for the new position of the downward leader channel is updated. The relation between the leader velocity and the current proposed by Gallimberti [50] is also used in the dynamic model.

Based on the predictions of the model, the effect of the tip radius on the efficiency of lightning rods is discussed in Paper II. It is also found that the initiation of upward connecting leaders depend on the average velocity of the downward approaching leader. Thus, it is shown that the striking - inception - distance increases as the average downward leader velocity augments. For a $10 \mathrm{~m}$ tall rod and a prospective return stroke peak current of $10 \mathrm{kA}$, the predicted striking - inception - distance for the lower and the higher limits of the downward leader velocity reported in the literature differs by more than $80 \%$.

\subsection{On the validity of the existing leader inception models for lightning studies}

The question about the validity of the leader inception models when applied to natural lightning dates back to the moment when the first laboratory-based model was used to evaluate the initiation of lightning positive leaders [61]. Due to the fact that the experimental measurements of lightning strikes to towers $[42,44,61]$ did not provide enough data related to the conditions for upward leader initiation under natural conditions, laboratory experiments were initially suggested to validate the models.

Hence, Bernardi et al [94] performed laboratory experiments to test the validity of the critical radius concept for lightning studies. A laboratory ar- 
rangement of grounded electrodes between ground and an energized net overhead was used, which is more similar to the real case of a grounded object under a thundercloud. Rods and conductors up to $21 \mathrm{~m}$ high were tested for gap distances (between the electrode and the overhead net) ranging between 3.5 and $7 \mathrm{~m}$. From this experiment, the theory of the critical radius was confirmed but with a different and constant value of the critical radius (equal to $0.28 \mathrm{~m}$ ) for both electrodes. After this, several other experiments have been carried out $[95,101]$ in order to test the validity of the critical radius concept [64] and the generalized leader inception model of Rizk [70].

However, laboratory leader discharges are apparently not long enough to become fully thermalized and therefore they require larger background electric fields to propagate in comparison with upward lightning leaders [76]. In addition, it appears that the switching voltage waveforms used in the laboratory do not resemble the electric fields produced by a downward moving leader. Therefore, the leaders in the laboratory have different features compared with upward leaders initiated under the natural conditions, as it is shown in Paper III. Since it has been found that laboratory experiments cannot adequately simulate the conditions under natural lightning [37, 72], they cannot be used to validate leader inception models used for lightning studies.

Due to the same reasons, empirical data taken from laboratory experiments cannot be directly used to model upward leaders under natural lightning [72]. This fact also brings serious doubts on the validity of leader inception models based on empirical equations or criteria taken from laboratory leaders when applied for lightning studies. This is the case of the critical radius concept [64] and the leader inception models of Rizk [70], Petrov and Water [96], and Bazelyan and Raizer [99].

In the case of the critical radius concept, laboratory experiments also show that critical radius varies with the rise time of the applied voltage [48] and the electrode geometry $[48,94]$. Therefore, the critical radius concept is strongly geometry dependant and the estimations of the leader inception conditions are highly influenced by the chosen critical radius, as shown in Papers I and II. On the other hand, the assumptions used to derive the leader inception model of Rizk [70] are only valid for critical rise time of about $500 \mu \mathrm{s}$ [48]. This condition does not apply for the rate of increase of the electric field experienced by upward connecting leaders.

With the development of rocket triggered lightning techniques, a better source of experimental data under natural conditions was available. One of the first measurements of electric field at ground level at the moment of initiation of upward leaders as a function of the rocket height was published in 1985 [102]. This experiment reported that upward leaders were initiated from the rocket at a height of about 100 to $200 \mathrm{~m}$ above ground when the ground electric fields ranged between 5 and $10 \mathrm{kV} \mathrm{m}^{-1}$. This data was later 
used to justify the validity of the leader inception model of Rizk to evaluate upward connecting leaders under natural conditions [69].

However, later experiments showed that there is no clear relationship between the altitude of the rocket at the moment of upward leader inception and the electric field at ground, contrary to the earlier investigations [103]. This is because a space charge layer is produced by corona at ground level due to the thundercloud electric field $[77,78]$. For this reason, measurements of electric field at ground level during the initiation of upward leaders from triggered rockets or tall instrumented towers cannot describe the effective background electric field at the triggering height and consequently cannot be used to validate leader inception models.

Even though other triggered lightning experiments were performed to gather more information about different aspects of the lightning flash [74, $75,104]$, the first measurements of the effective background electric field required to initiate upward leaders from a triggering rocket were not performed until 1999 [76]. In this experiment, the vertical ambient electric field profile beneath thunderstorms was measured with a second measuring rocket fired 1 second before the triggering rocket. In this way, the effective ambient electric field at the height of the rocket where the upward leader inception takes place was measured considering the electrostatic shielding produced by the space charge layer.

Figure 2.4 shows the background leader inception (static) electric fields computed with the different models and the average electric fields measured in the rocket triggered experiment [76]. Observe that the predictions of the Rizk model [67] and the first equation of Lalande [57] do not agree with the results of the triggered lightning experiment [76]. The other leader inception criteria, namely the Petrov and Waters model [96], the Bazelyan and Raizer model [99], the second equation of Lalande [75] and the proposed static leader inception model (Paper I), are in rather good agreement with the experimental values.

In particular, there is a good agreement of the model presented in Paper I with the measurements when the space charge left behind the rocket by aborted streamers and leaders is taken into account. Even though the space charge produced at the tip of grounded structures may influence the initiation of upward leaders [105-107], the space charge left behind the rocket also affects the leader inception conditions in triggered lightning experiments as shown in Paper I. This effect had not been taken into consideration by any other leader inception model before.

Note that despite of the apparent agreement of some models with the experimental data [76], it is still not possible to fully validate them to evaluate the inception of upward positive leaders triggered by tall structures. This is because the average leader inception electric fields measured in the triggered lightning experiment [76] only covered triggering heights larger than $200 \mathrm{~m}$. 


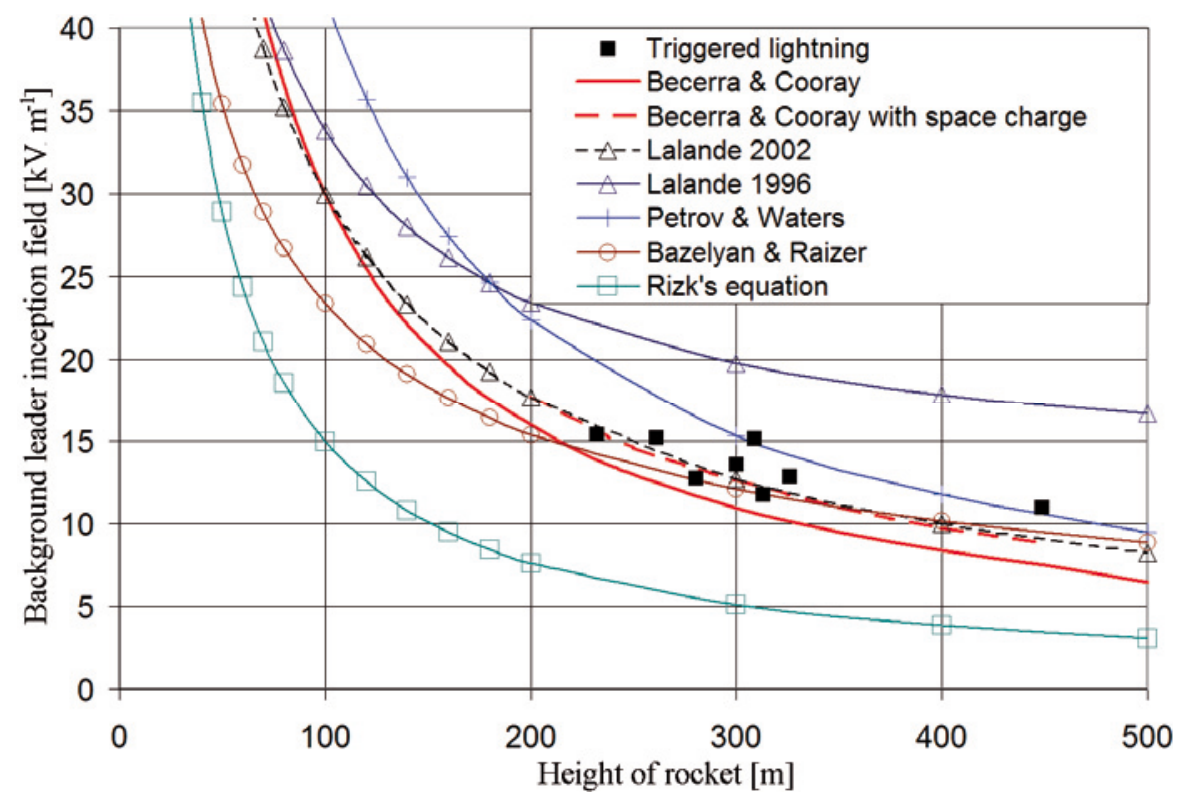

Figure 2.4. Comparison of the background average electric fields required to initiate stable upward positive leaders from a rocket, obtained with different leader inception models and measured in a classical rocket triggered lightning experiment [76].

Even though the existing data suggests that structures lower than $100 \mathrm{~m}$ do not normally initiate upward lightning [89], there are recent reports of upward initiated lightning from objects as short as $50 \mathrm{~m}$ on flat ground [108]. Due to the large differences between the leader inception models for heights lower than $200 \mathrm{~m}$, further experiments with instrumented towers and rocket triggered lightning are required to measure the effective background electric fields required to initiate upward leaders triggered by shorter structures.

On the other hand, Lalande and coauthors [74] performed an altitude triggered lightning experiment with simultaneous records of current, electric field and luminosity measured during the initiation and propagation of an upward connecting leader. In this experiment, the rocket first spooled out 50 $\mathrm{m}$ of grounded wire, followed by $400 \mathrm{~m}$ of insulating Kevlar and from it to the rocket tail a second (floating) copper wire [74]. Then, an upward positive leader is initiated from the top end of the floating wire and consequently a negative stepped leader is initiated from its bottom end. In response to this downward moving negative leader, an upward connecting positive leader is initiated from the top end of the grounded wire. The upward leader current, the electric field change produced by the descending negative leader (measured at $50 \mathrm{~m}$ from the wire) and the leader luminosity (with still and streak photography) were measured simultaneously during the experiment.

In order to reconstruct all the physical parameters during the inception of the upward connecting leader in this experiment [74], the time-dependent 
leader inception model presented in Paper II is used. Figure 2.5 shows the predictions of the model for the main physical parameters of the upward connecting leader in the experiment before and during its initiation. It is predicted that several streamers and aborted leaders are launched before the inception of the successful upward connecting leader, which takes place around $4 \mathrm{~ms}$. This calculated leader inception time is in good agreement with the experimentally estimated value of $4.02 \mathrm{~ms}$ [74]. As the downward stepped leader approaches to ground, the total corona charge in front of the upward connecting leader tip augments and its channel potential gradient decreases (Figure 2.5d). Consequently, the injected current and the velocity increases and the upward leader starts accelerating continuously reaching the stable propagation condition. Note the good agreement between the computed leader current and the main component of the measured current (Figure $2.5 b$ ).

Based on the reconstructed physical parameters of the upward connecting leader in the experiment (Figure 2.5), the validity of the assumptions considered in the Petrov and Waters [96, 98] and Bazelyan and Raizer [99] models are analyzed. No further discussion of the validity of the critical radius concept [64] and the generalized leader model of Rizk [67] is made given the inaccuracy of these models when applied to lightning. In addition, the leader inception equations of Lalande [56] are not discussed further since they only consider the initiation of leaders under static electric fields (in the absence of a downward stepped leader).

In first place, note that the length of the streamer zone during the creation of the successful leader in the experiment is about $1.7 \mathrm{~m}$ (Figure 2.5.a). This value is several times larger than the critical value of $0.7 \mathrm{~m}$ assumed by Petrov and Waters [96]. Moreover, the critical length of streamers at the moment of the unstable leader inception can vary between $0.7 \mathrm{~m}$ and $2 \mathrm{~m}$ due to the effect of the space charge produced by aborted streamers, as it can be seen in Paper II. This variation of the streamer length after unstable leader inception also occurs in the laboratory depending upon the rise time of the applied field [48], contradicting the constant value taken in [96].

As to the assumptions considered for the extension of the Petrov and Waters model [98], note that the velocity of an upward connecting leader can reach values as low as $10^{4} \mathrm{~m} \mathrm{~s}^{-1}$ (Figure 2.5.c), slower than the minimum upward leader velocity of $6 \times 10^{4} \mathrm{~m} \mathrm{~s}^{-1}$ considered in [98]. This value was used to estimate the critical rate of change in the induced potential at the rod's tip that would lead to the propagation of a stable upward connecting leader [98]. Since the velocity of upward connecting leaders can change from flash to flash as it is shown in Paper VI, it is not possible to define a constant critical rate of change in the induced potential as a measure of stable leader propagation, as it is assumed in [98]. 

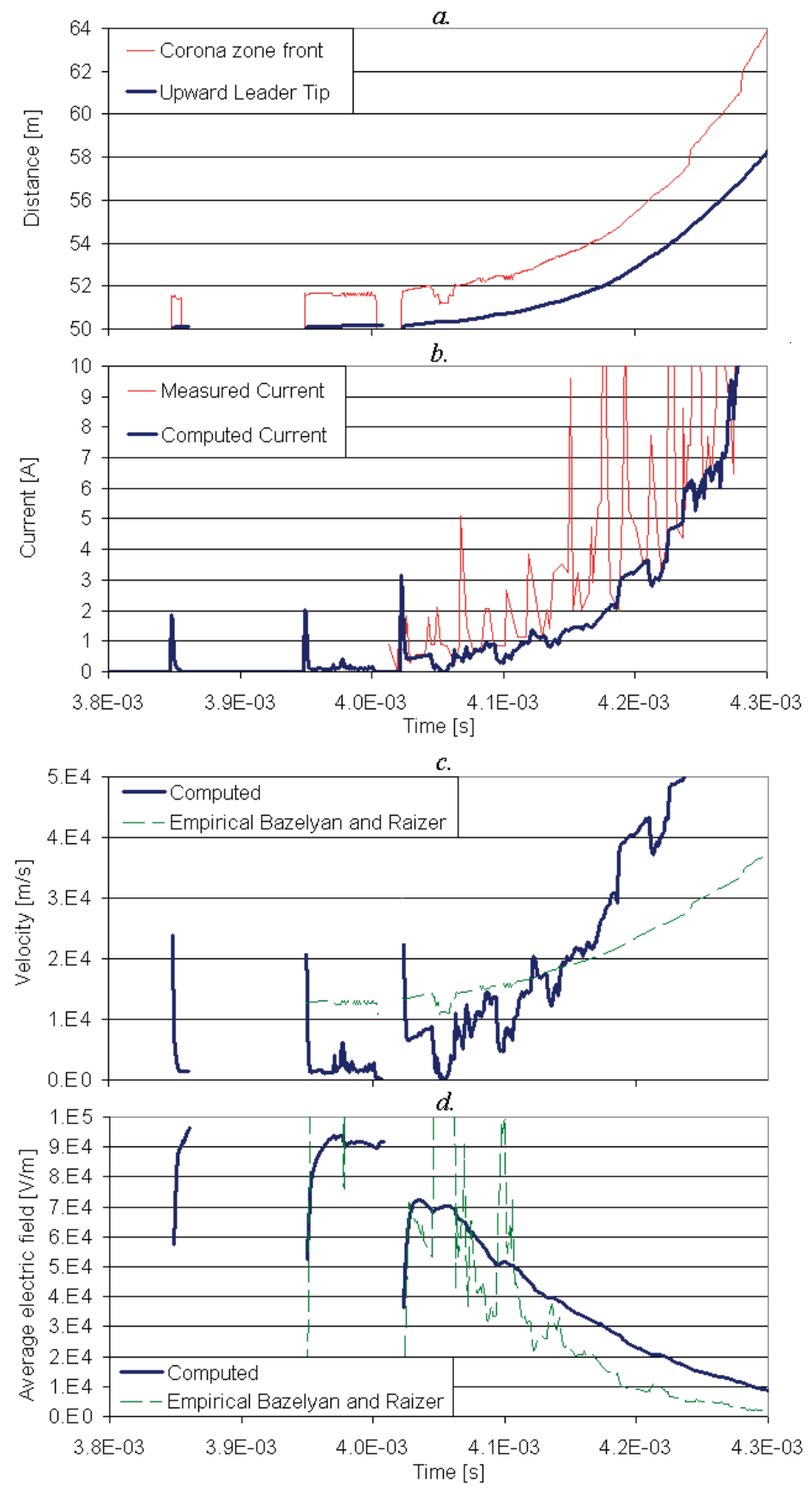

Figure 2.5. Predictions of the leader inception model presented in Paper II for the upward connecting leader in an altitude rocket triggered lightning experiment [76]. $a$ ) streak image, $b$ ) predicted and measured upward leader current, $c$ ) predicted upward leader velocity and values computed with an empirical equation [99], $d$ ) predicted leader channel average electric field and values computed with an empirical equation [99]. 
Regarding the leader inception model of Bazelyan and Raizer [99], it uses a set of empirical equations from laboratory experiments to estimate the upward leader velocity and the average leader channel electric field. For sake of comparison, the leader velocity and channel average field computed with these empirical equations are also shown in Figures $2.5 \mathrm{c}$ and $2.5 \mathrm{~d}$. Note that the empirical equations gives a higher velocity than the value estimated in the experiment, especially soon after the unstable leader inception takes place (Figure 2.5c). The empirical equation derived by Bazelyan and Raizer [99] gives a velocity of $1.2 \times 10^{4} \mathrm{~m} \mathrm{~s}^{-1}$ for any newly created leader, overestimating the propagation velocity of any leader immediately after its unstable initiation. On the other side, the empirical equation generally gives lower channel average electric fields than the estimated values. The combined effect of higher leader velocity and lower leader electric field obtained with the empirical equations of Bazelyan and Raizer [99] after unstable inception, would favor the propagation of unstable aborted leaders. This artifact of the model leads to the erroneous estimation of the stable leader inception time.

\subsection{On the validity of the Early Streamer Emission claim}

Even though the controversy over the extend to which results obtained in the laboratory can be applied to natural lightning is not new [8], it has been currently fuelled by the use of laboratory experiments to assess the efficiency of early streamer emission (ESE) terminals [33, 34]. However, the discussion of this issue together with the debate of the efficiency of the ESE terminals has been seldom based on actual test data or on enough theoretical evidence [30]. Although the testing of ESE terminals or lightning rods under natural conditions is the very best way to solve the controversy, it has obvious limitations [30]. Moreover, well-planned field experiments [85, 86] devoted to evaluate the efficiency of lightning rods have been subject of questions [30].

Due to these reasons, the manufacturers of ESE devices keep indiscriminately using laboratory experiments to justify their claims [33, 34]. They are usually substantiated by the fact that an earlier initiation of streamers in an air gap in laboratory under switching voltages leads to the reduction of the leader initiation time and therefore to a shorter time to breakdown [87-88]. This is the basis of the Early Streamer Emission concept. Consequently, the reduction on the leader initiation time in the laboratory has been arbitrarily extrapolated to the natural case by ESE supporters. The main assumption of this extrapolation is that the switching electric fields applied in laboratory "fairly approximate" the electric fields produced by the descent of a negative downward moving leader [87-88]. 
Thus, it appears that the theoretical modelling of the upward leader initiation from lightning rods offers the best approach to answer the essential questions of the on-going controversy. Nonetheless, such analysis requires the inclusion of the statistics of discharge initiation, which is generally avoided in the existing theoretical models [30, 109]. Given the fact that the model introduced in Paper II can resolve in time the development of upward leaders, it is possible to evaluate the early streamer concept in the laboratory and under lightning conditions. Therefore, Paper III presents the predictions of the time-dependent inception model presented in Paper II for the initiation and propagation of leaders under both conditions. The stochastic nature of the streamer initiation time has been included to evaluate the effect of an early streamer on the leader inception time. It is found that the emission of an early streamer from a rod in a laboratory air gap under switching voltage waveforms indeed leads to an earlier inception of a positive leader. However, this effect does not happen when the same rod is exposed to the electric fields produced by a descending negative leader. In this case, there is no reduction in the stable upward leader inception time by triggering an early streamer.
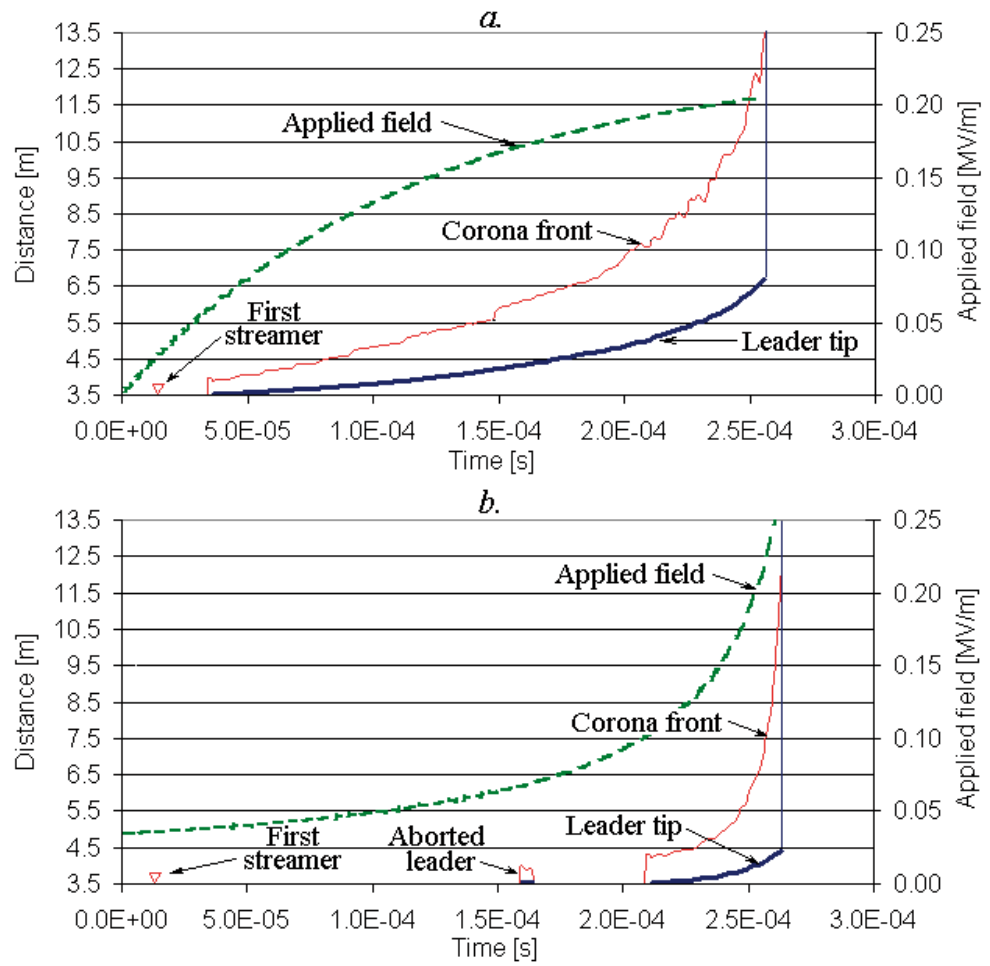

Figure 2.6. Simulated streak images of the initiation and propagation of a leader discharge under $a$ ) a laboratory switching electric field and under $b$ ) the electric field produced by the descent of a downward leader with prospective return stroke current of $5 \mathrm{kA}$ and average velocity of $2 \times 10^{5} \mathrm{~m} \mathrm{~s}^{-1}$. 
The reason why the early streamer concept found in the laboratory does not work under natural conditions is due to the differences in the rate of change of the electric field in both cases (Figure 2.6). The rate of increase of the lightning electric fields changes from slow to fast as the downward leader approaches, while the rate of change of the switching electric fields applied in laboratory changes from fast to slow. Due to this difference, the leaders in the laboratory have longer propagation times, are longer and are more dependent upon the inception of the first streamer (Figure 2.6a). In the case of lightning-like electric fields (Figure 2.6b), a stable leader is initiated a long time after the inception of the first streamer. It also can be preceded by one or several aborted leaders, and the initiated stable leader develops within a very short time. Thus, it is shown in Paper III that the switching voltage impulses used in the laboratory do not "fairly approximate" the electric fields produced by the descent of a downward leader, as claimed in [87-88]. These results leave without theoretical basis the claims of ESE manufactures. They also show that the leaders generated in laboratory have several differences compared with upward connecting leaders in natural lightning. Further discussion of other points regarding the ESE claims is also presented in Paper III.

\subsection{The space charge layer and the initiation of upward lightning}

Based on balloon electric field soundings, Standley and Winn [77] reported in 1976 that the electric fields aloft ground can be several times larger than at the surface. In one case, electric fields 6 times larger than at the ground surface were measured at $300 \mathrm{~m}$ above ground. This difference was attributed to the electrostatic shielding effect caused by the space charge layer formed by ions produced by corona at ground irregularities such as grass, bushes, etc. In this case, the maximum space charge concentration close to ground was estimated about $0.8 \mathrm{nC} \mathrm{m}^{-3}$.

Later, Chauzy and Raizonville [78] estimated charge densities at ground level ranging from 2 to $7 \mathrm{nC} \mathrm{m}^{-3}$ from the electric field profile in a thinner corona space charge layer (less than $200 \mathrm{~m}$ thick). In another experiment, the space charge layer extended up to an altitude of $600 \mathrm{~m}$ above ground with densities of about $1 \mathrm{nC} \mathrm{m}^{-3}$ close to ground [110]. From electric field measurements performed during a rocket triggered lightning experiment [76], the average charge density of a $500 \mathrm{~m}$ thick space charge layer was estimated as $0.3 \mathrm{nC} \mathrm{m}^{-3}$. The differences between the measured electric fields profiles and the estimated space charge densities in these experiments can be mainly attributed to variations of the neutral aerosol concentration $[78,111]$. How- 
ever, air motion (wind) of the sites can also influence the thickness and density of the space charge layer [111].

Due to the distortion produced by the space charge layer on the ambient electric field, it can influence the conditions for the initiation of upward leaders from grounded tall objects under thunderstorms [72]. Even though extensive work has been done on the local space charges created by corona at the tip of a grounded object [105-107], a thorough analysis of the effect of the space charge layer on the inception of upward leaders is not available in the literature. Thus, Paper VI presents the simulation of the space charge layer created during a thunderstorm and the analysis of its influence on the thundercloud electric fields required to incept upward lightning positive leaders from tall towers. In order to drive the calculation of the development of the space charge layer around a tall tower, the electric field measured at $600 \mathrm{~m}$ above ground during a triggered rocket experiment [110] was used as input parameter. The space charge profiles at the moment of four triggered lightning flashes to ground are obtained and used to evaluate the thundercloud electric field required to initiate upward lightning leaders from tall towers in the presence of the space charge layer. Different values for the neutral aerosol density and the corona current density of the site were also used to analyse the effect of these factors on the space charge layer profiles and the leader inception thundercloud electric fields.

It was found that the electrostatic shielding effect of the space charge layer does affect the conditions for upward positive leader inception from tall towers. Hence, considerably larger thundercloud electric fields are required to initiate upward leaders from tall towers immersed in a thick space charge layer than in a shallow or non-existing layer (as in the case of the sea). The neutral aerosol density is the factor that mainly influences the thickness of the space charge layer and consequently, the leader inception thundercloud electric field. Therefore, upward initiated lightning from towers is found to require lower thundercloud electric field in the case of polluted sites (with large neutral aerosol density) and coastal areas than in clean rural zones with low neutral aerosol density. 


\section{Interception of downward lightning stepped leaders by upward connecting leaders}

"The real voyage of discovery is not in discovering new lands, but in seeing with new eyes"

Marcel Proust.

As a downward negative lightning leader approaches to ground, one or several upward connecting leaders are initiated from protruding structures on the ground. These upward positive leaders propagate towards the downward moving leader driven by the electric field produced by its charge of opposite polarity. When any upward leader successfully intercepts the downward leader, a conducting path is created between the thundercloud charge center and the ground. Thus, the high lightning current is drained to ground, flowing through the place (struck point) where the successful upward connecting leader was initiated. This sequence of events represents the lightning attachment process.

Due to the better understanding of this process, the evaluation of the lightning exposure of grounded objects has been improved by the development of lightning leader propagation models [72, 113]. These models aim to predict the conditions required for the initiation and propagation of upward connecting leaders to finally estimate the point of connection between both leaders. Hence, the distance between the downward leader tip and the structure at the moment of the connection of the leaders, here called the interception distance, is the main output of these leader propagation models. In order to evaluate the lightning exposure of a ground structure, the models are applied for different horizontal distances between the structure and the downward leader channel. In this way, the lateral [65] or attractive distance [63] is obtained, which represents the maximum horizontal distance at which the connection of the downward leader is still possible. Together with the lightning flash density, this distance is generally used to evaluate the number of expected strikes to a structure per year.

In this chapter, the existing leader propagation models [62, 66, 69] are briefly described. A self-consistent leader propagation model is also introduced and used to evaluate the validity of the assumptions made by the exist- 
ing models. Furthermore, the lateral attractive distances computed with the self-consistent model for different possible conditions in a thunderstorm are shown in the last section of this chapter.

\subsection{Leader propagation models}

In 1979, Eriksson [61] suggested a pioneering method to evaluate the lightning attractiveness of grounded objects. Based on the analysis of photographs of lightning strikes to a tall instrumented tower, he suggested that the successful attachment of a downward stepped leader depends on the initiation of the upward leader and the relative velocity of the both leaders. The first condition, defined by the striking - inception - distance, determines the starting point of the propagation of the connecting leader. The later determines the upward connecting leader propagation length and defines a parabolic interception locus as shown in Figure 3.1a. Hence, Eriksson considered that the connection of the downward leader with the newly initiated upward leader is only possible within a volume defined by the surface generated by the striking distance and the parabolic locus. The lateral extension of this volume, called the collection volume, defines the lateral attractive distance. Eriksson used the critical radius concept [64] to evaluate the striking distance and assumed a unitary value for the velocity ratio of the downward and the upward leader. Since the inception conditions is driven mainly by the electric field produced by the downward leader charge, he assumed that the charge distribution increases linearly with the prospective return stroke peak current. Further, he assumed that the downward leader charge density is distributed linearly along its channel.

Based on his calculations, Eriksson [63] found that the lightning attractive distance does not only depend upon the prospective return stroke current (as the electrogeometric model suggests) but also upon the height of the analyzed object. Thus, he suggested an improved electrogeometric model based on the attractive distance, which is a function of both the prospective return stroke peak current and the height of the power transmission line [89]. However, Eriksson's model was soon questioned [112] since the calculated shielding angles of transmission lines were relatively insensitive to the conductor height, contrary to the predictions of the classical electrogeometric theory.

Dellera and Garbagnati $[65,66]$ proposed an iterative simulation of the propagation of both leaders based on electrostatic calculations, better known as the leader progression model (Figure 3.1.b). In contrast to Eriksson's, the leader progression model considers the electrostatic interaction between the downward and the upward leader to evaluate the direction of the upward leader propagation as well as the connection criterion. The downward leader is modeled by two line segments with uniform charge density. The lower 
$100 \mathrm{~m}$ of the downward leader channel is assumed to have a charge of 100 $\mu \mathrm{C} \mathrm{m}^{-1}$ while the charge of the rest of the channel is computed as a function of the prospective return stroke peak current. The charge of the thundercloud is represented by equivalent negative ring charges located at a height of $2 \mathrm{~km}$ above ground. The upward leader is modeled by line charge segments of constant density equal to $50 \mu \mathrm{C} \mathrm{m}^{-1}$ according to laboratory experiments. Both leaders are assumed to approach with a relative velocity ratio equal to four immediately after upward leader initiation and equal to one close to interception. The time variation of the velocity ratio was suggested to depend on the mean electric field between the tips of both leaders [72]. Similar to Eriksson's model, the critical radius concept [64] is used to evaluate the striking - inception - distance. The attachment of the downward leader is assumed to take place when the streamer zone of the upward connecting leader reaches the tip of the stepped leader.

Later, Rizk [67] pointed out that the results obtained with Eriksson [62, $63]$ and Dellera and Garbagnati $[65,66]$ models showed an excessive dependence of the interception distance on the structure height. This excess was attributed to the leader inception model - the critical radius concept used by these authors [67]. In order to overcome this problem, Rizk [67, 69] presented a model similar to Eriksson's, but based on his own leader inception model [70]. In this case, the propagation of the upward leader is simulated by assuming a unitary velocity ratio and an upward leader velocity vector directed towards the tip of the unperturbed downward leader (Figure 3.c). The charge of the downward leader was assumed to decrease linearly with height. The upward leader is modeled as a channel with a constant average potential gradient obtained from a semi-empirical expression from laboratory experiments [68].
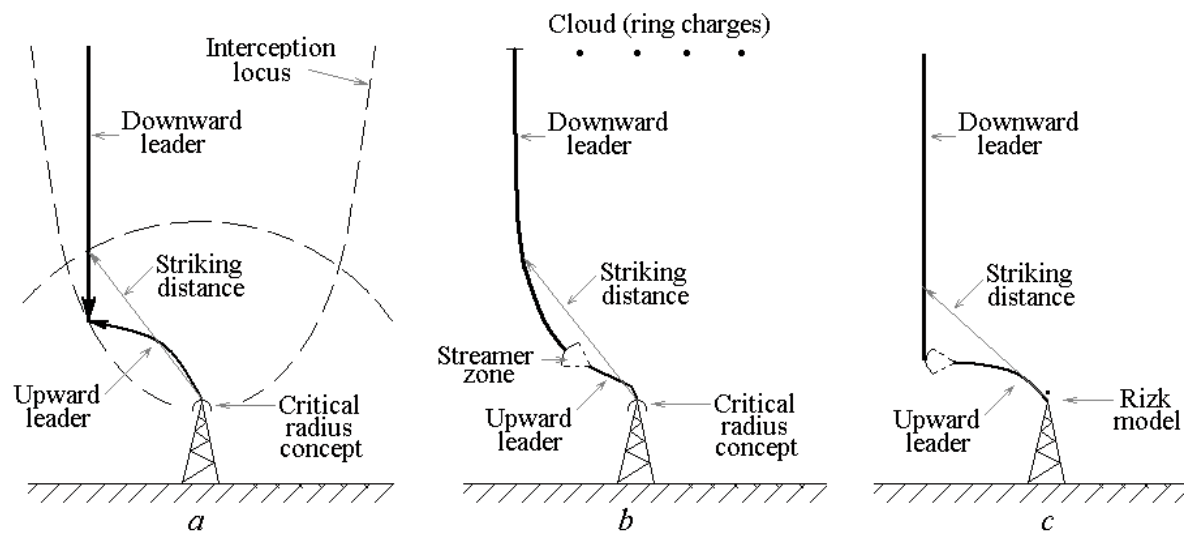

Figure 3.1. Sketch of the representation of the lightning attachment process by the $a$ ) Eriksson $[62,63], b)$ Dellera and Garbagnati $[65,66]$ and $c$ ) Rizk $[67,69]$ leader propagation models. 
Even though all these leader propagation models describe the main stages of the attachment of lightning flashes to grounded structures, they introduce different simplifying assumptions for each phase. Because of the lack of knowledge at the time when the models were proposed, different downward leader charge distribution, leader inception criterion, velocity ratio and upward leader properties were used in each case. For this reason, the results obtained with the leader propagation models are sometimes quite different, even for the same condition as it can be seen in Figure 3.2.

Unfortunately, sufficient field data to fully validate the leader propagation models is not available. Due to the inherent difficulties of controlled experiments to evaluate the lightning attractiveness of grounded objects, there are no direct estimates of lateral attractive distances. Nonetheless, the first attempt to indirectly estimate the lightning attractive distances from tall objects based on field observations was performed by Eriksson [63]. He gathered data of about 3000 observed lightning flashes to a variety of free standing structures with height ranging between $22 \mathrm{~m}$ and about $540 \mathrm{~m}$ in various regions in the world. Since the structures were located on places with different thunderstorm incidence (keraunic level) and unknown lightning flash density, he roughly normalized all the data to an arbitrary flash density of 1 flash $\mathrm{km}^{-2} \mathrm{yr}^{-1}$. By taking the normalized number of lightning strikes to the structures per year as a function of their height and considering a uniform lightning flash density of 1 flash $\mathrm{km}^{-2} \mathrm{yr}^{-1}$ for all the data worldwide, the lateral attractive distance of the structures was estimated.

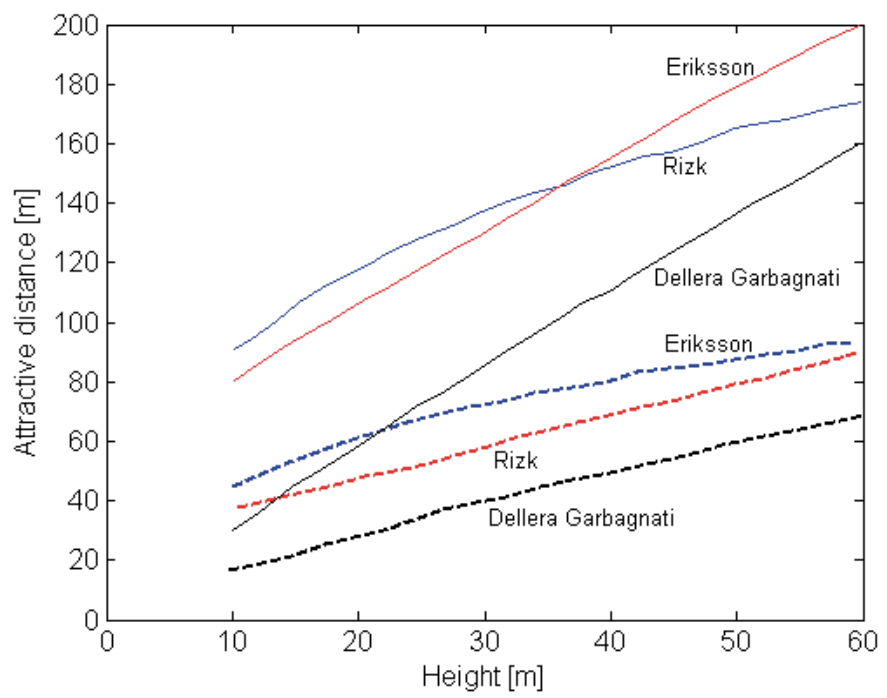

Figure 3.2. Comparison of the attractive distance of a free standing structure predicted by the Eriksson [62, 63], Dellera and Garbagnati $[65,66]$ and Rizk models $[67,69]$ for a prospective return stroke peak current of $20 \mathrm{kA}$ (solid line) and $60 \mathrm{kA}$ (dashed line). Adapted from [113]. 


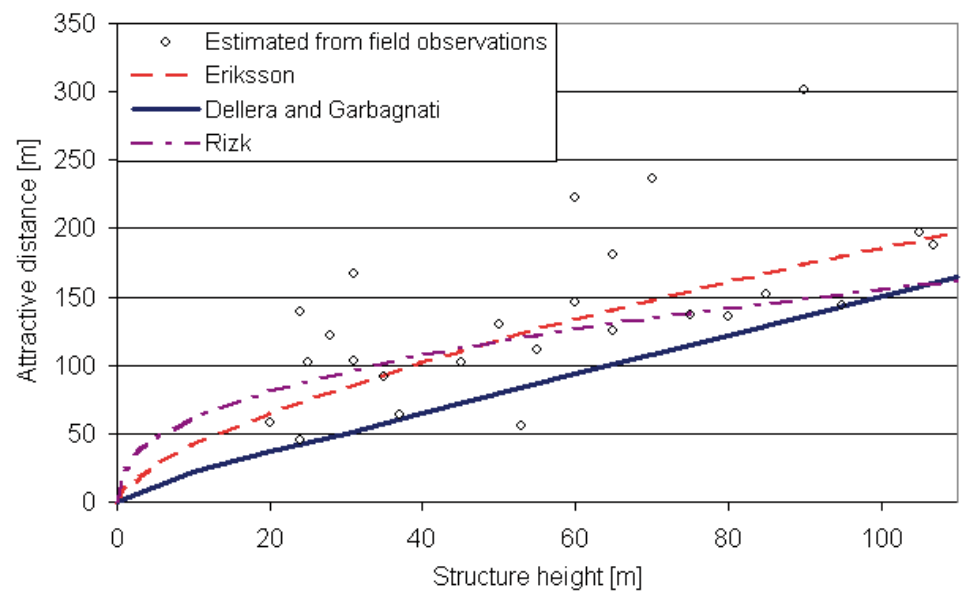

Figure 3.3. Lateral attractive distance estimated from field observations [63] and predicted by the Eriksson $[62,63]$, Dellera and Garbagnati $[65,66]$ and Rizk [67, 69] models for free standing structures as a function of height. A prospective return stroke peak current of $31 \mathrm{kA}$ was assumed for the models.

Figure 3.3 shows the comparison between the predictions of the Eriksson $[62,63]$, Dellera and Garbagnati [65, 66] and Rizk models [67, 69] with the attractive distances estimated from the field observations collected by Eriksson $[63,89]$. Notice the broad scatter of the attractive distances estimated from the field observations, which is caused by the various inadequacies in the collection, classification and normalization of the data. Especially, the normalization of the world wide results has significant errors due to the wide scatter of the relation between the flash density and the keraunic level used by Eriksson [114]. For instance, areas reporting a keraunic level of 20 thunderstorm days per year would have an estimated lightning density of 2 flashes $\mathrm{km}^{-2} \mathrm{yr}^{-1}$ even though they could in fact experience a flash density varying between 0.4 and 4 flashes $\mathrm{km}^{-2} \mathrm{yr}^{-1}$ [63]. This kind of error in the calculated lightning flash density leads to large errors in the estimated lateral attractive distances. For these reasons, the values estimated from the observed strike incidence to various structures by Eriksson [63] are inaccurate to be used for the validation of leader propagation models as done in $[63,68$, 72].

Other attempts to indirectly evaluate the accuracy of leader propagation models have been performed by comparing the predicted and observed shielding angles to effectively protect phase conductors in power transmission lines $[62,79]$. The field observations are based on the same dataset used by Whitehead and coauthors $[15,17-21]$ to calibrate the electrogeometric EGM theory. It corresponds to the observed effective shielding angles of high performance power transmission lines operating in the USA. Nevertheless, this kind of comparison is a gross validation since the shielding performance of power transmission lines is affected by several other factors 
such as environmental shielding (by trees), variations in the topography of the terrain, sag of the line, etc. $[14,15,115]$. Since these factors are difficult to evaluate or unknown for the transmission lines in the existing dataset, it is not possible to reproduce them with leader propagation models as to make a direct comparison between predicted and observed shielding angles.

\subsection{Self-consistent modelling of the upward leader propagation}

Even though some predictions of the leader propagation models agree with phenomena experienced in the field [72], they are based on some assumptions which have been questioned based on the current knowledge on the physics of leader discharges and lightning. Furthermore, some input parameters for the modeling of the upward connecting leader are unknown or difficult to estimate. Hence, most of these parameters have been taken from laboratory experiments given the similarities between lightning and laboratory long sparks. However, the physical properties of upward leaders in nature have been found to be different to those of leaders in the laboratory, as it is discussed in Section 2.5. Moreover, different experiments with natural and triggered lightning suggest that it is not possible to generalize the behavior of upward connecting leaders since it changes from flash to flash [61, 81].

For these reasons, it is required that a leader propagation model selfconsistently estimate the physical properties of upward connecting leaders in order to reduce the uncertainties of the calculations. These properties include the charge per unit length, the injected current, the leader channel gradient and the velocity of the upward connecting leader during its propagation towards the downward stepped leader. With this idea in mind, a self-consistent physical model to simulate the initiation and propagation of upward connecting positive leaders from grounded structures is introduced in Paper V. The model takes the time-dependant inception model presented in Paper II as a base, and extends the analysis of the upward leader propagation until the connection with the downward stepped leader. A careful analysis of the upward leader channel and the transition region in front of its tip is performed to self-consistently estimate the leader physical properties. The model uses a thermohydrodynamical model to estimate the leader channel properties together with a thermodynamic analysis of the transition zone where corona converges to the leader tip, both proposed by Gallimberti [50]. In this way, it is possible to extend the analysis performed in Paper II to simulate the advancement of upward connecting leaders even when they propagate several tens of meters towards the downward stepped leader.

Since it appears that the appropriate validation of a model should be performed in fine details, such as the reproduction of specific events, the alti- 
tude rocket triggered lightning experiment reported in [74] is analyzed in Paper V. In this experiment, a rocket is launched toward the cloud overhead, spooling $50 \mathrm{~m}$ of ground wire, followed by $400 \mathrm{~m}$ of insulating Kevlar and from it to the rocket tail a second (floating) copper wire. An upward leader is initiated and propagates upward from the top end of the floating wire, which leads to the initiation of a downward stepped negative leader at the floating wire bottom end. As a consequence, an upward connecting leader is initiated from the tip of the grounded wire in response to the triggered downward stepped leader. The leader current, the background ground electric field change at $50 \mathrm{~m}$ from the grounded wire and the leader luminosity (with static and streak photography) were measured simultaneously during the experiment [74].

To reproduce the experiment, the calculations presented in Paper $\mathbf{V}$ are driven by the downward leader charge, which was inferred based on the measured ground electric field at $50 \mathrm{~m}$ from the ground wire [74]. A good agreement between the estimations of the proposed self-consistent leader propagation model and the experimental data is found. The connecting leader in the experiment started its continuous propagation around $4.02 \mathrm{~ms}$, which is in excellent agreement with the leader inception time of $4 \mathrm{~ms}$ calculated by the model. There is also a good agreement between the simulated final jump time (at $4.33 \mathrm{~ms}$ ) and the value observed in the experiment (at $4.37 \mathrm{~ms}$ ). Furthermore, a good agreement between the predicted leader current and the continuous component of the current measured in the experiment was found.

Figure 3.4a shows the streak image for the altitude rocket triggered experiment [74] simulated with the self-consistent leader propagation model presented in Paper V. For sake of comparison, the predictions of the leader models of Eriksson [62, 63], Dellera and Garbagnati [65, 66] and Rizk [67, 69] are included in Figure 3.4.b. First, notice that the differences in the leader initiation time predicted by the existing propagation models are caused by the inception criterion used in each case. While Eriksson and Dellera and Garbagnati use the critical radius concept [64], Rizk uses his own leader inception model [70]. The introduction and discussion of the leader inception models is given in Chapter 2. Second, observe that the height of the downward leader tip, the connecting leader length and the time at the moment of the interception estimated by the existing leader propagation models differ considerably from the values computed in Paper V (Figure 3.4a). Since the charge of the downward moving leader was the same in all cases, these differences can only be attributed to the manner the connecting leader is represented by the different models. Consequently, the differences in the estimations shown in Figure 3.4b are the result of the combination of the errors introduced by the assumptions considered by each model regarding the inception, velocity and channel properties of the connecting leader. 


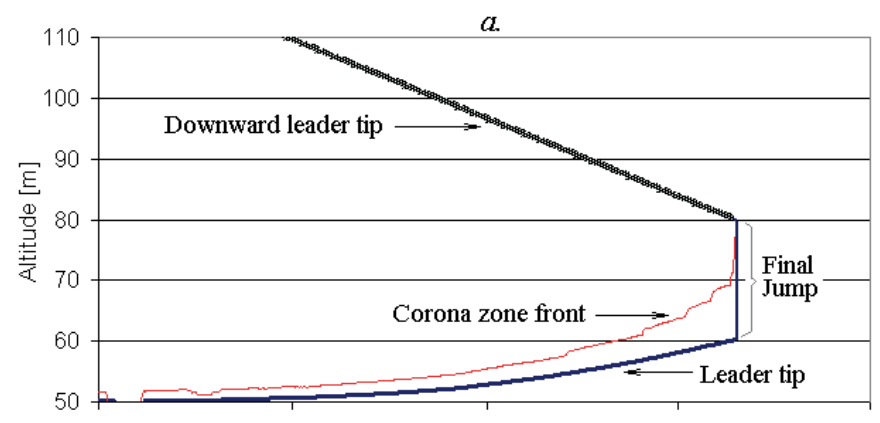

b.

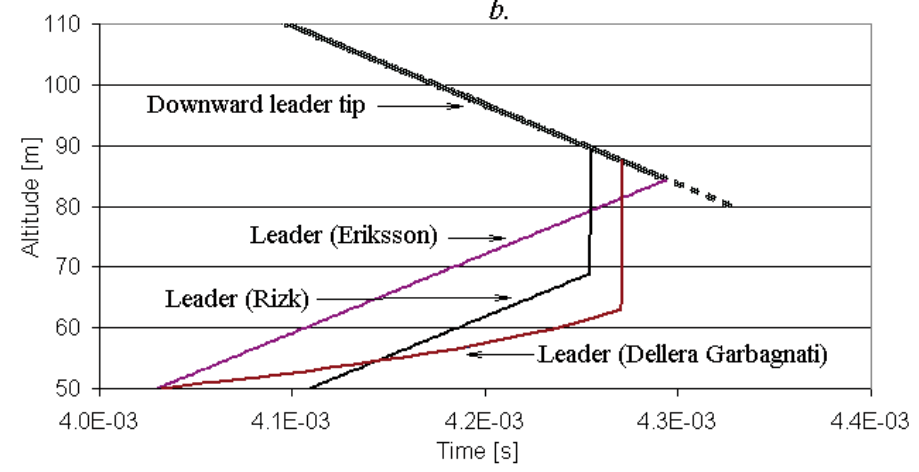

Figure 3.4. Comparison of the streak image computed for the rocket triggered experiment reported in [74] with $a$ ) the self-consistent model presented in Paper $\mathbf{V}$ and with $b$ ) the leader propagation models of Eriksson [62, 63], Dellera and Garbagnati $[65,66]$ and Rizk [67, 69].

In order to evaluate the validity of the assumptions of the leader propagation models regarding the upward leader properties, the main physical parameters of the leader in the experiment [74] are estimated with the self-consistent leader model presented in Paper V. The computed values of the velocity, average channel electric field and charge per unit length of the upward connecting leader are shown in Figure 3.5. Notice that the constant upward leader velocity assumed by Eriksson $[62,63]$ and Rizk [67, 69] exceeds by several times the computed values, especially immediately after inception (Figure 3.5.a). In the same way, the model of Dellera and Garbagnati [65, 66] also overvalues the connecting leader velocity, although in a lower degree. The direct effect of this overestimation of the upward leader velocity is the overestimation of the upward leader length and consequently to the evaluation of larger interception distances. Regarding the properties of the leader channel, observe that the average electric fields computed with the semi-empirical equation [70] assumed by Rizk [67, 69] in his model are lower than the self-consistently calculated values. The underestimation of the leader electric field causes the increase on the average electric field between the tips of both leaders, which is used to evaluate the final jump condition. This would force to the estimation of an early final jump time. 

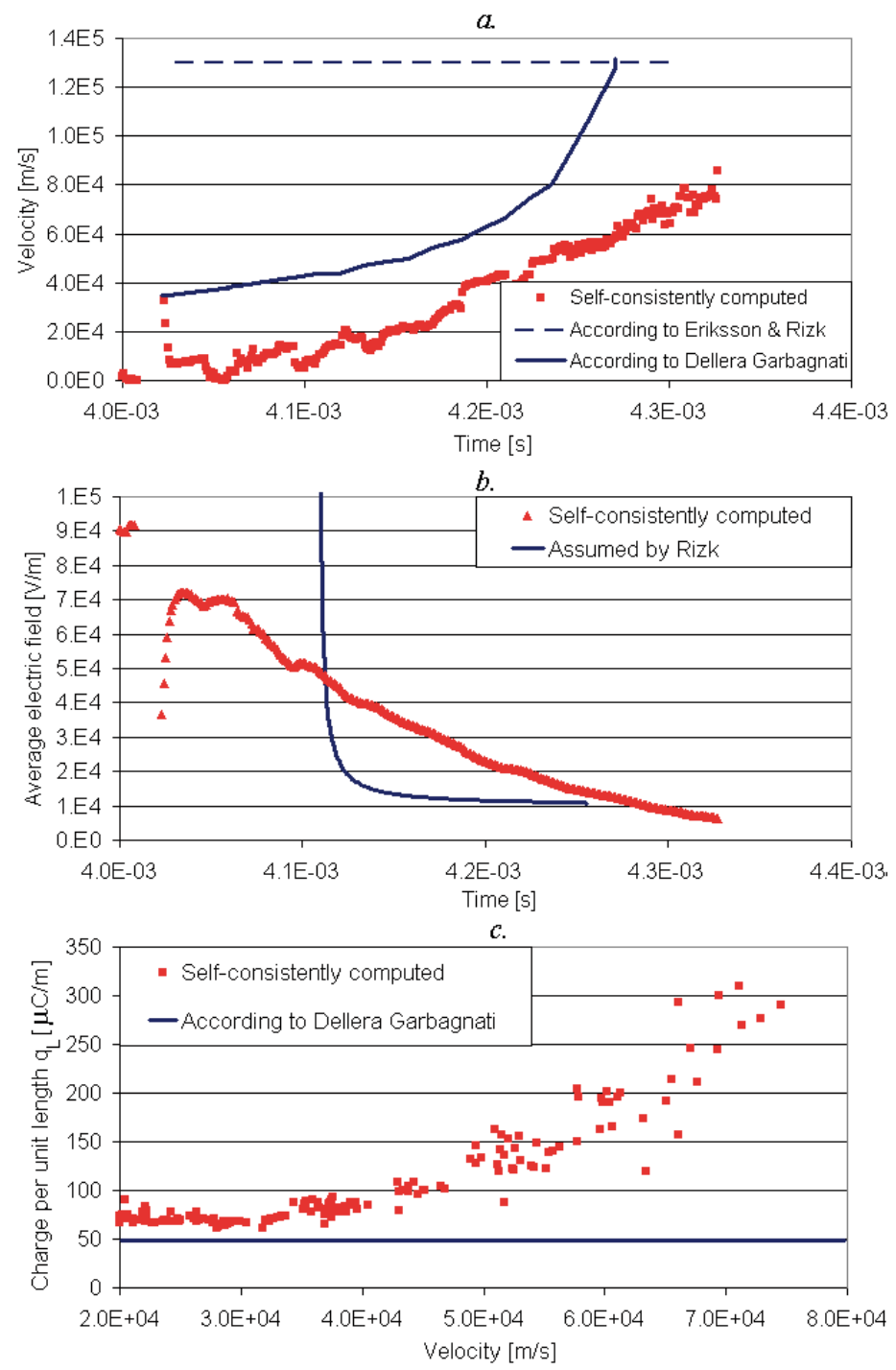

Figure 3.5. Comparison between the upward connecting leader parameters selfconsistently computed with the model presented in Paper $\mathbf{V}$ and the values assumed by the leader propagation models for the rocket triggered experiment reported in [74]: $a$ ) leader velocity, $b$ ) average electric field along the leader channel and, $c$ ) charge per unit length of the leader as a function of its velocity.

As for the charge per unit length of the connecting leader, the constant value assumed by Dellera and Garbagnati $[65,66]$ also disagrees with the values computed with the self-consistent model. Moreover, the leader charge per unit length was found to increase as the connecting leader speeds up, in contrast with the constant value assumed by Dellera and Garbagnati. It is also worth to mention that the representation of the upward leader channel by a 
line charge used by Dellera and Garbagnati $[65,66]$, leads to large errors in the evaluation of the potential at the tip of the leader channel. Since the total charge of the upward leader is distributed within its cover, its channel and the streamer corona zone, it is not appropriate to concentrate all of it only along the leader channel. This error causes the overestimation of the average electric field between the tip of the leaders, which affects the correct evaluation of the time variation of the velocity ratio as well as the final jump condition in the model of Dellera and Garbagnati $[65,66]$.

\subsection{A Self-consistent Lightning Interception Model -SLIM -}

The self-consistent leader propagation model presented in Paper $\mathbf{V}$ has been shown to be a better way to estimate the conditions for the attachment of a downward stepped leader by a connecting positive leader. For this reason, it has been applied in Paper VI to evaluate the factors that influence the velocity of the upward connecting leaders during lightning strikes. In order to facilitate the implementation of the model presented in Paper $\mathbf{V}$ for such analysis, a simplified procedure to evaluate the corona zone charge in front of the leader tip is used. It involves a numerical analysis of the background potential distribution as the leader propagates, in a similar way as for the simplified procedure introduced in Paper I. In addition, the charge per unit length of the downward stepped leader is evaluated with the equation proposed by Cooray et al. [116], which is based on electrostatic considerations.

In this way, the model presented in Paper $\mathbf{V}$ can be easily used to selfconsistently evaluate the initiation and propagation of upward connecting leaders in the presence of downward lightning stepped leaders. This version of the model is called SLIM, which stands for Self-consistent Lightning Interception Model. Paper VI shows an example of the predictive power of SLIM when applied to evaluate the attachment of a lightning flash to a grounded structure. Particularly, the case of the flash 771009 reported by Eriksson in his instrumented tower [61] is analyzed. It is found that parameters such as the downward leader average velocity, the prospective return stroke peak current, the lateral distance of the downward leader channel and the ambient electric field can influence the velocity of upward connecting leaders. This clearly shows that the velocity of connecting leaders changes from one flash to another due to the variations of these parameters. Thus, it is not appropriate to use generalized ratios between the velocity of the downward and upward leaders, as assumed by the existing leader propagation models $[62,63,65-67,69]$. Instead, the upward leader velocity has to be self-consistently computed for each case. 
Due to the strong effect of the upward connecting leader velocity on the attachment point, the aforementioned parameters also influence the attractiveness of any grounded structure to lightning flashes. Figure 3.6 shows the predictions of SLIM for the lateral attractive distance of a free standing structure under the influence of a downward leader moving with average velocity of $2 \times 10^{5} \mathrm{~m} \mathrm{~s}^{-1}$. In order to illustrate the effect of the downward leader velocity on the attractive distance, the calculations are also performed for the lower and upper limits of the measured values of the average stepped leader velocity [38]. Recent measurements with high-speed cameras show that the 2-D average velocity of downward negative stepped leaders is distributed between about $9 \times 10^{4}$ and $2 \times 10^{6} \mathrm{~m} \mathrm{~s}^{-1}$, with a median of $2.2 \times 10^{5}$ $\mathrm{m} \mathrm{s}^{-1}$ [117]. Thus, the variation on the computed attractive distances for downward leader velocities ranging between those limits is shown with bars in Figure 3.6. The predictions of the existing leader propagation models of the Eriksson [62, 63], Dellera and Garbagnati $[65,66]$ and Rizk models [67, 69] are shown as reference values.

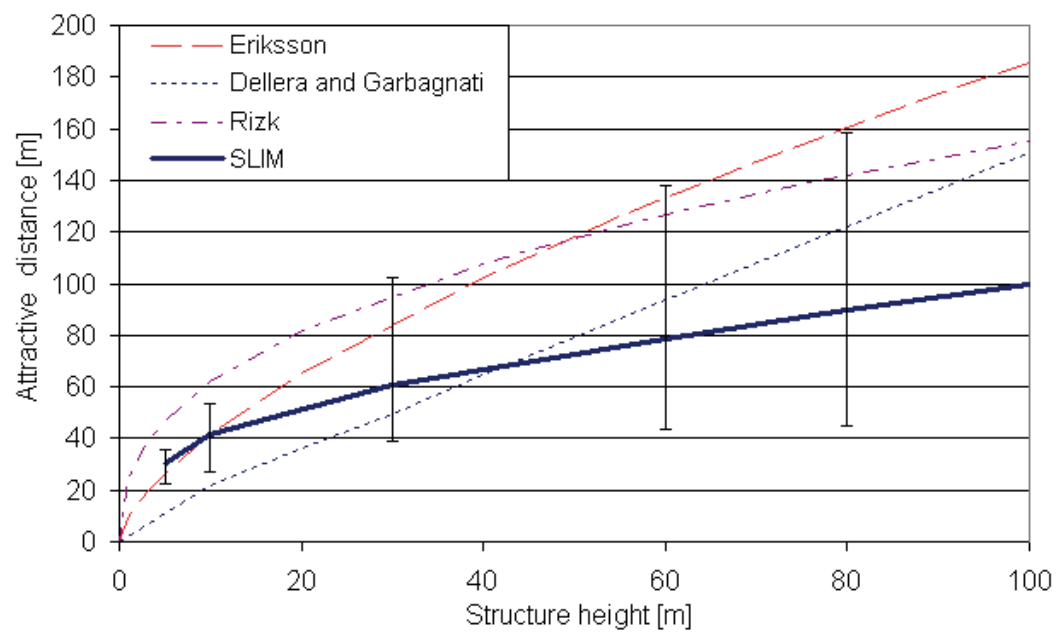

Figure 3.6. Attractive distance computed with SLIM for free-standing structures under a downward leader with prospective return stroke current of $31 \mathrm{kA}$ and average velocity of $2 \times 10^{5} \mathrm{~m} \mathrm{~s}^{-1}$. The error bars show the variation of the attractive distances due to the dispersion of the observed downward leader velocity probability distribution function. The predictions of the existing leader propagation models are shown as reference.

Note that the wide range of the estimated attractive distances is produced by the large spread of the values of the downward leader average velocity observed in nature. Therefore, the attractive distances of free-standing objects range between the limits shown with the bars in Figure 3.6, following the probability distribution function of the downward leader velocity. In this way, it is shown that the attractiveness of a free-standing object does not 
depend on the prospective return stroke current or the height of the structure only, but also on the downward leader average velocity. This result suggests that the analysis of the lightning attractive distances of grounded objects have to account also the downward leader probability distribution in order to give a better estimate of this parameter. 


\section{Lightning attachment to complex grounded structures}

"... the lightning did not fall upon the body of the house, but precisely on the several points of the rods, and was conveyed into the earth without any material damage to the building, tho' the conductors were sometimes not sufficiently large and complete to secure their own substance."

Benjamin Franklin. Experiments, observations and facts, tending to support the opinion of the utility of long pointed rods, for securing buildings from damage by strokes of lightning, 1772 .

There is nowadays an increasing need for the effective lightning protection of vulnerable structures such as nuclear plants, buildings with fire hazards, petrol service stations, refineries and oil storage tanks, houses for storage of explosives and flammable materials [118]. The protection of such structures requires special attention since it is mostly the direct effects of the lightning current flow which produce sparks that can cause fire, ignite flammables or detonate explosives [28]. Similarly, commercial or industrial buildings also demand an effective lightning protection system, especially in the cases where continuity of facility services is required. Particularly, practical lightning protection designs in such cases require of the maximization of efficiency and the minimization of costs [119]. However, the design of external lightning protection systems (i.e. lightning rods and shielding wires) for such sensitive structures still relies on empirical methods such as the protective angle, the mesh method and the rolling sphere method [27].

For these reasons, there is a considerable world-wide interest on the development of improved methods for location of lightning rods on complex and vulnerable structures [120]. This interest has also been motivated by the recent controversy about the efficiency of early streamer emission (ESE) terminals [30] and the new methods proposed for positioning of lightning rods [32].

In this chapter, the current international standard on lightning protection is shortly described. Furthermore, the physics-based methods proposed for analysis of lightning attachment to grounded complex structures are presented. 


\subsection{The International Standard on protection of structures against lightning}

The main guidelines for the evaluation, design and installation of lightning protection systems are given by the IEC International Standard on protection of structures against lightning [25-27]. It is a guide to protect common structures of ordinary use such as dwelling houses, farms, public and commercial buildings against the harmful effects of lightning strikes. The standard was restricted to structures up to $60 \mathrm{~m}$ tall $[25,26]$, but it has been extended without limitation of the structure height in its last edition [27]. For the design of the air termination system, the lightning standard still relies on empirical methods such as the protective angle, the rolling sphere and the mesh methods. Unfortunately, the new results of research conducted in the $20^{\text {th }}$ century have had very little effect on the standardization of lightning protection systems [71].

Thus, the IEC standard suggests the protective angle method for simple structures or for small parts of bigger structures. Therefore, air terminals, masts and wires should be positioned so that all parts of the structure to be protected are inside the volume defined by the surface generated by projecting a line from the air terminal or conductor to the ground plane, at an angle $\alpha$ with the vertical (Figure 4.1.a). The protective angle $\alpha$ takes different values for different heights of the air terminal above the surface to be protected.

The rolling sphere method, as used today in the lightning standard [2527], comes from a simplified version of the electrogeometric method [15] applied for the protection of buildings and industrial plants [22, 121]. It considers that protected and unprotected parts of a structure are identified by rolling a fictitious sphere over the surface of the earth and over the structure $[22,121]$. In this manner, any part of the structure that is touched by the sphere during its movement is considered to be susceptible to a direct lightning strike, while the untouched volume defines the lightning protected zone (Figure 4.1.b). The radius of the sphere $R$ is defined as a function of the prospective return stroke peak current, according to the lightning interception distance derived by Whitehead and coworkers for power transmission lines $[15,17,18]$. In the standard, the rolling sphere method is recommended as the main method to design the air terminal system for complex shaped structures [27].

For the protection of flat surfaces (Figure 4.1.c), the international standard recommends the mesh method. It is based on the principle of the Faraday cage [122] and considers the installation of a mesh of wire conductors on the whole exposed surface. It also includes the installation of wires on the exposed lateral surfaces as well as on edges and ridge lines of the roof of the structure. The mesh dimensions are specified according to the protection level used in the design. 

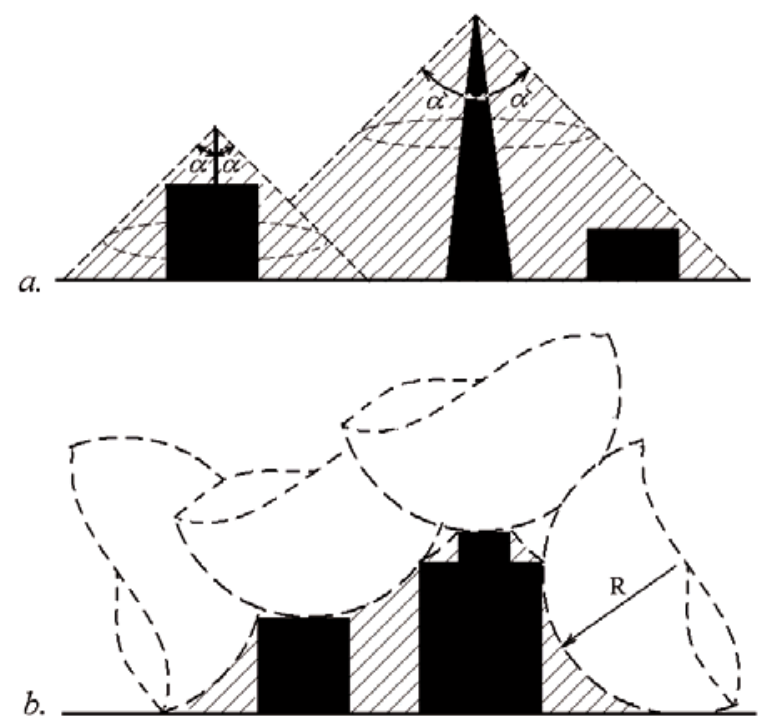

c.

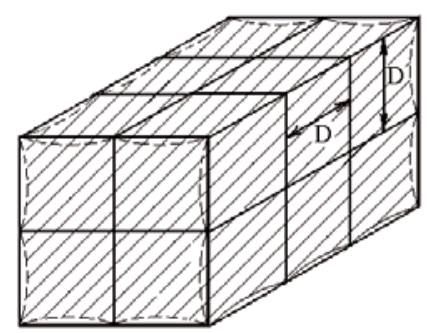

Figure 4.1. Methods used for the design of external lightning protection systems [24, $47,48]$. a) the protective angle method, $b$ ) the rolling sphere method, $c$ ) the protective mesh method. The dashed areas correspond to the lightning protected zones.

In contrast to the case of power transmission lines where the acceptable tolerance for lightning protection is given by the basic insulation level (BIL) of the system [121], the efficiency of the protection for common structures is given in levels labeled from I to IV [25-27]. These protection levels are related to the probability of a lightning strike with a prospective return stroke peak current equal to or larger than a given critical value. Thus, an external lightning protection system designed for a given protection level must provide full protection against lightning strikes with prospective return stroke currents larger or equal than the critical current. Lightning strikes with prospective return stroke currents lower than the critical peak current could strike either the structure to be protected or the air terminals of the lightning protection system. The corresponding values of efficiency, critical prospective return stroke current as well as the values used for the rolling sphere radius, the protective angle and the mesh width for the different protection levels are shown in Table 1. 
Table 1. Positioning of air terminals according to the protection levels defined by the IEC standard [25-27].

\begin{tabular}{|c|c|c|c|c|c|c|c|c|}
\hline \multirow[t]{3}{*}{$\begin{array}{l}\text { Protection } \\
\text { level }\end{array}$} & \multirow{3}{*}{$\begin{array}{l}\text { Critical } \\
\text { minimum } \\
\text { prospective } \\
\text { return } \\
\text { stroke peak } \\
\text { current } \\
{[\mathrm{kA}]}\end{array}$} & \multirow[t]{3}{*}{$\begin{array}{l}\text { Efficiency } \\
\text { of protec- } \\
\text { tion }\end{array}$} & \multirow[t]{2}{*}{$\begin{array}{l}\text { Rolling } \\
\text { sphere } \\
\text { method }\end{array}$} & \multicolumn{4}{|c|}{$\begin{array}{l}\text { Protective angle } \\
\text { method for different } \\
\text { heights of terminals } \\
{[\mathrm{m}]}\end{array}$} & \multirow[t]{2}{*}{$\begin{array}{l}\text { Mesh } \\
\text { method }\end{array}$} \\
\hline & & & & 20 & 30 & 45 & 60 & \\
\hline & & & $\begin{array}{l}\text { Sphere } \\
\text { radius } \\
R[\mathrm{~m}]\end{array}$ & \multicolumn{4}{|c|}{$\begin{array}{l}\text { Protective angle } \alpha \\
\text { [degrees] }\end{array}$} & $\begin{array}{l}\text { Maximum } \\
\text { distance } \\
D[\mathrm{~m}]\end{array}$ \\
\hline I & 3 & $99 \%$ & 20 & 25 & $*$ & $*$ & $*$ & 5 \\
\hline II & 8 & $97 \%$ & 30 & 35 & 25 & $*$ & $*$ & 10 \\
\hline III & 10 & $91 \%$ & 45 & 45 & 35 & 25 & $*$ & 10 \\
\hline IV & 16 & $84 \%$ & 60 & 55 & 45 & 35 & 25 & 20 \\
\hline
\end{tabular}

Despite of the widespread use of the rolling sphere method, there are several facts that call for modifications to its present form [123]. First, the rolling sphere method considers that it is equally likely a lightning strike to ground, to a sharp point or corner, to an edge or to a flat surface on a structure. However, field observations of buildings struck by lightning in Malaysia and Singapore $[36,120,124-126]$ have shown that nearly all observed strikes terminate on sharp points or protruding corners (more than $90 \%$ of the observed cases). Only few lightning strikes occurred to exposed horizontal or slanting edges (less than 5\%) and to elevated vertical edges (less than 2\%).

Second, the radius of the sphere used in the standard is obtained from a gross oversimplification of the physical nature of the lightning discharge and it is the result of compromises in standardization committees [71]. Since the rolling sphere method was proposed as used today $[22,121]$, the radius of the sphere has been directly taken from the interception distance derived and "calibrated" for power transmission lines according to the electrogeometric (EGM) theory $[17,18]$. Due to the lack of data available at that time, this extension of the EGM theory to other kind of structures was done without any further validation. However, the existing leader propagation models [62, $63,65-69]$ have shown that the attachment of lightning flashes to grounded structures does not exclusively depends upon the prospective return stroke peak current. It also depends upon the geometry of the structure to be protected, as it is shown in Papers VII and VIII. This fact casts serious doubts about the validity of using a rolling sphere radius which neglects the effect 
of the geometry of the structure on the lightning attractiveness and is only dependant on the prospective return stroke peak current.

Third, the rolling sphere method has not been useful for the evaluation of new lightning protection technologies introduced in the market such as the ESE terminals [30] or the Dissipation Arrays Systems [31]. Due to its empirical nature, the rolling sphere method cannot provide any scientific or technical information to either reject or accept this kind of devices. For the same reason, the rolling sphere method has not been useful either for the discussion of the recently introduced air terminal positioning methods [32, $33,34]$.

\subsection{Physics-based analyses of lightning attachment to grounded structures}

Due to the limitations of the existing empirical methods, physics-based studies have been proposed to assess the optimum location of air terminals on complex grounded structures. Thus, the leader progression model of Dellera and Garbagnati $[65,66]$ was implemented to evaluate the interception distances from the edges of square structures [72]. However, the interception distances from the corners of the structure could not be considered since this analysis was only performed in two dimensions [72]. Later, the collection volume concept proposed by Eriksson $[62,63]$ for free standing structures was used for the analysis of lightning strikes to buildings [32], together with electric field intensification factors [93]. Even though this method is claimed to be validated with field observations $[127,128]$, there are still doubts in the lightning community about its use $[35,36,120]$. Recently, a leader progression model similar to the one proposed by Dellera and Garbagnati $[65,66]$ was implemented in three dimensions to evaluate the lightning incidence to buildings [129].

In the aforementioned studies, the critical radius concept [64] was used to evaluate the initiation of the upward connecting leaders from the analyzed structures. Nevertheless, the critical radius concept has been found to be inappropriate to evaluate the initiation of upward leaders from structures, as discussed in Chapter 2. Furthermore, the mentioned methods are based on several assumptions questionable according to the current knowledge on the physics of leader discharges and lightning. As it has been discussed in Chapter 3 , the assumptions of the existing models lead to errors in the estimation of the lightning attractiveness of grounded structures.

In order to improve the accuracy of the previous studies, the leader inception model proposed in Paper I is implemented in Paper VII for the evaluation of upward positive leader initiation from the corners of actual complex structures. Since this model was devised for structures with and without 
symmetry, it can be appropriately used for any kind of grounded object.

Thus, different actual complex structures that have been struck by lightning in Kuala Lumpur $[36,124]$ were analysed. For sake of simplicity, the electric field produced by the downward leader is represented by an equivalent background quasi-uniform electric field close to ground. In this way, the static background leader inception electric field from all the corners of the analysed structures are computed and compared with the observed number of strikes $[125,130]$. A good correlation between the corners with the lower static leader inception electric fields and the observed lightning struck points was found. This result supports the hypothesis suggested by Golde [8] that a lightning flash strikes a grounded structure at the point where a stable upward leader is first incepted. Thus, the procedure presented in Paper VII can be used to identify the most likely lightning strike points on complex structures. This procedure would help lightning protection designers to take better decisions about the optimum location of air terminals.

As an example, Figure $4.2 \mathrm{~b}$ shows the lightning strike points predicted by the rolling sphere method on a complex structure such as the Ångström laboratory, Uppsala, Sweden (Figure 4.2a). Note that the rolling sphere method does not distinguish between a lightning strike to a sharp point, a corner, an edge or a flat surface. Thus, a large number of points on the structure are predicted to be equally susceptible to be struck by lightning, making it difficult to identify the optimum location for the air terminals.

On the contrary, the more likely places to be struck by lightning on the structure can easily be identified with the procedure presented in Paper VII. Figure 4.2c shows the predicted most likely lightning strike points on the Ångström Laboratory, based on the leader inception electric fields normalized to the minimum value computed in the structure. Since a lightning strike occurs when an upward moving leader intercepts the downward stepped leader, it is more likely that the point to be struck corresponds to the place where the first upward leader is incepted. Thus, the calculation of the conditions required to initiate upward leaders provides important information to pinpoint the optimum places where air terminals may be installed.

However, the initiation of an upward positive leader is not a sufficient condition to guarantee the attachment of a lightning flash to a grounded structure. The incepted connecting leader has to propagate towards the downward stepped leader and successfully intercept the downward stepped leader. Hence, the procedure presented in Paper VII does not provide information about the attractiveness of the air terminals installed on a structure. It is just the first step in the design of the lightning interception system since it identifies the optimum locations of the air terminals on the structure. Then, the next step is to evaluate the number of air terminals required to effectively protect the structure for a given protection level. Therefore, it is necessary to evaluate the lightning attractive zones of each air terminal and identify the protected and unprotected zones in the structure. 

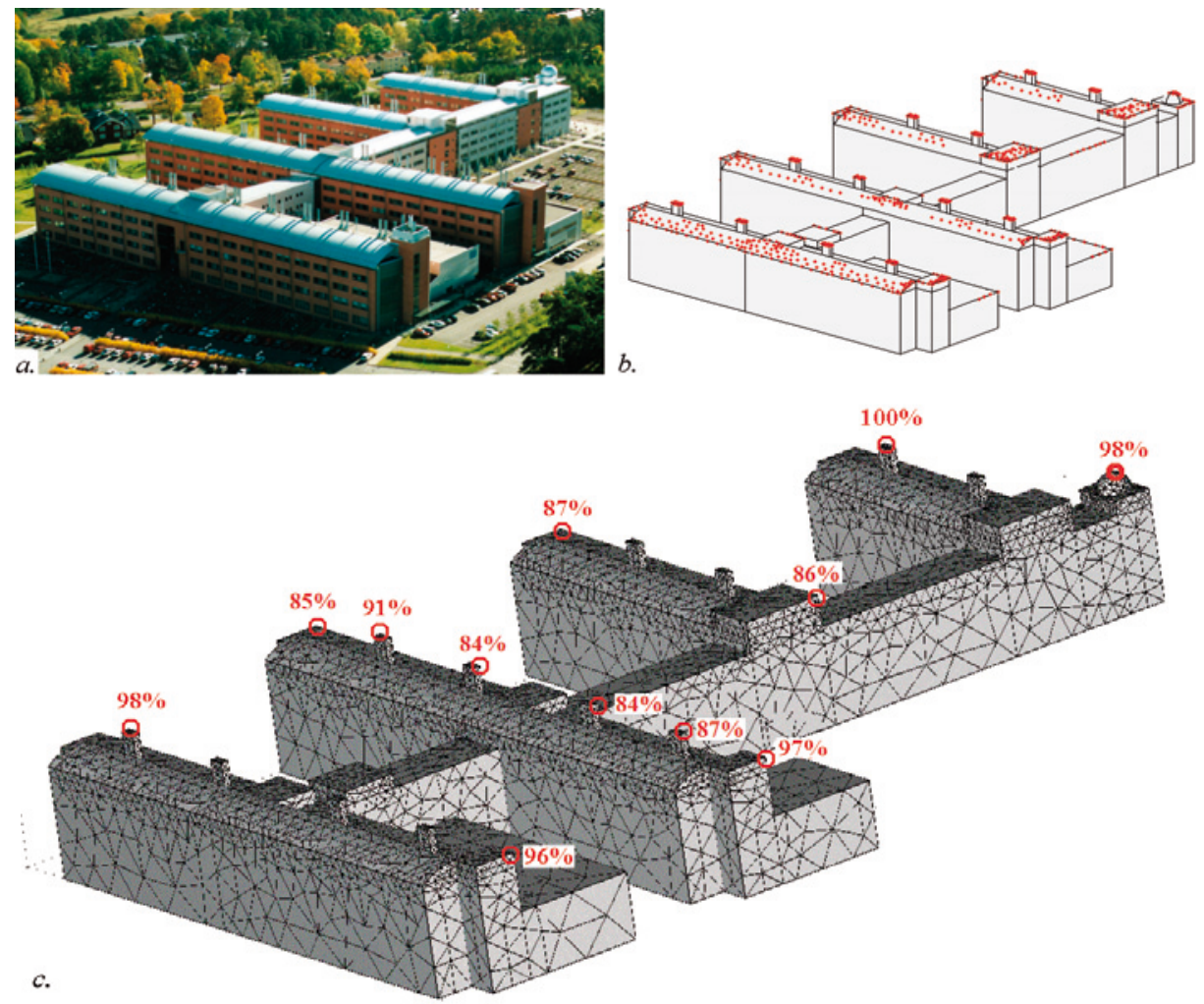

Figure 4.2. The Ångström Laboratory, Uppsala, Sweden. a) photograph of the structure, $b$ ) vulnerable points to be struck by lightning according to the rolling sphere method with a sphere radius of $60 \mathrm{~m} \mathrm{[27],c)} \mathrm{the} \mathrm{most} \mathrm{likely} \mathrm{lightning} \mathrm{strike} \mathrm{points}$ computed with the procedure presented in Paper VIII. The percentages correspond to the normalized static leader inception electric fields.

In order to provide qualitative information about the attractive zones of likely lightning strike points, the striking - inception - distances from the corners of two buildings struck by lightning in Kuala Lumpur are computed in Paper VIII. This calculation is performed taking into account the lateral location of the downward leader channel and assuming that its electric field does not change considerably during the leader initiation process (static leader inception). In this way, it is possible to evaluate the maximum lateral distance at which a downward leader can initiate an upward leader from a given point on a structure. This maximum lateral distance defines the upward leader inception zone (Figure 4.3).

Due to the fact that the propagation of both leaders is not taken into account, the effective lightning attractive zones are not evaluated in Paper IV. Nevertheless, the computed static leader inception zones are a first approximation of the lightning attractive zones since downward leaders located outside the leader inception zones cannot initiate upward leaders. It is found that 
upward leaders incepted from protruding corners in a structure are mostly initiated by downward leaders located outside its periphery. This result could explain the fact that some buildings in Kuala Lumpur and Singapure are struck by lightning at the corners even if lightning rods are installed at the center of the roof [124]. Conversely, downward leaders located above the roof have reduced chances to initiate upward leaders from the corners. Thus, the leader inception zone of a corner does not define a symmetrical circular region as it is assumed by the collection volume/field intensification method [32] (Figure 4.3b). In addition, the area and shape of the leader inception zones is found to depend not only on the prospective return stroke current as the rolling sphere predicts, but also on the geometry and height of the structure and the surroundings.
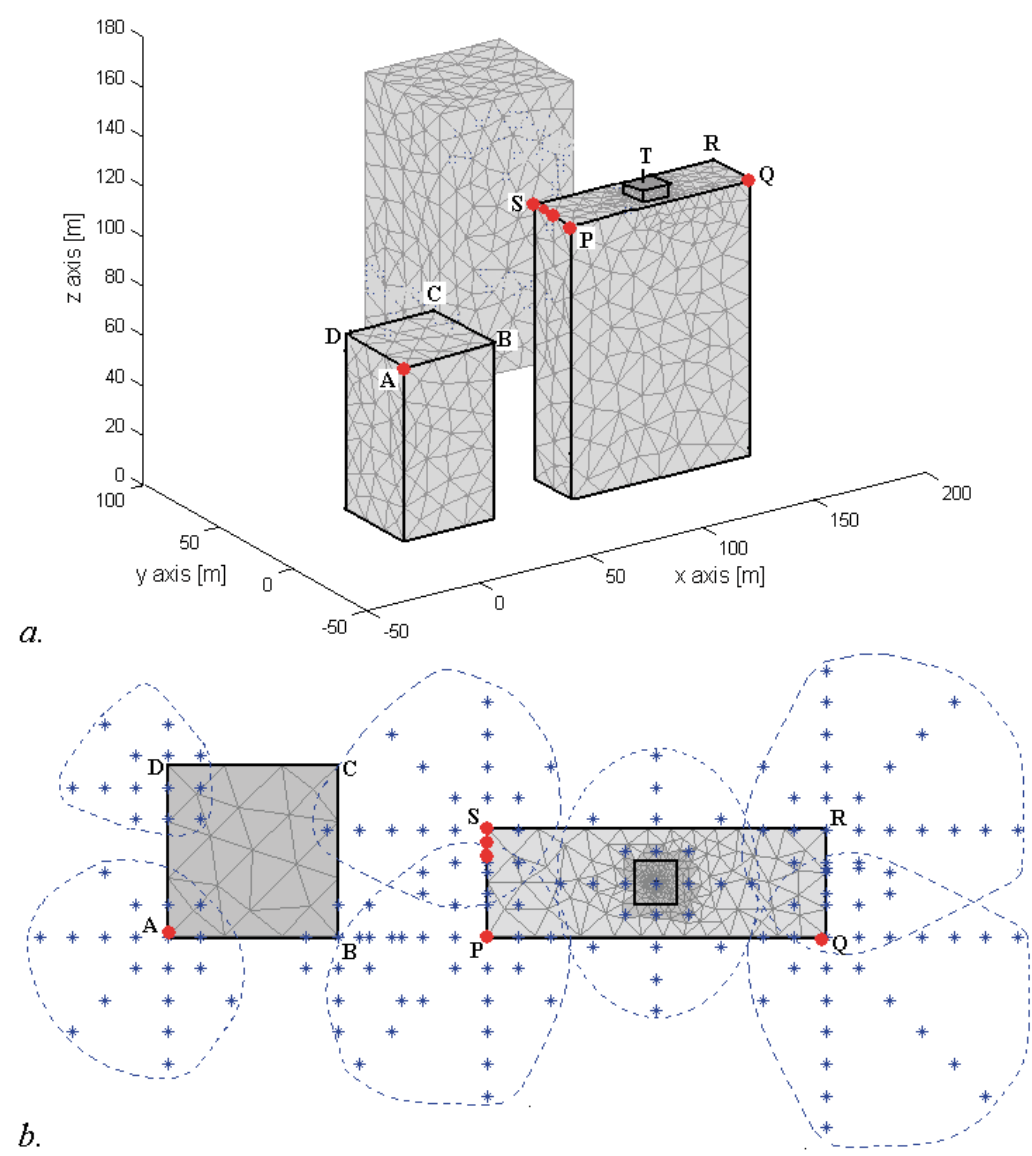

Figure 4.3. Observed lightning damaged points (dots) and the upward leader inception zones (dashed lines) from the corners of two bank buildings: Industry and Pembangunam in Kuala Lumpur, Malaysia, $a$ ) 3D plot, $b$ ) top view. The asterisks show the location of the downward leader channel where the leader inception takes place in the calculations. 
Even though the static analysis presented in Paper VIII considers the upward leader inception zones only, similar conclusions can also drawn based on the analysis of lightning attractive zones. Thus, to complement the analysis presented in Paper VIII, the lightning attractive zones of the two bank buildings shown in Figure 4.3 are computed with the Self-consistent Lightning Interception Model (SLIM) introduced in Section 3.3. In this case, the predictions of SLIM for a vertical downward leader propagating with an average velocity of $2 \times 10^{5} \mathrm{~m} \mathrm{~s}^{-1}$ and with prospective return stroke current of $16 \mathrm{kA}$, are shown in Figure 4.4.

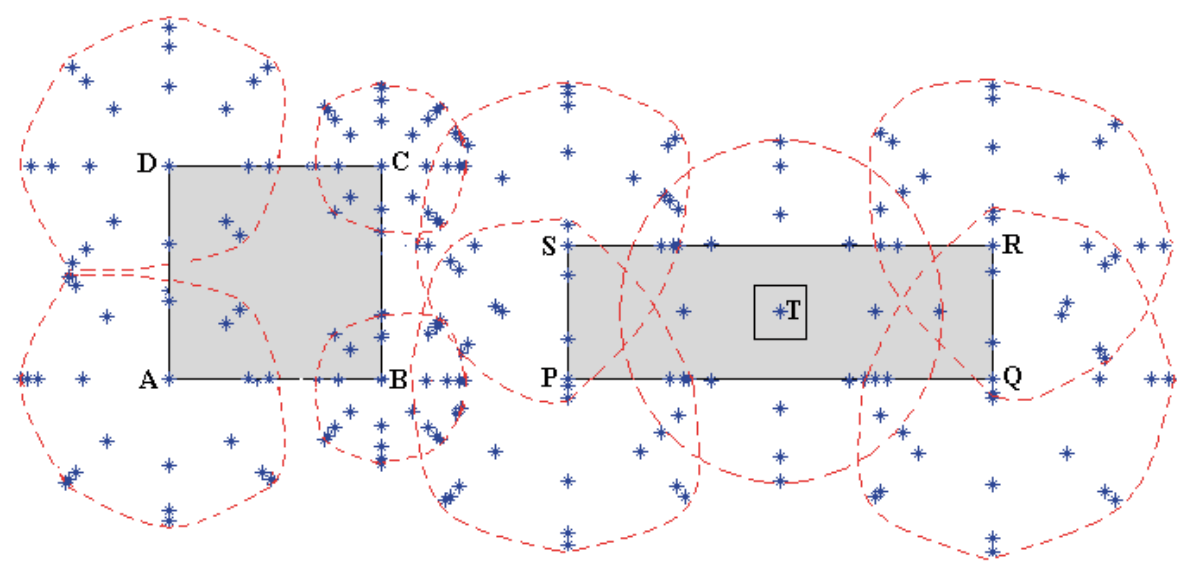

Figure 4.4. Top view of the lightning attractive zones of the corners of two bank buildings: Industry and Pembangunam in Kuala Lumpur, Malaysia computed with SLIM. The asterisks show the location of the downward leader channel where the connection with the upward positive leader takes place in the calculations.

Notice that the qualitative analysis of the static leader inception zones predicted in Paper VIII (Figure 4.3), also apply for the lightning attractive zones calculated with a fully dynamic leader inception and propagation model (Figure 4.4). However, it is important to mention that it is not possible to make a direct comparison between the areas of the leader inception zones presented in Paper VII and the lightning attractive zones computed with SLIM. Since the striking - inception - distances in Paper VII are computed for a static condition, the estimated leader inception zones in that case are larger than the actual leader inception zones under the influence of a descending stepped leader, as in the simulations made with SLIM.

Since the effective lightning attraction zones can be easily calculated with SLIM, it is also possible to make a quantitative comparison of its predictions with the results of the rolling sphere method. Figure 4.5 shows an example of the lightning attractive zones predicted by SLIM for a simple square structure protected according to the rolling sphere method with an air terminal at the center of the roof. Since the protection level IV is considered in the 
calculations, the structures (including their corners) are inside the protected zone given by the rolling sphere with radius of $60 \mathrm{~m}$ (corresponding to a critical return stroke peak current of $16 \mathrm{kA}$ ). Only vertical downward stepped leaders propagating with average velocity of $2 \times 10^{5} \mathrm{~m} \mathrm{~s}^{-1}$ are taken into account. Due to the symmetry of the geometry, only the attractive zones of one corner are computed.
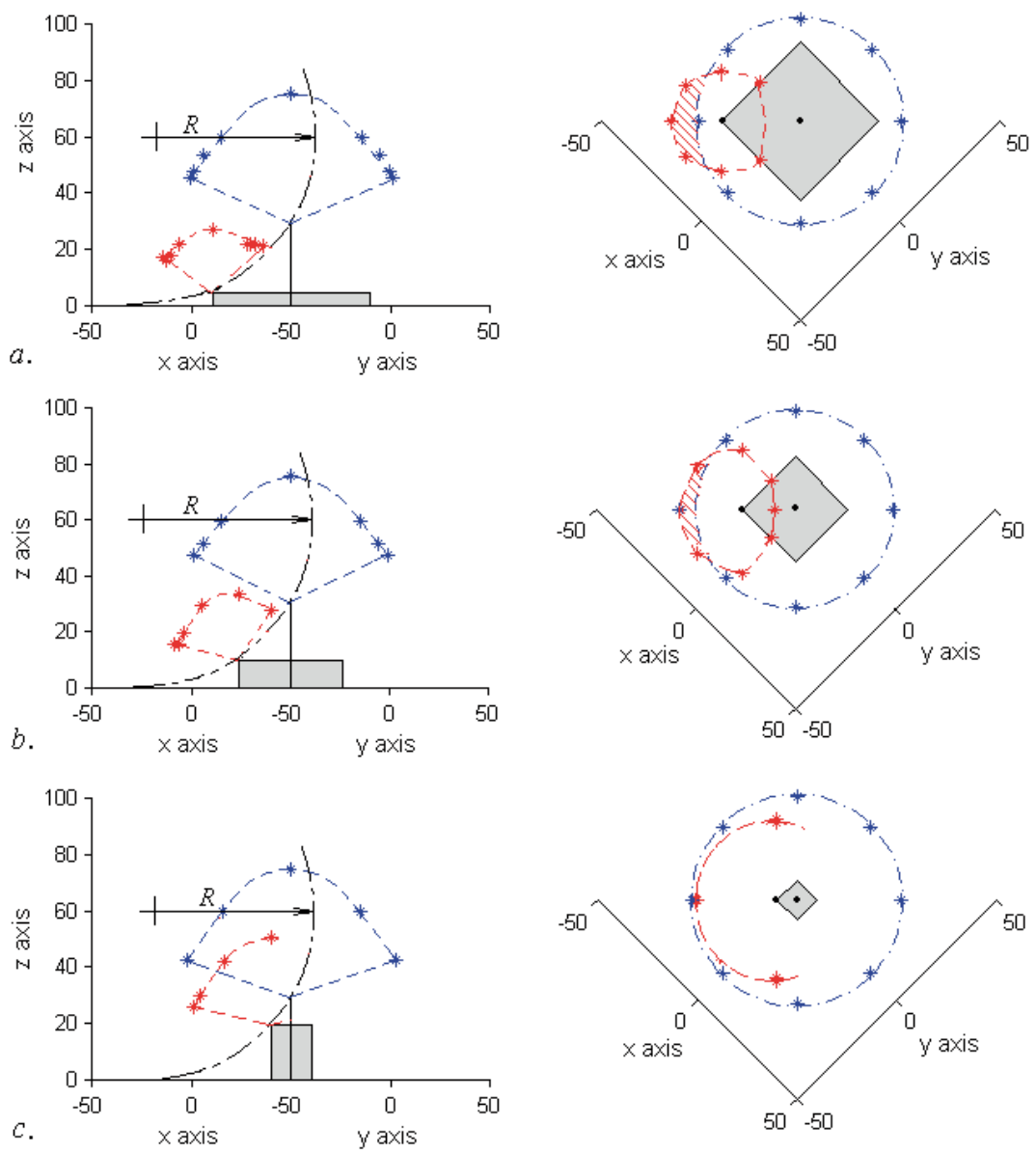

Figure 4.5. Side and top view of a square structure $a) 5 \mathrm{~m}, b) 10 \mathrm{~m}$ and c) $20 \mathrm{~m}$ tall protected according to the rolling sphere method $(R=60 \mathrm{~m})$ with an air terminal at the center of its roof. In all cases, the air terminal tip is located at $30 \mathrm{~m}$ above ground. The lightning attractive zones simulated with SLIM of one corner and the air terminal are also shown. The dashed area in the top view corresponds to the exposure area of the corner to vertical downward stepped leaders.

Notice that the lightning attractive zones of the corners of the structure are not entirely covered by the attractive zone of the air terminal in some cases (Figures $4.5 \mathrm{a}$ and $\mathrm{b}$ ). Therefore, the corners are exposed to direct vertical 
lightning strikes, even though they are "protected" according to the rolling sphere method. Conversely, the lightning attractive zones of the corners protected according to the rolling sphere method are indeed entirely covered by the attractive zones of the air terminals, as in the case shown in Figure 4.5c.

Thus, the analysis of the attractive zones simulated with SLIM can give valuable information of the conditions under which the rolling sphere method succeeds or fails to properly identify protected and unprotected zones. Consequently, a more suitable radius of the rolling sphere can be suggested based on this kind of analysis. Further study of other study cases and a preliminary discussion of the validity of the rolling sphere method to locate air terminals on simple structures is presented in [131]. 


\section{Conclusions}

In the present thesis, a self-consistent physical model based on the physics of leader discharges has been introduced for the evaluation of the initiation and propagation of upward lightning positive leaders. The model considers separately the case of upward leaders initiated from tall structures under the influence of an active thundercloud with dominant negative charge and the case of upward connecting leaders initiated under the influence of a downward stepped leader. In the first case, the predictions of the (static) leader inception electric fields are in good agreement with values measured in a classical rocket-triggered lightning experiment. Particularly, excellent agreement between the measurements and the predictions of the model is found in Paper I when the space charge left behind the rocket is taken into account in the model. In the later case, the calculated (dynamic) leader inception times are found to be in good agreement with the results of laboratory long air gap experiments and an altitude rocket triggered lightning experiment (Paper II). Since the model also self-consistently simulates the propagation of upward connecting leaders from their initiation to the final connection with the downward stepped leader, its predictions are also compared with the measured parameters of an altitude triggered lightning experiment in Paper $\mathbf{V}$. There is good agreement between the model predictions and the measured leader current and the experimentally inferred spatial and temporal location of the final jump.

Since the proposed model is based on the state-of-the-art modeling of the basic physical processes involved in the initiation and propagation of positive leader discharges, the model is able to generate testable predictions. In addition, the simplification of time-consuming steps in the model facilitates its implementation for practical cases. Given the predictive power and high application level of the developed model, the main contributions made in this thesis to the better understanding of the lightning attachment process are the following:

- The tip radius of a lightning rod slightly affects the conditions required to initiate upward connecting leaders. However, there is an optimum radius that is slightly more efficient (with an improvement of only $10 \%$ in the striking - inception - distance) than other rod radii to initiate upward leaders. This optimum radius agrees with the observations of competing rods in New Mexico [85, 86] although the outstanding 
differences observed between sharp and blunt rods are attributed in Paper II to be caused by the setup of that experiment.

- The initiation of upward connecting positive leaders is also strongly affected by the average velocity of the downward stepped leader. Similar to the case in the laboratory [47], the initiation of positive leaders under natural lightning is affected by the rise time of the applied electric field (Paper II). For the same prospective return stroke current, the estimated striking - inception - distance under the influence of downward leaders propagating with velocities ranging between the upper and lower limits observed in nature differ by more than $80 \%$.

- The initiation of a positive leader requires a lower background electric field under the changing electric fields produced by an approaching downward leader (dynamic inception) than under the slowly changing fields produced by a thundercloud (static inception). Thus, the striking - inception - distances calculated assuming the static condition (Paper I) are shorter than in the dynamic case (Paper II).

- The Early Streamer Emission concept does not work under lightning conditions. Even though a leader can be launched earlier by triggering an early streamer in the laboratory under switching voltages, this effect does not happen under lightning-like electric fields. In Paper III it is shown that the time development of positive leaders in the laboratory is different to the case under natural lightning. Thus, the switching voltage impulses used in the laboratory do not "fairly approximate" the electric fields produced by the descent of a downward leader, as claimed by supporters of Early Streamer Emission ESE devices.

- The space charge layer created by corona at ground level significantly increases the thundercloud electric field required to initiate upward lightning leaders from tall objects. The neutral aerosol particle concentration of the site is found to have a significant influence on the critical thundercloud electric field required to initiate upward positive leaders. Therefore, it is found in Paper IV that lower thundercloud electric fields are required to trigger an upward lightning flash from a tall tower in the case of sites with high neutral aerosol particle concentration such as polluted areas or coastal regions.

- The assumptions of the existing leader propagation models $[62,63$, 65, 66-69] regarding the physical properties of upward connecting leaders, are not in agreement with self-consistently obtained values during an altitude rocket triggered lightning experiment. This result suggests that a more physical and proper evaluation of the attachment of the downward stepped leader is obtained when the upward 
connecting leader parameters are self-consistently computed by the leader propagation model. For instance, it is shown in Paper $\mathbf{V}$ that the charge per unit length of the upward leader channel changes in time as it propagates towards the downward leader. In the same way, it is found in Paper VI that the velocity of the upward connecting leader depends on the downward leader average velocity, the prospective return stroke peak current, the lateral distance of the downward leader channel and the ambient electric field. Hence, the upward leader velocity changes from flash to flash due to variations of these parameters, in contrast to the constant values assumed by the existing leader propagation models.

- The corners of actual buildings struck by lightning in Kuala Lumpur, Malaysia coincide rather well with the places characterized by low leader inception electric fields. Consequently, the background leader inception electric fields can be used to evaluate the most likely lightning strike points on complex grounded structures and to assess the optimum location of air terminals. In Paper VII it is also found that the geometry of the buildings significantly influences the conditions necessary to initiate upward leaders and therefore the location of the most likely lightning strike points.

- The striking - inception - distance from sharp features on complex structures depend not only on the prospective return stroke current and the geometry of the building, but also on the lateral position of the downward leader channel. Hence, the leader inception zones of the corners of complex structures do not define symmetrical and circular regions as it is generally assumed [13, 32, 125]. Interestingly, upward leaders from the corner of a building are mostly initiated by downward leaders located outside the periphery of the structure (Paper VIII). This result can explain the field observations of buildings in Kuala Lumpur and Singapore which have been struck by lightning at the corners even if lightning rods are installed at the center of the roof [124]. 


\section{Future work}

Due to the complexity of the lightning attachment phenomenon, it has been always necessary to consider several assumptions and simplifications in order to formulate leader propagation models [72]. For this reason, the present thesis constitutes another effort to use the up-to-date physical knowledge of leader discharges to avoid unnecessary assumptions in the evaluation of the lightning exposure of structures. Particularly, the work presented in this thesis was focused on the development of a state-of-the-art, physicsbased model to self-consistently simulate the initiation and propagation of upward positive leader discharges from any kind of grounded structure. However, after more than four years following that aim, there are still many open questions and several undone studies, which define the framework for the future steps after this thesis.

In first place, the constant need for experimental data to validate and improve theoretical lightning attachment models call for further experiments with rocket triggered lightning and with instrumented towers. One major requirement is that several parameters are measured simultaneously during the initiation and propagation of upward positive leaders. These parameters include mainly the static and high frequency electric fields at different locations, low and high range leader currents and leader luminosity (stereo still photography and streak photography or high speed video). Nonetheless, other measurements such as optical spectrometry, gamma rays and X-rays detectors would be of high interest for the study of energetic processes of streamer and leader discharges under lightning.

Further studies with the models presented in this thesis should also be continued. First, the inception model presented in Paper I could be extended to evaluate the upward leader initiation from floating (non-grounded) objects such as airplanes or spacecraft. However, further experimental data of the physical parameters of streamers and leaders at pressures lower than atmospheric would be required in such case. This also applies for the analysis of the formation of large-scale transient luminous phenomena in the upper atmosphere such as blue jets and blue starters. These transient luminous discharges develops upwards from electrically active thunderclouds to terminal altitudes up to $40 \mathrm{~km}$ [132] and are believed to correspond to streamers from a positive leader initiated from the top of a thundercloud [133]. Second, the lightning attachment process of dart negative leaders could be studied. Even though the self-consistent leader inception and propagation model presented 
in Papers II and $\mathbf{V}$ considers the case of downward stepped leaders, it can be extended to study the attachment of the high-velocity dart negative leaders by upward connecting leaders. Third, the theoretical analysis of the propagation of downward positive leaders can complement the latest measurements made with high speed cameras [84, 117]. Such study can provide relevant information such as the charge per unit length of the leader channel and the factors that influence the downward positive leader velocity.

Particularly, other studies can also be performed by implementing the Self-Consistent Lightning Simulation Model - SLIM - proposed in this thesis to other different structures. For instance, the study of lightning attachment to moving grounded objects such as the blades of windmills can be continued. Moreover, the existing theory of protection of traditional structures such as power transmission lines, free-standing structures and buildings can be re-evaluated with SLIM. Especially, the simulation of specific welldocumented incidents where the predictions of the electrogeometric model of Whitehead and coauthors $[17,18]$ disagree with field observations would be very useful. In this way, better values for the protective and shielding angles, the distance between wires in a protective mesh and the radius of the rolling sphere could be suggested.

Further development of complementary models to evaluate other mechanisms not considered in the present theses is important for an integral understanding of the lightning attachment processes. Due to the increasing importance of the effective protection against positive lightning, it is necessary to extend the leader propagation models to evaluate the attachment process of downward positive leaders [72]. Thus, the improvement of the numerical models to simulate the initiation and propagation of negative leader discharges, similar to the one reported in [60], are required for analyses in a practical level. Furthermore, additional experiments and theoretical studies related to the glow discharge from the tip of grounded objects under thunderstorms and its transition into streamers are necessary. This kind of analysis should consider the effect of wind, rain and the thundercloud electric field changes. On the other hand, it is also essential that better estimations of the downward negative leader charge distribution including branching, become available in the literature. In the same way, a better knowledge on the physical conditions required for the change of direction in the propagation of leader discharges are necessary for the proper modeling of downward moving leaders. 


\section{Svensk sammanfattning}

Denna avhandling behandlar fysikalisk modellering av uppåtriktade positiva urladdningar (positive leader discharges) i samband med blixtnedslag. Detta slags urladdningar kan startas från jordade föremål genom inverkan av ett yttre elektriskt fält. Källan till detta fält är då antingen den negativt laddade nedre delen av ett aktivt åskmoln, eller en negativ stegurladdning (negative stepped leader discharge) som rör sig nedåt från åskmolnet. En numerisk beräkningsmodell har utvecklats utifrån de senaste rönen om åskurladdningar för att analysera dessa två situationer. Resultaten av de teoretiska beräkningarna stämmer väl överens med resultat från experiment, där blixtar startas med raketer.

Tack vare denna modell har vi kunnat göra flera bidrag till den fysikaliska förståelsen av "leader"-urladdningar. Dessa urladdningar beror endast svagt av krökningsradien hos spetsen på en stavformig åskledare. Istället spelar medelhastigheten hos den annalkande stegurladdningen en mycket större roll.

Modellen har också använts för att simulera positiva uppåtriktade urladdningar, i laboratoriemiljö samt under naturliga förhållanden. Det visade sig att urladdningar i laboratoriet inte duger som en ungefärlig beskrivning av "leader"-urladdningar. Man kan således inte på ett enkelt sätt hänvisa till laboratorieexperiment för att utvärdera förmågan hos åskledare att dra till sig blixtar. Resultaten visar också att en ny typ av åskledare, kallade ESE (Early Streamer Emission), inte har större förmåga att dra till sig blixtar än vad vanliga Franklin-stavar har.

Modellen har också använts för att utvärdera inverkan av ett lager elektriska rymdladdningar på uppkomsten av uppåtriktade "leader"-urladdningar. Detta laddningslager skapas av små korona-urladdningar vid geometriska oregelbundenheter nära markytan, t.ex. gräs och buskar. Vi har funnit att rymdladdningslagret tydligt ökar det elektriska bakgrundsfält, som behövs för att starta uppåtgående "leader"-urladdningar. Den här effekten beror av tjockleken hos rymdladdningslagret, vilket i sin tur i huvudsak beror av den lokala förekomsten av mycket små fasta partiklar (aerosoler) i luften.

Vidare har vi funnit att hastigheten hos en "leader"-urladdning, som ansluter till en nedåtgående stegurladdning (den första blixten från åskmolnet), inte enbart beror av stegurladdningens hastighet, vilket man förut brukade anta. "Leader"-urladdningens hastighet beror också av toppströmstyrkan hos 
huvudurladdningen (return stroke), liksom av det horisontella avståndet till stegurladdningen samt av det elektriska bakgrundsfältet från åskmolnet.

Modellen har också använts för att analysera tillkomsten av uppåtriktade "leader"-urladdningar från kanter och hörn på stora byggnader med invecklad geometri. Beräkningar har gjorts för verkliga byggnader i Malaysias huvudstad, Kuala Lumpur. Det visar sig, intressant nog, att observerade blixtnedslagspunkter stämmer rätt väl överens med punkter med låga beräknade värden på det elektriska fält som behövs för att starta en uppåtgående "leader"-urladdning. Således kan man använda teoretiska beräkningar för att förutsäga vilka punkter på en byggnad som sannolikast kan träffas av blixtnedslag. Dessutom har det visat sig att de tredimensionella områdena med förhöjd nedslagssannolikhet inte har enkla geometrier (avhuggna sfärer etc.), så som man tidigare har antagit. Istället beror nedslagsområdena både på blixtens toppströmstyrka liksom på geometri och höjd hos byggnaden, samt på omgivningen i övrigt. 


\section{Acknowledgments}

"To my friends I owe the patience of tolerating my sharp thorns, my changes of mood, the negligence, the vanity, the dreads and the doubts"

Alberto Cortez

"A mis amigos les adeudo la paciencia de tolerarme las espinas más agudas, los arrebatos de humor, la negligencia, las vanidades, los temores y las dudas"

Alberto Cortez

In first place, I would like to express my sincere gratitude to my supervisor, Prof. Vernon Cooray. It has been fantastic to work and share all these years with a man like Vernon. He is a brilliant scientist and mentor, deep in knowledge, sparkling with ideas, and more importantly, he has been a friend to me.

I would like also to thank Johan Schleimann-Jensen, my supervisor at Jensen Devices $A B$, for supporting and trusting the idea of a Ph.D student working in his company. I am also indebted to Prof. Rajeev Thottappillil and Prof. Mats Boman, my co-supervisors. Particularly I have to thank Rajeev for supporting my ideas and my participation in the COST ACTION P18. Also the help and encouragement given by Mats during some tricky moments is deeply acknowledged, especially for helping me when I had to do last minute spectroscopy tests.

The work presented in this thesis would not have been possible without the education given to me by Prof. Francisco Roman at the National University of Colombia. I am grateful to him for the patience, effort and time spent in constructing the basis of the researcher I am now. In the same way, I will also take the opportunity to acknowledge the National University of Colombia and the Colombian tax payers for the undergraduate and M.Sc education I received during almost eight years.

The financial support of the Swedish Institute through the Guest Research Scholarship during my first nine months in Sweden is highly appreciated.

I would like to thank to all my friends (and colleagues) at the Division of Electricity and Lightning Research, Uppsala University, for all the enjoyable time we have spent together. Especially, the support given by Raúl Montaño 
in both personal and academic matters during the first years of my studies is deeply acknowledged. In the same way, I have to thank Daniel Månsson for the things of life and science that we have shared during these years. The personal and scientific discussions with Nelson Theethayi are also greatly appreciated. Mahbubur Rahman is also thanked for his cooperation in our research group. I want to also thank Surajit Midya, Ziya Mazloom and Jakke Makela for their friendship and for the many times we have worked or joked together. The help of Marcus Berg in the translation of the summary of this thesis into Swedish is highly appreciated. Furthermore, I would like to thank the guest researchers who have worked with us, especially Mahesh Edirisinghe, Prassana Liyanage, Alberto Conti, Mahendra Fernando and Sharma Shriyog, for all the moments we worked and laughed together.

Special thanks to Gunnel Ivarsson and Ylva Johansson for taking care of the administration issues related to my studies. Thomas Götschl is thanked for keeping my computers working! My sincere thanks to Ulf Ring for the technical support and for all the laughs we had together. All the rest at the Division of Electricity and Lightning research is thanked and appreciation is given where appreciation is due. The help provided by Lars Landström, Oscar Alm, Wendy Fredriksson and Erika Widenkvist from the Department of Material Chemistry, Uppsala University during the spectroscopy and microscopy tests are also acknowledged.

The staff of Jensen Devices AB is remembered for their kind help and patience during these years. In particular, I would like to thank Janne Nilsson for sharing with me his practical experience and for the many times he stopped his work to help or advice me. Special thanks are also due to Therese Jansson, Bullent Arslan, Hans Ohlsson, Marcus Kuang and Kjell Ohman for their help and support.

I would like to also thank all the researchers who have supported my work during this time. The cooperation of the coauthors of my papers, Prof. Serge Soula, Prof. Earle Williams, Prof. Alexandre Piantini, Prof. Serge Chauzy, Hartono Zainal Abidin, Mike Valente and Acacio Silva is highly acknowledged. Special thanks to Prof. Fridolin Heidler, Prof. Vladimir Rakov, Prof. Philip Krider, Prof. Gerhard Diendorfer, Wolfgang Schulz, Prof. Marcelo Saba, Mauricio Ballarotti, Prof. Nickolay Aleksandrov, Arturo Galvan and Davide Pavanello for the scientific discussions and personal interactions during meetings and conferences. I am also indebted to Prof. Aage Pedersen for his constant interest and his critical comments to my work.

My sincere thanks to all my friends in Uppsala for making my life more enjoyable. A mi querida Magda Lezcano por el apoyo que me ha dado desde el mismo momento en que nos conocimos. A Omar Gutierrez por las agradables noches cantando Silvio y por lo que hemos vivido juntos. A Loany Calvo por la alegría de las noches bailando salsa. A Issabel (Beli) Beneyto por el abrazo, la calidez y la amistad al principio de esta 
experiencia. To Alessandro Gambini for all the nice moments we spent together in Bologna or in his beloved Uppsala. To all my friends either at Hotel Uppsala or in Flogsta for teaching me a lot of things necessary to live in a small complex society called "corridor".

A todos mis amigos en Colombia tengo que darles un inmenso abrazo de agradecimiento por todo el amor y fortaleza que me han brindado a pesar de la distancia. A Adriana Rodríguez por su amor y por orar por mí aún cuando las cosas no salieron como planeábamos. A Diana García por persistir en escribirme a pesar de mis tardíos mensajes de respuesta. A mis amigos de siempre, Leo Aguilar, Jennifer Fernandez, Isabella Romero, Milena Chivatá y José Carlos Manzano por la paciencia de tolerarme las espinas más agudas, los arrebatos de humor, la negligencia, las vanidades, los temores y las dudas. A mis amigos del grupo de investigación, especialmente a Liliana Arévalo y Oscar Díaz por su amistad y por los momentos compartidos. A Marcela Martínez, Jacklyn Miranda, Harold Andres Marciales, Juan Pablo Preciado y Carlos Trujillo por el interés y el trabajo desarrollado como estudiantes dirigidos por mí en la distancia. A mis colegas y amigos de la universidad, especialmente a Alfredo Gil por mantener vivo el contacto conmigo y por unas cuantas conversaciones que nos han ayudado a los dos. A mis amigos de colegio que a pesar de tantos años siguen compartiendo el mismo espíritu que cuando éramos unos niños.

También tengo que agradecer a mis amigos mexicanos por estar conectados conmigo a pesar que no los veo personalmente por varios años. A mi estimado Prof. Marcos Moreno por la juventud de sus años y por la madurez de sus palabras. A Amelia Arechavala por tratarme como un hijo y aconsejarme como una madre. A Mely Arredondo por ser otra hermana para mí.

Finally, I want thank my family for all their love, patience and support during these years. A mi madre por sus lágrimas durante mi partida, por el inmenso gozo que me hace sentir cuando hablo con ella y por sus continuas oraciones que mantienen a María pendiente de mí. A mi hermana por estar pendiente de mis viejos y por preocuparse por me. A mi hermano, por acompañarme, por volver y por estar. To my princess, Silvia Diener, for all we have shared, for all we love and for all we will learn together.

Marley Becerra

Uppsala, April 4, 2008 


\section{References}

[1] M. A. Uman, The lightning discharge, Academic Press Inc. London, 1987.

[2] B. Diebner, Benjamin Franklin, in Lightning, Volume 1, Edited by R.H. Golde, Academic Press Inc. London, 1977.

[3] B. F. J. Schonland, The work of Benjamin Franklin on thunderstorms and the development of the lightning rod, J. Franklin Inst. Vol. 253, 1952, pp. 375.

[4] I. Bernard Cohen, The two hundredth anniversary of Benjamin Franklin's two lightning experiments and the introduction of the lightning rod, Proceedings of the American Philosophical Society, Vol. 96, No. 3. 1952, pp. 331366.

[5] R. H. Golde, The lightning conductor, J. Franklin Inst. Vol. 283, No. 6, 1967, pp. 451-477.

[6] B. Franklin, How to secure houses from lightning, in Poor Richard's Almanack, 1753; reproduced in Benjamin Franklin's experiments, I. B. Cohen, Ed. Cambridge, MA., Harvard Univ. Press, 1941, pp. 348-358.

[7] E. Nickson, XV Sundry papers relative to an accident from lightning at Purfleet, May 15, 1777, report to the Secretary of the Royal Society, Philos. Trans. R. Soc. Lond, A, Vol. 68, 1778, pp. 232-235.

[8] R. H. Golde, Lightning Conductor, Chapter 17 in Golde, R. H. (Ed.), Lightning, vol. 2, Academic Press: London, 1977.

[9] AIEE, Lightning reference book, American Institute of Electrical Engineers, New York, July 1937.

[10] C. F. Wagner, G. D. McCann, G. D. and G. L. MacLane, Shielding of transmission Lines, AIEE Transactions, Vol. 60, 1941, pp. 313-328.

[11] C. F. Wagner, G. D. McCann, C. M. Lear, Shielding of substations, AIEE Transactions, Vol. 61, 1942, pp. 96-100.

[12] IEEE Std 998-1996, IEEE Guide for direct lightning stroke shielding of substations, The Institute of Electrical and Electronics Engineers, Inc., 1996, ISBN 1-55937-768-2.

[13] N. Szedenik, Rolling sphere -method or theory?, Journal of Electrostatics, 51-52, 2001, pp. 345-350.

[14] E. R. Whitehead, Protection of transmission lines, in Lightning, Vol. 2, Edited by R.H. Golde, Academic Press Inc. London, 1977. 
[15] E. R. Whitehead, Final report of Edison Electric Institute -Mechanism of lightning flashover research project-, EEI Project RP50, Mechanism of lightning flashover on transmission lines, EEI, 1972, pp. 72-900.

[16] F. S. Young, J. M. Clayton, A.R. Hileman, Shielding of transmission lines, IEEE Trans. Power Apparatus and Systems (Supplement), Vol. 83, 1963, pp. 132-154.

[17] H.R. Armstrong, E.R. Whitehead, Field and analytical studies of transmission line shielding, IEEE Trans. PAS-87, No. 1, 1968, pp. 270-279.

[18] G. W. Brown, E. R. Whitehead, Field and analytical studies of transmission line shielding: Part II, IEEE. Trans. PAS-88, No. 5, 1969, pp. 617625.

[19] C. F. Wagner Relation between stroke current and the velocity of the return stroke, IEEE Trans. Power Apparatus and Systems, Vol. 82, 1963, pp. 609-617.

[20] D. W. Gilman, E. R. Whitehead, The mechanism of lightning flashover on high-voltage and extra high voltage transmission lines, Electra, No. 27, 1973, pp. 65-96.

[21] H. R. Armstrong, E. R. Whitehead, A lightning stroke pathfinder, IEEE Trans. Power Apparatus and systems, Vol. 83, 1964, pp. 1223-1227.

[22] R. H. Lee, Lightning protection of buildings, IEEE Transactions on Industry Applications, Vol. IA-15, No. 3, 1979, pp. 236-240.

[23] M. A. Sargent, Monte Carlo simulation of the lightning performance of overhead shielding networks of high voltage stations, IEEE. Trans. Power Apparatus and Systems, 91, 1972, pp.1651-1656.

[24] C. H. King, T. P. Ogden, Analysis technique for lightning attachment zoning of aircraft, Proceedings of the International Conference on Lightning and Static Electricity, Bath, England, 1989, pp. 26-28.

[25] IEC 61024-1, Protection of structures against lightning, Part 1: General principles, 1990.

[26] IEC 61024-1, Protection of structures against lightning, Part 1: General principles, 1995.

[27] IEC 62305-1, Protection against lightning - Part 1: General principles, Ed. 1.0 b, 2006

[28] R. B. Anderson, Lightning research: where do we go from here?, Power Engineering Journal, Vol 6, No. 4, 1992, pp. 179-190.

[29] J. Takami, S. Okabe, Characteristics of direct lightning strokes to phase conductors of UHV transmission lines, IEEE Trans. Power Delivery, Vol. 22, 1, 2007, pp. 537-546.

[30] R. J. Van Brunt, T.L. Nelson, K. L. Stricklett, Early streamer emission lightning protection systems: An overview, Electrical Insulation Magazine IEEE, 16, 2000, pp. 5-24, ISSN: 0883-7554.

[31] R. B. Carpenter, M. M. Drabkin, Improvements of lightning protection against direct strokes, IEEE Intern. Symp. on EMC, 1997, pp. 403-405. 
[32] F. D'Alessandro, J.R. Gumley, A collection volume method for the placement of air terminals for the protection of structures against lightning, Journal of Electrostatics, Vol. 50, No. 4, 2001, pp. 279-302.

[33] French Standard, Protection of structures and open areas against lightning using ESE air terminals, French Standard, NF C 17 102, 1995.

[34] Spanish Standard, Protection of structure and of open areas against lightning using early streamer emission air terminals, UNE 21186, 1996.

[35] A.M. Mousa, Proposed research on the collection volume method/field intensification method for the placement of air terminals on structures, Power Engineering Society General Meeting, 1, 2003, pp. 301-305.

[36] Z.A. Hartono, I. Robiah, The field intensification method: an assessment based on observed bypass data on real buildings in Malaysia, Report submitted to Standards Australia Committee EL-024, September 2002.

[37] K. Berger, The earth flash, Chapter 5 in Golde, R. H. (Ed.), Lightning, Vol. 1, Academic Press, London, 1977.

[38] V. A. Rakov, M. A. Uman, Lightning: Physics and effects, Cambridge. University Press, Cambridge, U.K, 2003, ISBN 0-521-58327-6

[39] B. F. J. Schonland, H. Collens, Progressive lightning, Proceedings of the Royal Society of London. Series A, 143, 1934, pp. 654-674.

[40] B. F. J. Schonland, D. J. Malan , H. Collens, Progressive Lightning II, Proceedings of the Royal Society of London. Series A, 152, 1935, pp. 595625.

[41] B. F. J. Schonland, Thunderstorms and their electrical effects, Proc. Phys. Soc., 55, 1943 pp. 445-458.

[42] K. B. McEachron, Lightning to the Empire State Building, J. Franklin Inst. 227, 1939, pp. 149-217.

[43] M. A. Uman, Lightning, Dover publications, Inc, New York, 1969.

[44] K. Berger, Novel observations of lightning discharges: results of research on Mount San Salvatore, J. Franklin Inst., 283, 1967, pp. 478-525.

[45] R. H. Golde, Lightning and tall structures, Proc. IEEE, 125, 4, 1978, pp. 347-351.

[46] Les Renardiéres Group, Research on long air gap discharges at Les Renardieres, Electra 23, 1972, pp. 53-157.

[47] Les Renardiéres Group, Research on long air gap discharges-1973 results, Electra 35, 1974, pp. 47-155.

[48] Les Renardiéres Group, Positive discharges in long air gaps-1975 results and conclusions, Electra 53, 1977, pp. 31-132.

[49] Les Renardiéres Group, Negative discharges in long air gaps. Electra, 74, 1981, pp. 67-216.

[50] I. Gallimberti, The mechanism of long spark formation, J. Physique Coll. 40, C7, Suppl. 7, 1972, pp. 193-250.

[51] A. Bondiou, I. Gallimberti, Theoretical modeling of the development of the positive spark in long gaps, J. Phys. D: Appl. Phys., 27, 1994, pp. $1252-$ 1266. 
[52] N. Goelian, P. Lalande, A. Bondiou-Clergerie, G. L. Bacchiega, A. Gazzani, I. Gallimberti, A simplified model for the simulation of positivespark development in long air gaps, J. Phys. D: Appl. Phys., 30, 1997, pp. 2441-2452.

[53] P. Ortega, P. Domens, A. Gibert, Predictive modelling of positive leader propagation under standard and oscillatory impulse shapes, J. Phys. D: Appl. Phys., 27, 1994, pp. 1233-1241.

[54] A. Bondiou-Clergerie, P. Lalande, P. Laroche P, J. C. Willet, D. Davis, I. Gallimberti, The inception phase of positive leaders in triggered lightning: comparison of modeling with experimental data, Proceedings of the 11th Int. Conf. on Atmospheric Electricity ICAE, Alabama, USA, June 1999.

[55] A. Bondiou, P. Laroche, I. Gallimberti, Theoretical modeling of positive leader in rocket triggered lightning, International aerospace and ground conference on lightning and static electricity ICOLSE, Mannheim, Germany, 1996, pp. 23-32.

[56] P. Lalande, A. Bondiou-Clergerie, G. Bacchiega, I. Gallimberti, Observations and modeling of lightning leaders, C.R. Physique, 3, 2002, pp. 13751392.

[57] P. Lalande, Study of the lightning stroke conditions on a grounded structure, Doctoral thesis, Office National d'Etudes et de Recherches A'erospatiales ONERA, 1996.

[58] M. Becerra, V. Cooray, Time dependent evaluation of the lightning upward connecting leader inception, J. Phys. D: Appl. Phys., 39, 2006, pp. $4695-4702$.

[59] M. Becerra, V. Cooray, A self-consistent upward leader propagation model, J. Phys. D: Appl. Phys. 39, 2006, pp. 3708-3715.

[60] G. L. Bacchiega, A. Gazzani, M. Bernardi, I. Gallimberti, A. BondiouClergerie, Theoretical modelling of the laboratory negative stepped leader, International aerospace and ground conference on lightning and static electricity, Mannheim, Germany, 1996, pp. 13-22.

[61] A. J. Eriksson, The lightning ground flash -an engineering study, Ph.D thesis, Faculty of Engineering, University of Natal, Pretoria, 1979.

[62] A. J. Eriksson, An improved electrogeometric model for transmission line shielding analysis, IEEE Trans. Vol. PWDR-2, 1987, pp. 871-877.

[63] A. J. Eriksson, The incidence of lightning strikes to power lines, IEEE Trans. Vol. PWDR-2, 1987, pp. 859-870.

[64] G. Carrara, L. Thione, Switching surge strength of large air gaps: a physical approach, IEEE Trans., Vol. PAS-95, No. 2, 1979, pp. 512-524.

[65] L. Dellera, E. Garbagnati, Lightning strike simulation by means of the Leader Progression Model, Part I: Description of the model and evaluation of free-standing structures, IEEE Trans., Vol. PWRD-5, 1990, pp. 20092023.

[66] L. Dellera, E. Garbagnati, Lightning strike simulation by means of the Leader Progression Model: II. Exposure and shielding failure evaluation of 
overhead lines with assessment of application graphs, IEEE Trans. Power Delivery, PWRD-5, 1990, pp. 2023-2029.

[67] F. Rizk, Modeling of transmission lines: exposure to direct lightning strokes, IEEE Trans. Power Delivery, PWRD-5, 1990, pp. 1983-1989.

[68] F. Rizk, Modeling of lightning incidence to tall structures Part I: Theory, IEEE Trans. Power Delivery, PWRD-9, 1994, pp. 162-171.

[69] F. Rizk, Modeling of lightning incidence to tall structures Part II: Application, IEEE Trans. Power Delivery, PWRD-9, 1994, pp. 172-193.

[70] F. Rizk, A model for switching impulse leader inception and breakdown of long air-gaps, IEEE Trans. on Power Delivery, Vol. 4, No. 1, 1989, pp. 596-603.

[71] T. Horvath, Standarization of lightning protection based on the physics or on the tradition, J. Electrostatics, 60, 2004, pp. 265-275.

[72] L. Dellera, E. Garbagnati, M. Bernardi, A. Bondiou, V. Cooray, I. Gallimberti, A. Pedersen, F. Ruhling, Lightning exposure of structures and interception efficiency of air terminals, CIGRE Report, Task Force 33.01.03, 1997.

[73] J. Lowke, On the physics of lightning, IEEE Trans. Plasma Sci., 32, 2004, pp. 4-17.

[74] P. Lalande, A. Bondiou, P. Laroche, A. Eybert, J. Berlandis, B. Bador, A. Bonamy, M. Uman, V. Rakov, Leader properties determined with triggered lightning techniques J. Geophys. Res. 103, 1998, pp. 14109-15.

[75] P. Laroche, A. Eybert-Berard, L. Barret, J. P. Berlandis, Observations of preliminary discharge initiating flashes triggered by the rocket and wire technique, Proc. Int. Conf. Atmospheric Electricity, USA, 1988, pp 327-33.

[76] J. C. Willet, D. A. Davis, P. Laroche, An experimental study of positive leaders initiating rocket-triggered lightning Atmos. Res. 51, 1999, pp. 189219

[77] R. B, Standler, W. P. Winn, Effects of coronae on electric fields beneath thunderstorms, Quart. J. R. Met. Soc, 105, 1979, pp. 285-302.

[78] S. Chauzy, P. Raizonville, Space charge layers created by coronae at ground level below thunderclouds: Measurements and modeling, J. Geophys. Res., 87(C4), 1982, pp. 3143-3148.

[79] CIGRE Working Group 01 on Lightning, Guide to procedures for estimating the lightning performance of transmission lines, CIGRE document, No. 63, October 1991.

[80] S. Yokoyama, K. Miyake, T. Suzuki, S. Kanao, Winter lightning on Japan sea coast -development of measuring system on progressing feature of lightning discharge-, IEEE Trans. Power Delivery, Vol, 5, No. 3, 1990, pp. $1418-1425$.

[81] Y. Kito, K. Horii, Y. Higashiyama and K. Nakamura, Optical aspects of winter lightning discharges triggered by the rocket-wire technique in Hukuriku district of Japan, J. Geophys. Res. 90, 1985, pp. 6147-6157. 
[82] A. Asakawa, K. Miyake, S. Yokoyama, T. Shindo, T. Yokota, T. Sakai, Two types of lightning discharges to a high stack on the coast of the sea of Japan in winter, IEEE Trans. Power Delivery, Vol. 12, No. 3, 1997, pp. $1222-1231$.

[83] A. Wada, A. Asakawa, T. Shindo, S. Yokoyama, Leader and return stroke speed of upward-initiated lightning, Proceedings Intern. Conf. Atmosph. Electricity ICAE, 2003, paper C3-20.

[84] M. Saba, High speed video measurements of a upward connecting positive leader, personal communication, 2007.

[85] C. B. Moore, G. D. Aulich, W. Rison, Measurements of lightning rod responses to nearby strikes, Geoph. Research Lett, Vol. 27, No. 10, 2000, pp $1487-1490$.

[86] C. B. Moore, W. Rison, J. Mathis, G. Aulich, Lightning rod improvements, J. Appl. Meterol. 39, 2000, pp. 593-609.

[87] G. Berger, Leader inception field from a vertical rod conductor Efficiency of electrical triggering techniques-, Conference record of the 1996 IEEE International Symposium on Electrical Insulation, Montreal, Canada, 1996, pp. 308-311.

[88] G. Berger, Determination of the inception electric fields of the lightning upward leader, Proceedings of the Int. Symp. High Voltage Engineering ISH, Yokoyama, Japan, 1993, pp. 225-229.

[89] A. J. Eriksson, Lightning and tall structures, Trans. SA Inst. Elect. Eng. August, 1978, pp. 1-16.

[90] K. Hoori, K. Nakamura, S. Ichi Sumi, Review of the experiment of triggered lightning by rocket in Japan, Proceedings $28^{\text {th }}$ International Conference on Lightning Protection ICLP, 2006, pp. 44-51.

[91] V. P. Idone, The luminous development of Florida triggered lightning, Res. Lett. Atmos. Elect., 12, 1992, pp. 23-28.

[92] A. Kumar, Macroscopic inception criterion for the upward leaders of natural lightning, IEEE Trans. on Power Delivery, Vol. 20, 2, 2005, pp. $904-$ 911.

[93] F. D'Alessandro, The use of "Field Intensification Factors" in calculations for lightning protection of structures, J. Electrostatics, 58, 2003, pp.1743.

[94] M. Bernardi, L. Dellera, E. Garbagnati, G. Sartorio. Leader progression model of lightning: updating of the model on the basis of recent test results, Proceedings of the $23^{\text {rd }}$ ICLP, Florence, 1996, pp. 399-407.

[95] N. Aleksandrov, G. Berger, C. Gary, New investigations in the lightning protection of substations, CIGRE TF. No. 14, 1994.

[96] N. I. Petrov and R. T. Waters, Determination of the striking distance of lightning to earthed structures, Proc. R. Soc. A, 450, 1995, pp. 589-601.

[97] M. Akyuz, V. Cooray, The Franklin lightning conductor: conditions necessary for the initiation of a connecting leader, Journal of Electrostatics, Vol. 51-52, 2001, pp. 319-325. 
[98] N. I. Petrov, F. D'Alessandro, Theoretical analysis of the processes involved in lightning attachment to earthed Structures, J. Phys. D: Appl. Phys. 35, 2002, pp. 1788-95.

[99] E. M. Bazelyan, Y. P. Raizer, Lightning physics and lightning protection, Bristol, Institute of Physics, 2000.

[100] S. F. Madsen, Interaction between electrical discharges and materials for wind turbine blades -particularly related to lightning protection-, Doctoral thesis, Technical University of Denmark, 2006.

[101] F. D. Alessandro, C. J. Kossmann, A. S. Gaivoronsky, A. G. Ovsyannikov, Experimental study of lightning rods using long sparks in air, IEEE Trans. Dielectrics and Electrical Insulation, Vol. 11, No. 4, 2004, pp. 638649.

[102] K. Horii, H. Sakurano, Observation on final jump of the discharge in the experiment of artificially triggered lightning, IEEE Trans. Power Apparatus and Systems, Vol. PAS 104, No. 10, 1985, pp. 2910-2915.

[103] K. Horii, M. Nakano, Artificially triggered lightning, In Handbook of Atmospheric Electrodynamics, Chapter 6, Vol. 1. ed. H. Volland, pp. 151166.

[104] V. A. Rakov, M. A. Uman, K. J. Rambo, M. I. Fernandez, R. J. Fisher, G. H. Schnetzer, R. Thottappillil, A. Eybert-Berand, J. P. Berlandis, P. Lalance, A. Bonamy, P. Laroche, A. Bondiou-Clergerie, New insights into lightning processes gained from triggered lightning experiments in Florida and Alabama, J. Geophys. Res. Vol. 103, No. D12, 1998, pp. 14117-14130. [105] N. L. Alekandrov, E. M. Bazelyan, R. B. Carpenter, M. M. Drabkin, Y. Raizer, The effect of coronae on leader inception and development under thunderstorm conditions and in long air gaps, J. Phys. D: Appl. Phys, 34, 2001, pp. 3256-3266.

[106] N. L. Alekandrov, E. M. Bazelyan, M. M. Drabkin, R. B. Carpenter, $\mathrm{Yu}$. P. Raizer, Corona discharge at the tip of a tall object in the electric field of a thundercloud, Plasma Physics Reports, 28, 2002, pp. 1032-1045.

[107] N. L. Aleksandrov, E. M. Bazelyan, Y. P. Raizer, The effect of a corona discharge on a lightning attachment, Plasma Physics Reports, Vol. 31, No. 1, 2005, pp. 75-91.

[108] M. Miki, Observation of current and leader development characteristics of winter lightning, Proceedings on the $28^{\text {th }}$ International Conference on Lightning Protection, ICLP 2006, Kanazawa, Japan, pp. 14-19.

[109] V. Cooray, N. Theethayi, The striking distance of lightning flashes and the early streamer emission (ESE) hypothesis, J. Electrostatics, Vol. 65, 5-6, 2007, pp. 336-341.

[110] S. Soula, S. Chauzy, Multilevel Measurement of the electric field underneath a thundercloud 1: A new system and the associated data processing, J. Geophys. Res., 96(D12), 1991, pp. 22319-22326. 
[111] X. Qie, S. Soula, S. Chauzy, Influence of ion attachment on the vertical distribution of the electric field and charge density below a thunderstorm, Ann. Geophysicae, 12, 1994, pp. 1218-1228.

[112] A. R. Hileman, Discussion of A. J. Eriksson, An improved electrogeometric model for transmission line shielding analysis, IEEE Trans. Vol. PWDR-2, 1987, pp. 884-885.

[113] G. Baldo, Lightning protection and the physics of discharge, Proceedings of the High Voltage Engineering Symposium, ISH 1999, pp. 2.1792.176 .

[114] A. M. Mousa, Discussion of A. J. Eriksson, The incidence of lightning strikes to power lines, IEEE Trans. Vol. PWDR-2, 1987, pp. 867.

[115] J. T. Whitehead, Lightning performance of TVA-s $500 \mathrm{kV}$ and $161 \mathrm{kV}$ transmission lines, IEEE Trans. Power App. Sys. Vol. PAS 102, No. 3, 1983, pp. 752-768.

[116] V. Cooray, V. Rakov, N. Theethayi, The lightning striking distance revisited, J. Electrostatics, Vol. 65, 5-6, 2007, pp. 296-306.

[117] M. Saba, Z. L. Campos, M. Ballarotti, O. Pinto, Measurements of cloud-to-ground and spider leader speeds with high-speed video observations, Proceedings 13th International Conference on Atmospheric Electricity, August, 2007, Beijing, China.

[118] EPA, Lightning hazard to facilities handling flammable substances, EPA 550-F-97-002c, 1997.

[119] K. Aniserowicz, Methods of creation of lightning protection zones near tall telecommunication structures according to different national standards, TCSET 2002, pp. 197-199.

[120] Z. A. Hartono, I. Robiah, M. Darveniza, A database of lightning damage caused by bypasses of air terminals on buildings in Kuala Lumpur, Malaysia, Proceedings of VI International Symposium on Lightning Protection SIPDA, Santos Brazil, 2001, pp. 211-216.

[121] R. H. Lee, Protect your plant against lightning, Instruments and control systems, Vol. 55, No. 2, 1982, pp. 31-34.

[122] M. Szczerbinski, A discussion of 'Faraday cage' lightning protection and application to real building structures, Journal of Electrostatics, 48, 2000, pp. 145-154.

[123] M. Darveniza. A modification to the rolling sphere method for positioning air terminals for lightning protection of buildings. Proceedings of the $25^{\text {th }}$ International Conference on Lightning Protection, ICLP Rhodes Greece, 2000, pp. 904-908.

[124] Z. A. Hartono, I. Robiah, A method of identifying the lightning strike location on a structure, Int. Conf. on Electromagnetic Compatibility, ICEMC, 1995, pp. 112-117.

[125] Z. A. Hartono, I. Robiah, The collection surface concept as a reliable method for predicting the lightning strike location, Proceedings $25^{\text {th }}$ Interna- 
tional Conference on Lightning Protection, ICLP Rhodes, Greece, 2000, pp. 328-333.

[126] Z. A. Hartono, I. Robiah, A study of non-conventional air terminals and striken points in a high thunderstorm region, Proceedings $25^{\text {th }}$ International Conference on Lightning Protection, ICLP Rhodes, Greece, 2000, pp. $357-361$.

[127] N. I. Petrov, F. D'Alessandro, Assessment of protection system positioning and models using observations of lightning strikes to structures, Proceedings of the Royal Society A: Mathematical, Physical and Engineering Sciences, 458, 2002, pp. 723-742.

[128] F. D'Alessandro, N.I. Petrov, Field study on the interception efficiency of lightning protection systems and comparison with models, Proceedings of the Royal Society A: Mathematical, Physical and Engineering Sciences, 462, 2006, pp. 1365-1386.

[129] S. Ait-Amar, G. Berger, A 3-D numerical model of negative lightning leader inception: Application to the collection volume construction, Proceedings $25^{\text {th }}$ International Conference on Lightning Protection, ICLP Avignon, France, 2004.

[130] Z. A. Hartono, I. Robiah, Optimum design of lightning protection system in a clustered building environment, Proceedings of the $25^{\text {th }}$ Int. Conf. Lightning Protection, ICLP Avignon France, 2004, pp. 369-373.

[131] M. Becerra, F. Roman, V. Cooray, Lightning attachment to common structures: is the rolling sphere really adequate?, to be presented at the $29^{\text {th }}$ International Conference of Lightning Protection ICLP 2008, Uppsala, Sweden.

[132] V. P. Pasko, J. J. George, Three-dimensional modeling of blue jets and blue starters, J. Geophys. Res., Vol. 107, No. A12, 1458, 2002.

[133] N. I. Petrov, G. N. Petrova, Physical mechanism for the development of lightning discharges between a thundercloud and the ionosphere, Tech. Phys., 44, 1999, pp. 472-475. 


\section{Acta Universitatis Upsaliensis}

Digital Comprehensive Summaries of Uppsala Dissertations from the Faculty of Science and Technology 438

Editor: The Dean of the Faculty of Science and Technology

A doctoral dissertation from the Faculty of Science and Technology, Uppsala University, is usually a summary of a number of papers. A few copies of the complete dissertation are kept at major Swedish research libraries, while the summary alone is distributed internationally through the series Digital Comprehensive Summaries of Uppsala Dissertations from the Faculty of Science and Technology. (Prior to January, 2005, the series was published under the title "Comprehensive Summaries of Uppsala Dissertations from the Faculty of Science and Technology”.)

ACTA 